Florida International University FIU Digital Commons

$1-2-1999$

\title{
The identification of early factors related to academic achievement among deaf students
}

Lisa Namey Cunningham

Florida International University

DOI: $10.25148 /$ etd.FI14061569

Follow this and additional works at: https://digitalcommons.fiu.edu/etd

Part of the Curriculum and Instruction Commons

\section{Recommended Citation}

Cunningham, Lisa Namey, "The identification of early factors related to academic achievement among deaf students" (1999). FIU Electronic Theses and Dissertations. 2693.

https://digitalcommons.fiu.edu/etd/2693 
FLORIDA INTERNATIONAL UNIVERSITY

Miami, Florida

\title{
THE IDENTIFICATION OF EARLY FACTORS RELATED TO ACADEMIC ACHIEVEMENT AMONG DEAF STUDENTS
}

\author{
A dissertation submitted in partial fulfillment of the \\ requirements for the degree of \\ DOCTOR OF EDUCATION \\ in
}

CURRICULUM AND INSTRUCTION

by

Lisa Namey Cunningham

1999 
To: Dean Robert Vos

College of Education

This dissertation, written by Lisa Namey Cunningham, and entitled The Identification of Early Factors Related to Academic Achievement in Deaf Students, having been approved in respect to style and intellectual content, is referred to you for judgment.

We have read this dissertation and recommend that it be approved.

Barbara Burian

Paul A. Rendulic

Stephen Strichart

Judith J. Slater, Major Professor

Date of Defense: January 22, 1999

The dissertation of Lisa Namey Cunningham is approved.

Dean Robert Vos College of Education

Dean Kichard L. Campball Division of Graduate Studies

Florida International University, 1999 
(C) Copyright 1999 by Lisa Namey Cunningham

All rights reserved 


\section{DEDICATION}

I dedicate this dissertation to the three most important people in my life, my parents Norman and Phyllis, and my husband, Rick. Without their patience, understanding, support, and most of all love, the completion of this work would not have been possible. 


\section{ACKNOWLEDGMENTS}

I would like to thank several people, personally, for their assistance in the completion of this dissertation. First, to my committee, Dr. Judith Slater, Dr. Barbara Burian, Dr. Stephen Strichart, and Dr. Paul Rendulic, thank you for your guidance, your suggestions, and your encouragement. My admiration and respect for you has grown throughout this project. You have touched my life in ways beyond this dissertation. I want to extend a special thanks to Dr. Rendulic for his endless support, encouragement, and continuous assistance.

To the stakeholders of Broward County Schools, thank you for your participation in this research study. A special note of gratitude is extended to the families of those who participated in this dissertation. Thank you for your kind words and participation. I also want to thank Patrick Mulvihill and Lisa Thompson for their assistance, as well as Norma Jenkins for her expert editing skills.

To my parents, Norman and Phyllis, thank you for making me the person I am today, for sharing in my dream to attain this degree, for your support, emotionally and financially, and finally for believing in me and teaching me to believe in myself.

Finally to my husband, Rick, thank you for your endless hours of editing, for your incredible support, for your understanding when writing prevented me from being with you, and mostly for your never ending encouragement and love every step of the way. You are truly the love of my life. 


\author{
ABSTRACT OF THE DISSERTATION \\ THE IDENTIFICATION OF EARLY FACTORS RELATED TO \\ ACADEMIC ACHIEVEMENT IN DEAF STUDENTS \\ by \\ Lisa Namey Cunningham \\ Florida International University, 1999 \\ Miami, Florida \\ Professor Judith J. Slater, Major Professor
}

The purpose of this research study was to examine specific factors believed to be related to academic achievement in deaf children. More specifically, this research sought to determine whether there was a significant difference in achievement between those students whose parents use oral communication only and those whose parents use some type of sign language. An additional purpose of this research was to determine if there was a significant difference in academic achievement with those deaf students who used amplification devices early in life. This study also sought to determine whether providing early intervention programs which emphasizes and enables parents to develop a language rich environment had a significant impact on the academic achievement of deaf children and whether the age at which initial services are received influence deaf student's subsequent academic achievement. This study examined the relationship, if any, between intellectual ability and academic achievement among deaf children. Finally, this study sought to investigate the relationship between the degree of hearing loss and academic achievement.

Purposive sampling was used to select subjects for this study. All 228 eligible Deaf/Hard of Hearing (DHH) students enrolled in a Broward County Public School were 
included in the original sample. Sixty-one students actually participated in this study. A correlational method of statistical analysis as well as a cross classification (crosstabs) was used to analyze the data.

The results show that academic achievement in the areas of reading and mathematics was significantly related to parental mode of communication and the mode of communication used in school. Academic achievement, in the area of reading, was also signficantly related to intellectual ability. The reading achievement was also found to be significantly related to degree of hearing loss. Written language was not significantly related to any factors investigated in this study.

Additional research should be conducted to further investigate the low academic achievement among deaf children. The diversity among signing systems at school and between home and school should also be analyzed. Finally, future studies should examine curriculum and instruction methods to increase the academic achievement of deaf children. 


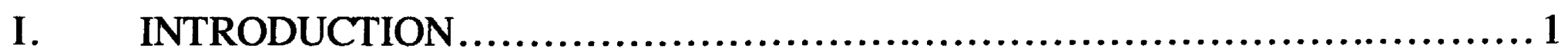

Introduction........................................................................ 1

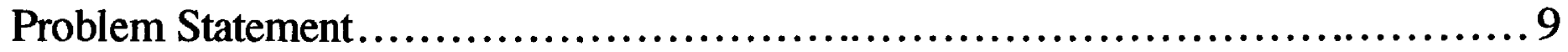

Purpose of the Study ......................................................... 10

Research Question .......................................................... 10

Subsidiary Questions....................................................... 10

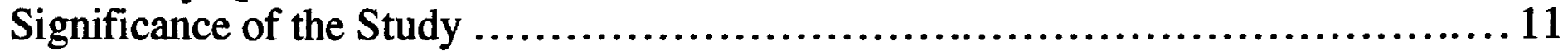

Assumptions................................................................. 12

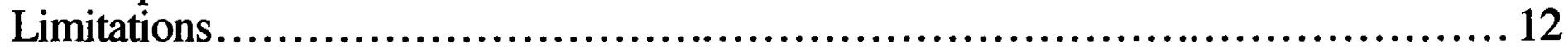

Delimitation ................................................................... 13

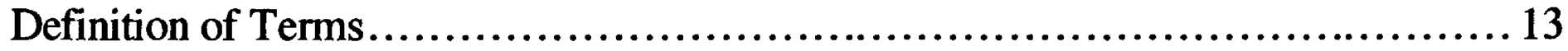

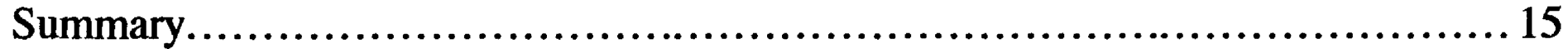

II. REVIEW OF RELATED LITERATURE................................ 16

Introduction................................................................... 16

Historical Overview ......................................................... 18

Deaf Education in the United States......................................20

The Identification of a Hearing Loss ........................................ 25

Suspicion of a Hearing Loss.............................................25

Diagnosis of a Hearing Loss........................................... 27

Classification of a Hearing Loss............................................28

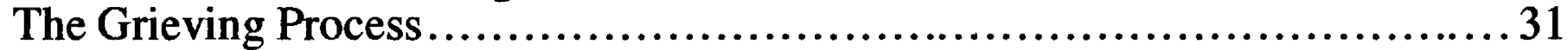

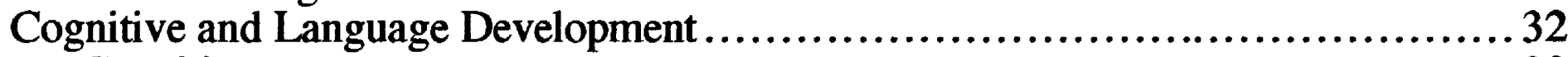

Cognition ................................................................... 32

Critical Period........................................................... 34

Normal Language Development ........................................... 35

Deaf Children of Deaf Parents ............................................... 37

Language Development in Deaf Children..................................... 39

Communication .............................................................. 41

Sign Language Communication . .......................................... 43

Oral Communication ............................................................ 48

Amplification ..................................................................... 50

Placement Options ....................................................... 52

Public Law 92-142 .....................................................5 57

Early Intervention ................................................................... 58

Public Law 99-457........................................................64

Academic Achievement. ....................................................65

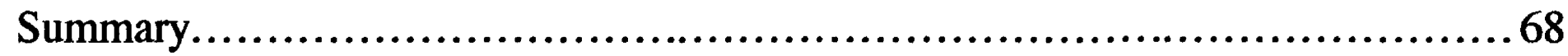

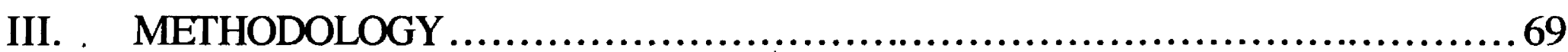

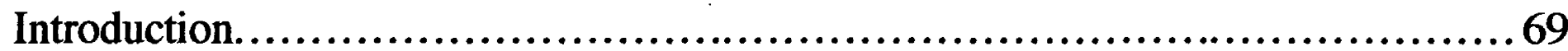

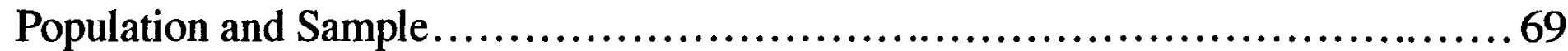

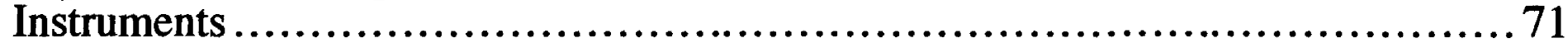

Questionairre............................................................ 71

Students' School Files .................................................... 73

Intelligence Tests ............................................................... 74

Academic Achievement Tests ............................................ 75

Research Design ........................................................ 78 


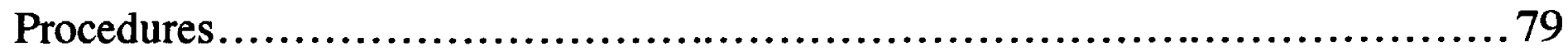

Data Analysis............................................................ 79

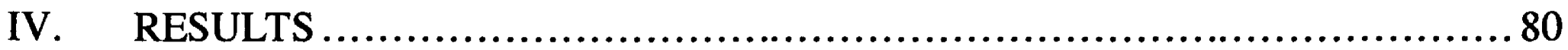

Introduction............................................................... 80

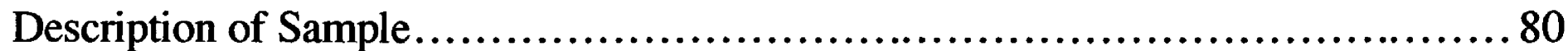

Results ..................................................................... 83

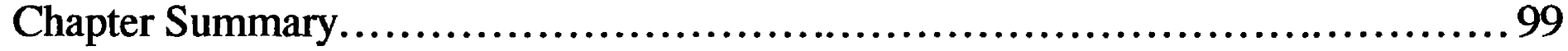

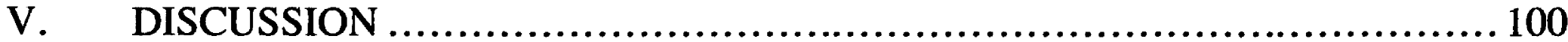

Introduction................................................................ 100

Summary of Significant Findings............................................ 100

Limitations of Findings ....................................................... 107

Implications and Recommendations ......................................... 109

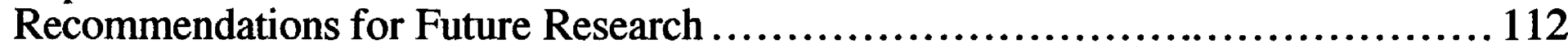

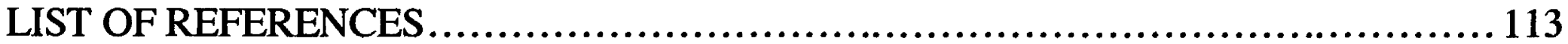

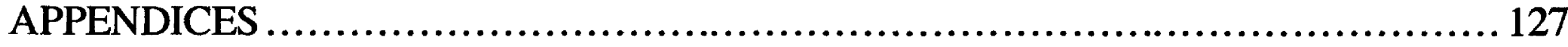

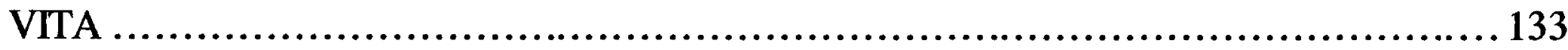




\section{LIST OF TABLES}

TABLE

PAGE

$1 \quad$ Number of students by Placement within School Level ...................... 71

$2 \quad$ Number of students by Placement within School Level (sample) ............... 81

3 Number of students by Placement within School Level within Parental mode of communication .............................................................. 81

4 Number of students by Placement within School Level within mode of communication used in school ........................................... 82

$5 \quad$ Number of students by Placement within Severity of Hearing Loss ............ 82

6 Differences between grade level performance and actual grade level by parental mode of communication (reading achievement) .............................. 84

7 Differences between grade level performance and actual grade level by parental mode of communication (written language achievement) ...................... 85

8 Differences between grade level performance and actual grade level by parental mode of communication (mathematics achievement) ......................... 86

9 Differences between grade level performance and actual grade level by mode of communication used in school (reading achievement) ......................... 87

10 Differences between grade level performance and actual grade level by mode of communication used in school (written language achievement) ................. 88

11 Differences between grade level performance and actual grade level by mode of communication used in school (mathematics achievement) ..................... 89

12 Relationship between age of amplification by difference between grade level

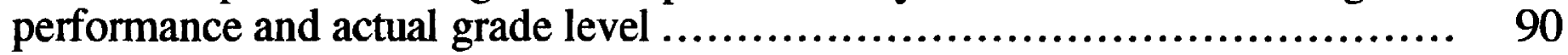

13 Differences between grade level performance and actual grade level by type of early intervention program (reading achievement)

14 Differences between grade level performance and actual grade level by type of early intervention program (written language achievement) ....................... 92

15 Differences between grade level performance and actual grade level by type of early intervention program (mathematics achievement) ........................... 93

16 Relationship between age attended pre-school program by difference between grade level performance and actual grade level

17 Relationship between age deafness detected by difference between grade level performance and actual grade level 
18 Relationship between intellectual ability by difference between grade level performance and actual grade level

19 Differences between grade level performance and actual grade level by degree of hearing loss (reading achievement) ....................................... 96

20 Differences between grade level performance and actual grade level by degree of hearing loss (written language achievement) 97

21 Differences between grade level performance and actual grade level by degree of hearing loss (mathematics achievement) 98

22 Early factors influencing academic achievement 101 


\section{CHAPTER I \\ INTRODUCTION}

\section{$\underline{\text { Introduction }}$}

Formal education of deaf children in the United States dates back to the early 1800's. Dr. Mason Fitch Cogswell, whose daughter was deaf, requested that his neighbor, Reverend Thomas Gallaudet, learn more about the educational system used to teach deaf children in Europe (Liben, 1978). In France, Gallaudet met Laurent Clerc, a deaf instructor at the National Institution of Deaf-Mutes, and persuaded Clerc to accompany him back to the United States. During their trip, Gallaudet learned sign language and Clerc learned English. The American School for the Deaf was established by the pair in 1817 and the mode of communication used was sign language (Wolkomoir, 1992).

During this same time period, a group of people existed who believed that oral communication was a better method of communication than sign language to use with deaf children. Oral communication included communication through speech, speechreading, the use of residual hearing, and auditory training (Greenberg, 1980). "Oralists", or antisigners, believed that sign language would interfere with the deaf child's motivation to develop oral-aural skills. Those individuals who espoused an "oral only" method of communication also believed that the use of sign language would prohibit the deaf child's integration into a hearing community. Finally, they suggested that sign language was limited in use to concrete thinking (Liben, 1978). This limitation could impact the deaf person's ability to use abstract reasoning, problem-solving, and critical thinking. They lobbied against the use of sign language for the above reasons and, at the 1880 International Conference of Educators of the Deaf in Milan, Italy, the majority of those who attended decided that oral communication would be the preferred mode of communication used with deaf children (Wolkomoir, 1992). This issue of which mode of communication 
was preferred for teaching deaf children, oral or sign, was not put to rest by the outcome of that conference. It continues to be a critical issue today in the field of deaf education.

Identification of a hearing loss is the first step in providing appropriate educational services to deaf/hard of hearing children. Hearing loss can be classified by four parameters: degree of hearing loss, type of hearing loss, cause of hearing loss, and age of onset. Miller (1988) distinguished among five levels of hearing and hearing loss: normal hearing ( 0 - 20 $\mathrm{dB})$, mild hearing loss (21-40 dB), moderate hearing loss (41-60 dB ), severe hearing loss $(61-80 \mathrm{~dB})$, and profound hearing loss $(81+\mathrm{dB})$. There are also five types of hearing loss, according to Newby (1979). They are conductive, sensory-neural, mixed, central auditory disorder, and functional or non-organic. The wide range of causes of deafness will be further explained in Chapter II. Finally, age of onset is simply the age the child became deaf.

According to Marschark (1997), more than $90 \%$ of deaf children are born into hearing families. In many instances, hearing parents do not detect their child's deafness or impairment at birth. Typically, deafness is not diagnosed until a deaf child is between the ages of two and three (Marschark, 1997). Parents typically experience a variety of feelings such as anxiety, sadness, depression, and confusion following the diagnosis (Adams, 1997). Additionally, once the hearing loss is detected, parents are often in denial and this further delays the language development of the deaf child (Desselle, 1994). This delay in detection and acceptance impacts the deaf child's ability to process language through the auditory channel as do hearing children. As long as deaf children have equal opportunities, e.g., language-rich environments and access to incidental language, they can be as happy, smart, and successful as hearing children (Marschark, 1997). According to Desselle (1994), deaf children of hearing parents experience language delays because their deafness is not detected early enough to enable normal language development. The critical time of language development is between birth and five years of age. During this time, hearing 
parents make decisions regarding the primary mode of communication (oral or sign) they will use with their deaf child, whether or not they, themselves, will learn sign language, what type of amplification will be used, if any, and what, if any, early intervention (preschool) programs are available to their child. Decisions made at this point will have a critical impact on the deaf child's future academic achievement. "For most hearing parents of deaf children, their child's hearing loss is at first seen as a major problem that will interfere with family life, education, and potential success" (Marschark, 1997, p. 7). Family life certainly is different, but a hearing loss should not create any insurmountable obstacles to a child's career or educational success (Marschark, 1997).

As noted earlier, basic language skills develop during the first five years of life, and the critical period for learning is the first two to three years (Marschark, 1997). According to Wolkomoir (1992, p. 36), permanent linguistic impairment may occur if children do not learn language prior to the brain's neural connections becoming compete, which occurs by the fifth year. The reality is that deaf children of hearing parents typically learn language for the first time when they enter school (Padden, 1990). At this time, they are compared to hearing children who use their incidentally learned knowledge of spoken English to assist them in learning to read and write. This language deficit for the deaf, in addition to the need for immersion in an appropriate communication environment, then requires specialized instruction (e.g. whole language, social skills training, and a visual-kinesthetic approach to instruction) by specially-trained teachers (fluent sign language users and/or those trained in oral communication) (O’Donnell, Moores, \& Kluwin, 1992).

Language development and cognitive development are interdependent. "What a child says is related to what he knows. What he knows influences the ways in which his language grows" (Streng, Kretschmer, \& Kretschmer, 1978, p. 79). It is imperative, therefore, for deaf children to assimilate a language during the optimal time between birth and five years of age, so that their cognitive abilities will develop to their fullest capacity. 
According to Fromkin (1988), language acquisition is not dependent on the ability to use and hear sounds, but rather on cognitive ability. According to Brasel \& Quigley (1977), anything that hinders the development of this early language foundation will interfere with all subsequent learning. The development of language is important for the cognitive development of all youngsters, regardless of the language (spoken or sign) that is learned. The human brain appears to be equipped for the acquisition and use of any language to which a child is exposed (Fromkin, 1988). Parasnis (1983) found that deaf children of deaf parents perform better on tests of academic achievement than do deaf children of hearing parents. This may be the result of having an early language base on which to build cognitive knowledge. The early establishment of the visual mode of communication is a crucial pre-requisite to the internalization of language (McEntee, 1994). This internalization of language may then be used to establish oral and written language skills.

Deaf students do not develop language in the same manner as hearing children (Soderfeldt, Ronnberg, \& Risberg, 1994). Hearing children progress through very specific stages in the acquisition of language. Infants as young as four weeks of age can discriminate among forty consonant sounds. Cooing in hearing babies occurs during the first few months after birth. Babbling begins at approximately six to seven months of age, while single-word utterances emerge at approximately one year of age (Santrock, 1983). In children with normal hearing, the verbal language acquired during early childhood provides a foundation for later language development and learning (Brasel \& Quigley, 1977). According to Swisher \& Thompson (1985), children with normal hearing receive much of their information through the spoken language of their primary care-givers, which is critical to their language development.

Since deaf children cannot acquire information through their auditory channel, reception of information and language learning takes place through the visual channel. This different method of acquisition of language can best be illustrated through the use of 
sign language between deaf children and their deaf parents. Even though it is not the same mode of communication used by hearing children with hearing parents, the use of sign language by their deaf parents provides deaf children with a language-rich environment.

Thus deaf children with deaf parents have the opportunity to develop language similar to the way hearing children with hearing parents develop language. They will have natural exposure to language which will lead to their passing through developmental stages at the same rate as hearing children (Marschark, 1997). According to McEntee (1994), the age at which deaf children with deaf parents acquire signs and sign combinations parallels the spoken word and word combination acquisition process of hearing children with hearing parents. Acquisition of sign language in deaf children with deaf parents is just as effortless as the acquisition of spoken language in hearing children with hearing parents (McEntee, 1994). Deaf babies babble with their hands and use their hands to explore the building blocks of their language (Wolkomoir, 1992). Vocabulary acquisition is even accelerated in deaf children as compared to hearing children since motor control of arms and hands can be acquired prior to motor control of the vocal mechanism. In addition, deaf parents of deaf children can actually construct and contour the hands of their deaf children in order to mold appropriate hand shapes (Tabor, 1988).

Approximately $88 \%-90 \%$ hearing parents of deaf children have no communication system at home with their deaf children other than gestures (Meyers \& Bartee, 1992). The gestures hearing parents use are usually invented by the hearing members of the family. Without exposure to a formal communication system, the process of learning receptive language by the child is impaired. Deaf infants are at a very high risk for difficult and delayed language acquisition if the mothers do not learn sign language (Spencer, 1992).

Deaf children of deaf parents typically are exposed to sign language prior to a medical diagnosis of their deafness. Research indicates that deaf children of deaf parents experience greater academic and language progress than deaf children of hearing parents 
(Ritter-Brinton \& Stewart, 1992). One explanation for these differences may be the early use of sign language. Deaf children with early exposure to sign language have higher reading and receptive communication scores than deaf children in oral only communication environments (Greenberg, 1980). In a study conducted by Vernon \& Koh (1970), significantly higher educational achievement, including superior reading skills and written language, were demonstrated by students exposed to sign language early in life.

With some deaf children, when oral communication is actively and consistently pursued, impressive results can be obtained. These students typically have above average intelligence, literate and highly motivated parents, and are taught by professionals who are committed to and highly trained in oral methods of communication (Quigley \& Kretschmer, 1982). According to Altshuler (1974, p. 374), "parents should be informed that every method of communication must be used early and consistently".

In addition to the early exposure to language, early use of amplification may also be related to academic achievement in deaf children. Ross \& Giolas (1978) found that children who wore hearing aids had a slight improvement over those students who were unaided over a two year nine month period of time. The use of amplification could provide deaf children with increased use of their residual hearing in the process of language learning. Thus, some (Ross \& Giolas, 1978) maintain that early amplification is necessary for maximum development of speech and language when using an auditory approach.

Parents of deaf children have a continuum of educational options available to them for their children. Residential schools for the deaf, both public and private, provide specialized instruction for all subjects. They usually employ deaf house-parents who serve as communication role models for deaf students. Residential programs were developed to provide services for deaf students from a wide geographic area and who can not access necessary services in their boundaried school districts. Specialized day schools, public or private, are similar to residential schools in services, curriculum and learning environment, 
but do not provide dormitories (Meadow, 1978). The major differences between private and public programs are the fees charged and the selectiveness of their student body (Meadow, 1978). According to Meadow (1978), the majority of private schools follow an oral-only philosophy of education for deaf children and, in terms of the student's intellectual ability and residual hearing, are selective as to which students they admit to their program.

Another option available to parents of deaf children is a public school program in the student's boundaried school district. This environment provides opportunities for deaf students to participate with their hearing peers in a variety of curricular and extra-curricular activities, including advanced academic programming, a wide variety of competitive sports, and clubs or organizations. Options within this setting include self-contained programs, partial or full inclusion in general education classes, with internal and/or external teacher and/or interpreter support (W. Gonsher, personal communication, September 10, 1998).

Early intervention programs are also a necessary component in educating deaf children. They can provide deaf children and their families with the essential tools for an effective education. According to Goetzinger \& Rousely (1959), there is a positive influence of preschool training on the future educational achievement of deaf children. Intervention programs have been developed to provide young deaf children with a variety of social and educational experiences. These programs also provide parents of deaf children with support and necessary information (Marschark, 1997).

Early intervention programs include a wide range of services: speech/language therapy, pre-academic training, counseling services to the parents and family, transmission of factual information on deafness and its implications, and information and training in communication techniques (Moores, 1982). In Broward County Public Schools, services can be provided through a homebound model, in which a teacher of deaf children works with the parent(s) and the deaf child at their home. This type of service is generally 
provided to children from birth to age three. At three years of age, deaf/hard of hearing children can then attend a five-hour per day school program at a designated regular elementary school. They receive services from a teacher of deaf/hard of hearing children and a speech-language pathologist in a self-contained environment (all deaf/hard of hearing children) for total communication students, and in an integrated preschool program (deaf and hearing children) for those students receiving instruction through oral communication only (W. Gonsher, personal communication, September 10, 1998). According to Watkins \& Clark (1988), accelerated language growth is an advantage of early intervention programs. If deaf children are exposed to language for the first time once they reach school, according to Padden (1990), should they not begin attending school as early as possible?

"Research shows that deaf children born to the majority of hearing parents are linguistically disadvantaged" (McEntee, 1994, p.5). Therefore, most deaf children attending elementary school learn basic language skills, (i.e., oral and/or sign) through formal instruction along with the basic curriculum taught to all children. This may be a causative factor in lower achievement scores for deaf children on standardized tests, such as the Stanford Achievement Test (SAT), when compared with equivalent ability level hearing students. Deaf children have not mastered the basic language skills necessary to learn academics. These deficits are evident at all levels of schooling, but are most evident at the high school level. As information in school becomes more abstract, the educational gap between hearing and deaf children becomes greater (Goetzinger \& Rousely, 1959).

In the State of Florida, students must pass the High School Competency Test (HSCT) to graduate with a regular diploma. This test requires students to pass a twosection academically-based test (Communication and Mathematics). In Broward County, less than $10 \%$ of the deaf/hard of hearing students taking the HSCT are able to pass this test, thereby leaving them without a regular high school diploma (W. Gonsher, personal 
communication, September 10, 1998). In the State of Florida, standards required for earning a high school diploma are increasing. Students seeking a regular diploma in Broward County must maintain a 2.0 cumulative grade point average (G.P.A.), pass one credit of algebra, earn 25 credits and pass the HSCT. Over the years, the mathematics section of the HSCT has become more algebra-based, with more applied problems. The district has provided training for teachers and all high schools provide additional tutoring sessions for students who do not pass the HSCT. There has been no specific training for teachers of deaf and hard of hearing students or teachers of elementary and middle school students. In addition, most tutoring sessions are held after school, and since the majority of deaf students attend a program at a school other than their neighborhood school, transportation becomes a problem. If the gap between overall academic achievement and the measured intellectual ability of deaf children cannot be decrease, many of them will not be able to complete the requirements for a regular high school diploma, thereby limiting their future opportunities.

\section{Problem Statement}

Research shows that deaf children's academic achievement is usually not commensurate with their measured intellectual ability (Brasel \& Quigley, 1977; Desselle, 1994; Padden, 1990). Academic achievement continues to be an important aspect of schooling. In the State of Florida, standards required for a high school diploma are increasing. Since fewer than 10\% of the 1997-1998 graduating class of deaf/hard of hearing students in Broward County passed the HSCT, higher standards currently being instituted, such as passing a more language-based HSCT and a minimum of a 2.0 Grade Point Average, may result in a decrease of the number of deaf students who earn a regular high school diploma. Given this problem, this study seeks to identify the early factors that are associated with increased academic achievement of deaf children. 


\section{Purpose of this Study}

Previous research suggests that, if the factors contributing to better academic achievement of deaf children of deaf parents can be identified, these factors might suggest those that would also benefit deaf children of hearing parents. The purpose of this study is to identify the early factors that influence academic achievement in deaf children. Identifying these factors could lead to the development of more effective communication with families of newly-identified deaf children, more effective curriculum and programming at all grade levels, and the development of a more enriched language environment for deaf children in order to maximize their future potential and high school success.

\section{$\underline{\text { Research Question }}$}

What are the early factors that relate to academic achievement in public school children who are deaf?

\section{$\underline{\text { Subsidiary Questions }}$}

1. What is the relationship between parental mode of communication and academic achievement in deaf children?

2. What is the relationship between school mode of communication and academic achievement?

3. What is the relationship between age at which amplification was first used and academic achievement in deaf children?

4. What is the relationship between type of early intervention programs and academic achievement in deaf children?

5. What is the relationship between age at which early intervention was provided and academic achievement in deaf children? 
6. What is the relationship between age at which deafness was detected and academic achievement in deaf children?

7. What is the relationship between intellectual ability and academic achievement in deaf children?

8. What is the relationship between degree of hearing loss and their academic achievement in deaf children?

\section{Significance of the Study}

“An unacceptable large number of deaf adolescents continue to graduate from high school unable to express themselves in written English or unable to comprehend simple printed material" (Moores and Sweet, 1990, p. 178). Research indicates that profoundly deaf high school students rarely read with comprehension above a fourth grade level (Furth, 1973). Greenwood-Logsdon (1990, p. 4), found that "deaf children continue to graduate from high school with an average reading level of third grade. Less than ten percent attended college; the majority were employed in unskilled, manual labor jobs". According to Altshuler (1974), deafness, without additional handicapping conditions, does not limit intelligence, emotionality, or normal growth and maturation. Therefore, why do deaf children not perform well academically? Deaf children's academic deficits are related to several factors which include a lack of a language-rich environment, lack of early identification of deafness, lack of early use of amplification, and lack of an early intervention (preschool) program (Desselle, 1994; Brasel \& Quigley, 1977; Ross \& Giolas, 1978; Goetzinger \& Rousely, 1959). These factors may be causative factors directly related to the gaps between deaf children's ability and their actual achievement. The goal of all schooling is effective education and the method of achieving this goal is related directly to learning language as early as possible (Mitchell, 1982). According to O’Donnell, Moores, 
\& Kluwin (1992), effective education is achieved by producing high academic achievement scores on standardized tests.

Fewer than 10\% of the 1997-1998 graduates from Broward County Public Schools who are deaf were able to graduate with a regular high school diploma. Identifying the early factors that are related to academic achievement in deaf children could result in developing more effective programs and curricula at all grade levels so that academic achievement may be increased leading to more deaf children graduating with a regular high school diploma. It could also lead to the development of more effective communication with families of newly identified deaf children. The development of a more enriched language environment for deaf children in Broward County Public Schools could narrow the gap between ability and academic achievement in their deaf children, thereby maximizing their future potential and high school success.

\section{Assumptions}

1. The parents responses to the self - reporting survey will be truthful and accurate.

2. The parents will be willing to participate in the research study.

3. The information ascertained from each student's folder is accurate and sufficient.

4. The student's hearing loss has remained constant.

5. The student does not have other handicapping conditions which impact academic achievement.

\section{Limitations}

1. Inaccurate information may be recorded in the Broward County Public School database, resulting in incorrect addresses being utilized so that those questionnaires did not reach the correct persons, thereby reducing the sample size. 
2. The researcher used a self-reporting survey since it was the only method of gaining factual information from the parents.

\section{Delimitations}

1. The researcher limited the scope of the study to Broward County Schools, Florida.

2. The researcher used existing data available through school records, rather than observations or further administration of standardized tests.

3. The STANFORD 9, a test of academic achievement, was administered off-level to the deaf/hard of hearing students.

\section{Definitions of Terms}

American Sign Language - A distinct visual language with its own grammar, syntax, and semantics separate from English (Schwartz, 1996).

Cluster Programs for Deaf/Hard of Hearing - Programs which include students who need a full-time program, with services not provided at the boundaried school, i.e. certified teachers of the deaf/hard of hearing, interpreters, and counseling services from a certified counselor of the deaf (W. Gonsher, personal communication, September 10, 1998). Deaf - The sense of hearing is non-functional for ordinary purposes of life, and includes those individuals whose hearing disability precludes successful processing of linguistic information through audition, with or without a hearing aid (Newby, 1979).

Deaf Culture - A way of life shared by deaf individuals which includes sharing and educating each other to a deaf way of life, and customs and traditions shared among deaf people and communicated through a shared system of communication, American Sign Language (Walkney, 1984). 
Grade level differences - A measure of the difference between student's actual grade-level placement and grade-level results on tests of academic achievement; commonly used in achievement tests (e.g. STANFORD 9)

Manually Coded English(MCE) - A generic term which includes all of the sign systems devised to represent English grammar (Shroyer, 1982).

Oral method of communication (Oral-Aural Method) - Communication through the use of speech, speechreading, residual hearing, and auditory training (Greenberg, 1980).

Pidgin Sign English - A signing system that uses a combination of grammar and vocabulary from American Sign Language and English (Schwartz, 1996).

Residential School for the Deaf - An educational setting where children receive a specialized education, complete with living facilities (Newby, 1979).

Rochester Method - A system of communication which uses fingerspelling only (Schwartz, 1996).

Seeing Essential English - A signing system in which signs are based on English root words rather than the meaning of the word (Schwartz, 1996).

Signing Exact English - A signing system in which the same signs are used when words meet two of three criteria: same sound, same spelling, and same meaning (Schwartz, 1996).

Signed English -A signing system which uses American Sign Language signs in English word order (Schwartz, 1996).

Sign Language - Any language that makes primary use of the hands and face to communicate through visual-gestural means (Marschark, 1997).

Total Communication - Communication using speech, speech reading, gestures, formal sign language, fingerspelling, residual hearing, and auditory training ( Caccamise \& Newell, 1984). 


\section{Summary}

Research shows that deaf children's academic achievement is not as high as their measured intellectual ability (Brasel \& Quigley, 1977; Desselle, 1994; Padden, 1990). The research also indicates that academic deficits are related to a variety of factors which include lack of early identification of deafness, lack of early amplification, lack of language-rich environments during early language acquisition, and lack of early intervention programs (Desselle, 1994; Brasel \& Quigley, 1977; Ross \& Giolas, 1978; Goetzinger \& Rousely, 1959). In view of this research, further investigation into identification of the early factors which lead to increased academic achievement appears to be warranted.

It is the purpose of this study to first determine the factors associated with the academic achievement of deaf children. Next, this study will seek to answer the questions of whether the deficits in academic achievement are reduced if deaf children acquire a language base as early as possible and whether there is a significant difference in academic achievement based on mode of communication. Third, the study will investigate the significance of early amplification. Finally, this study will investigate the impact of early intervention programs on the academic achievement of deaf children. 


\section{CHAPTER II \\ Review of Related Literature}

\section{Introduction}

This chapter presents a review of literature which pertains to the education of deaf children. There are nine sections presented in this chapter.

Section one of the review of literature presents a brief historical overview of the evolution of deaf education in the United States. There have been two distinct philosophies in the field of deaf education. One philosophy espoused that only oral communication be used to teach deaf children. Oral communication was defined as communication through speech, speechreading, residual hearing, and auditory training (Greenberg, 1980). Total communication utilizes sign language, use of the hands, body language, and facial expressions to communicate through visual-gestural means in conjunction with speech, speechreading, gestures, fingerspelling, residual hearing, and auditory training (Caccamise $\&$ Newell, 1984). This researcher uses the term sign language as a general term to refer to all types of sign language communication throughout this research study. The various types of sign languages will be discussed further in section five of this review of literature. Section one will also review each of the philosophies and their histories.

The second section of the review of literature describes the process of identifying a hearing loss. The initial step in this process is the suspicion of a hearing loss, followed by the diagnosis of a hearing loss. Hearing loss can be classified in a variety of ways. The different types, causes, and degrees of hearing loss will be described in this section. Finally, a brief description of the stages through which parents progress in their acceptance of their child's hearing loss will be included. This section of the review of literature is the conceptual framework for the relationship between age deafness was detected and academic 
achievement, as well as the relationship between degree of hearing loss and academic achievement.

The third section of the review of literature presents an overview of cognition and language development in all children. A discussion of the critical age for language acquisition, as well as an overview of the stages of language development in hearing children, will also be included in this section. This section concludes with a description of the language-acquisition process of deaf children with deaf parents and deaf children with hearing parents. This section is the conceptual framework for the relationship between intellectual ability and academic achievement.

Section four of the review of literature describes the impact of the lack of communication on language and learning. The various types of communication used with deaf children, including different forms of sign language and oral-only communication, will be discussed. This section is the conceptual framework for studying the relationship between parental/school mode of communication and academic achievement.

The next section of the review of literature presents an overview of amplification devices, which are used to make sounds louder and outlines the need for amplification with deaf children. A basic description of the mechanics of an amplification system, along with the types of amplification, will also be outlined in this section. This section is the conceptual framework for the relationship between age at which amplification was first used and academic achievement.

The sixth section of the review of literature presents a general description of the educational options available for deaf children, including those available through Broward County Public Schools. These educational options range from residential programs to local public school day programs. In addition, a brief description of PL 94-142, the Individuals with Disabilities Educational Act (IDEA) will be presented. 
The seventh section of the review of literature describes the types of preschool programming of deaf children, as well as options within Broward County Public Schools. Public Law 99-457 ensured an education for handicapped children from birth through five years of age; this will also be reviewed in this section. This section is the conceptual framework for studying the relationship between type of preschool program and academic achievement, as well as the age at which the child began a preschool program and academic achievement.

The final section of the review of literature explores the academic achievement of deaf children and the services/opportunities provided in Broward County Public Schools. This section will also include a discussion regarding the various diploma options available to deaf/hard of hearing students in Broward County, as well as the requirements for each type of diploma.

\section{Section One: Historical Overview of Deaf Education}

The history of deaf education dates back to sixteenth century Spain, when the first documented attempt to educate deaf children was made by the Spanish monk, Pedro Ponce deLeon. Ponce deLeon was successful in his attempt to educate a group of deaf children from Spanish aristocracy (Kluwin, Moores, \& Gaustad, 1992). The students were first taught the names of objects and then how to pronounce them orally. Writing appeared to be the primary goal of instruction (Scouten, 1984).

As early as the eighteenth century, two distinct philosophies, or methods of instruction, have been prominent in the field of deaf education. Sign language and oral communication continue to be the primary modes of communication used with deaf children. There are other methods of communication that exist along a continuum between oral-only communication and sign language which will be identified and explained in a later section. 
There are three distinct circumstances that influenced the field of deaf education in the United States. Martha's Vineyard, Massachusetts was the site of the first important circumstance in the history of deaf education in the United States. The island, settled in 1720 , was heavily populated by deaf people due to the combination of inbreeding of the population and the presence of recessive genes for deafness (Moores, 1992). This large deaf population led to a community of hearing and deaf people who all used sign language to communicate (Carroll, 1997). This sign language was indigenous to the islanders (Lane, 1984). The sign language used by the inhabitants of Martha's Vineyard, in combination with the sign language brought to the United States by Clerc, formed the basis of what is known today as American Sign Language.

The second circumstance which later influenced deaf education in the United States was the establishment of an oral school for the deaf by Samuel Heincke in 1755 in Germany (Scouten, 1984). Heincke believed that spoken language was fundamental and he began to teach deaf children using the German Method, known today as the pure oral method (Heiling, 1995). Oral communication was supplemented with the use of the sense of taste as a way to teach students vowel sounds, as a specific vowel was associated with a specific flavor (Scouten, 1984). The oral method of communication was later brought to the United States as the choice method in the mode of communication used for the instruction of deaf children.

At approximately the same time, the third circumstance that later influenced deaf education in the United States occurred in Paris. The first school for deaf children to use sign language was established by Abbe Charles Michel de l'Epee (Kluwin, Moores, \& Gaustad, 1992; Scouten, 1984). He emphasized the importance of the manual alphabet and sign language as an avenue for the intellectual and religious development of deaf children (Heiling, 1995). The Abbe de l'Epee considered lip reading and articulation therapy as too time consuming compared to the aim of education, the transmission of knowledge (Heiling, 
1995). The method of sign language used by de l'Epee was known as methodical signs, or the French Method (Fischer, 1993).

\section{Deaf Education in the United States}

The concept of specialized schools or education for deaf children in the United States did not occur until 61 years later. Until the early nineteenth century, deaf children did not attend school. In 1816, Dr. Mason Cogswell, who lived in Connecticut with his deaf daughter, Alice, asked his neighbor, Thomas Gallaudet to become Alice's teacher. Gallaudet was home on vacation from his ministry studies and agreed to work with Alice. Gallaudet taught Alice her first words and her father was so pleased with her learning that he asked Gallaudet to go to Europe to learn more about the teaching of deaf children (Wolkomoir, 1992).

Gallaudet first visited an oral school in England run by the Braidwood family; sign language was not permitted. The Braidwoods did not want to share their methods of instruction with Gallaudet, who then traveled to Paris (Lane, 1984). While in Paris, Gallaudet met Laurent Clerc, a deaf instructor at the National Institute of Deaf-Mutes, where sign language was utilized as the mode of instruction. Gallaudet persuaded Clerc to return to the Untied States with him and assist in establishing the first school for deaf children in America (Wolkomoir, 1992). During the 52-day boat trip to America, Gallaudet learned French Sign Language while Clerc learned English. With contributions from friends, Gallaudet, Clerc, and Cogswell opened the Connecticut Asylum for the Education and Instruction of Deaf and Dumb Persons on April 15, 1817. It was later re-named the American School of the Deaf and is still open today (Lane, 1984).

During this time, there were three critical areas of focus in the education of the deaf. According to Moores $(1992$, p. 8), the three concerns were providing religious and moral training, vocational training, and the ability to read and write. The basis for the curriculum used at the time was derived from the National Institute of Deaf-Mutes in Paris and 
modified at the American School of the Deaf. It consisted of reading, writing, arithmetic, religion, and the rules of conduct (Moores, 1992). The curriculum was developed based on the teachings of Friedrich Froebel of Germany. Froebel advocated a curriculum focused on language and mathematics, with religion permeating the curriculum (Schubert, 1986).

Shortly thereafter, schools for the deaf began to be established throughout the United States. In 1818, the New York Institute for the Instruction of the Deaf and Dumb, now known as the New York School for the Deaf, was opened by John Stanfield. In 1820, the Pennsylvania Institute in Philadelphia was opened. One of the first industrial training programs in the United States was established at the American School for the Deaf in 1822 (Moores, 1992). Starting in the early 1900 's, that vocational education became an integral part of secondary curricula, although the Land Grant College Act was passed in 1862 (Kliebard, 1987). The Kentucky School, in Danville, was the first state supported school and it opened its door in 1823 (Lane, 1984). The National Deaf-Mute College in Washington, DC, later re-named Gallaudet University, was established in 1864 by an act of Congress. It was the first post-secondary program for deaf students in the United States (Quigley \& Kretschmer, 1982). Courses offered at Gallaudet included ancient and modern languages, social sciences, history, mathematics, philosophy, political science, and most importantly, a teacher-training program (Winzer, 1993). Clearly, the emphasis on vocational education now turned toward a more traditional, liberal arts curriculum which was supported at this time (Schubert, 1986). Even today, Gallaudet is the only liberal arts college in the United States which primarily serves deaf/hard of hearing students (Marschark, 1997).

Almost all deaf students in the United States, between 1817 and 1867, attended residential schools for the deaf. They all used the same method of instruction, sign language, and followed the same curriculum used at the American School for the Deaf. By 1867, 24 residential schools had been established (Moores, 1992). 
In 1867, The New York Institute for the Improved Instruction of Deaf-Mutes, the first pure oral school for the deaf in the United States, was established. This school continues to practice an oral philosophy today and is known as the Lexington School for the Deaf. At that time, Gardiner Hubbard was also attempting to establish an oral school for the deaf in Massachusetts. With private contributions, the Clarke School for the Deaf, in Northampton, Massachusetts, was also opened 1867 and today still follows an oral-only philosophy (Lane, 1984).

During this period of time, advocates of oral education began to publicly espouse their philosophical beliefs. One of the most prominent advocates was Alexander Graham Bell, who had married Mabel Hubbard, an oral deaf woman. Even though Bell knew sign language, he never used it with his wife. Dr. Bell suggested that deaf children be educated with hearing children and, furthermore, that deaf people should socialize with hearing people rather than just deaf people. He believed that residential schools led to marriages between deaf people, with the result that deaf couples would produce deaf children (Lane, 1984). Through his publications and testimony before the United States Senate, Bell proposed the elimination of the "educational segregation of the deaf," sign language, and the use of deaf instructors (Moores, 1992, p. 16). Bell's efforts in the Senate proved successful in recommendations being made to restrict sign language usage in classrooms and to allow deaf instructors to teach vocational courses only or to teach older deaf children (Moores, 1992). This marked the rise in the use of oral communication and a decline in the use of sign language in the education of deaf children.

Many deaf and hearing individuals disagreed with Bell's philosophy. His main opposition came from Edward Miner Gallaudet, the youngest son of Thomas Gallaudet. He was raised by a deaf mother and grew up with the deaf students at his father's Connecticut school. Gallaudet was also the president of the National Deaf-Mute College 
where a combined method of sign language and speech was advocated in the instruction of deaf individuals (Lane, 1984).

Oralists, those who used oral communication exclusively in the education of deaf children, believed that sign language would interfere with the deaf child's motivation in developing oral-aural skills, and that use of sign language would prohibit a deaf child's integration into a hearing community. Oralists also suggested that sign language was limited in use to the development of concrete thinking (Liben, 1978). This group lobbied against the use of sign language at the International Conference of Educators of the Deaf in Milan, Italy, in 1880. At this conference, it was decided that oral communication should be the preferred mode of communication used in the education of deaf children (Wolkomoir, 1992).

The debate between oral communication and sign language continued into the twentieth century. The early 1900's saw the birth of the publication, Silent Worker. The Silent Worker began as a school newspaper, but George Porter, a deaf instructor at the New Jersey School for the Deaf, expanded it to include the accomplishments of deaf people throughout the United States, as well as the world. The publication of this newspaper was suspended in 1929 when the new superintendent of this school advocated the exclusive use of oral communication. He also fired the majority of deaf teachers employed at the school and forced Porter to retire (Buchanan, 1993).

During the early 1900 's, oralism continued to gain prominence. Schools for the deaf where both sign language and speech were being used began to follow an oral-only philosophy. Some schools for the deaf only allowed the use of sign language with students believed to be mentally unable to advance through oral instruction (Buchanan, 1993).

The Silent Worker was re-established in 1948 by the National Association of the Deaf. The newspaper called for the re-introduction of sign language in the education of 
deaf students and the hiring of additional deaf teachers. It was not until 1976 that sign language was re-introduced at the New Jersey School for the Deaf and not until 1989 that they appointed their first deaf superintendent (Buchanan, 1993).

The two years between 1963-1965 marked an event which would greatly impact the field of deaf education. During this time, there was a rubella epidemic. According to Marschark (1997), between 30,000 and 40,000 deaf babies were born during this two year period. Between 1965 and 1975, due to the rubella epidemic and changes in legislation, the number of deaf students attending local public schools began to significantly increase.

According to Vernon (1988), the appointment of a deaf man, I. King Jordan, as president of Gallaudet University, was considered the single most important event in the history of deafness, which occurred after the student-body protest during March 1988 gained the attention of much of the world. Students shut down the University in protest over the appointment of a hearing president. On March 6, 1988, Elizabeth Zinser, a hearing woman, was named president of Gallaudet University. She was unable to sign, and, according to Orlans (1989), this was preferred over choosing a president who knew sign language. The Board felt that the ability to communicate among themselves and with Congress would be better than the ability to communicate with students and alumni. This belief was shared by many hearing parents who preferred that their child learned to talk rather than be able to communicate fluidly through sign language. On Monday, March 7, 1988, students marched from the campus to the Capitol and then on to the White House. On Wednesday, March 9, the faculty announced their support of the student protest and Zinser was asked to resign. Her resignation was submitted on Friday, March 11, 1988. Finally, the first deaf president of Gallaudet, I. King Jordan, was elected on Sunday, March 13, 1988 (Orlans, 1989).

The student protest was instrumental to the passage of the Americans with Disabilities Act (ADA) that benefits millions of Americans (Gannon, 1996). The ADA 
guarantees all handicapped students full access to private and public services (Marschark, 1997). For the deaf, this includes access to TDD's (telecommunication devices for the deaf), which are telephone systems for the deaf, as well as interpreters to facilitate communication between deaf and hearing individuals, at no charge to the deaf person.

\section{Section Two: The Identification of a Hearing Loss}

The first step in providing appropriate educational services for deaf children is the identification of their deafness. There are known factors which place babies at risk for hearing loss. In addition, babies exhibit certain behaviors which lead parents to suspect a hearing loss, which will be outlined in this section. The next step in the identification process is diagnosis of the hearing loss. This is achieved through an audiological assessment and will be reviewed in this section. The classification of a hearing loss by type, cause, age of onset, and degree will also be reviewed. Finally, once a hearing loss is confirmed, parents progress through a grieving process which may affect language development and this realization process. Finally, the determination of a course of action will conclude this section.

\section{Suspicion of a Hearing Loss}

Several factors have been identified that would place an infant "at risk" for a hearing loss and cause their name to be placed on a high-risk register at birth. A family history of hearing loss is the first factor. A history of maternal illness or maternal ototoxic drug intake during pregnancy is the second factor. The third factor is low birth weight and is considered to be a factor if the infant is below 3.3 pounds. The presence of other head, facial, or external ear abnormalities is the fourth factor. Prolonged neonatal jaundice also places an infant at risk for hearing loss. A sixth indicator that an infant is at risk for hearing loss is a low Apgar rating, which is a test given to all newborns to determine normal neurological functioning. A score of three or less one minute after birth, or a score of six or 
less five minutes after birth, places children at risk. Finally, admission to a newborn intensive care unit is an indication that the infant is at risk for hearing loss (Epstein, 1996). If a child displays any of these risk factors, an audiological assessment should be completed at once.

At specific ages, hearing children display typical behaviors. If babies fall behind or do not demonstrate these behaviors, they may have a hearing loss. By three months of age, a baby should be startled, cry, or be awakened by unexpected loud noises. A baby should stop playing when an interesting sound is made and enjoy playing with toys that make noise by six months of age. Babies who are nine months old should turn to sound and respond to specific words such as "no" and "bye-bye". A baby should attempt to imitate speech by twelve months of age, follow simple spoken directions, and say simple words by fifteen months of age (Diefendorf \& Weber, 1994).

Miller (1988) reports that babbling, which is the repetition of syllables (e.g., "ba ba ba") develops normally in deaf children, but will reach a plateau and cease. Deaf children are very aware visually and use vision to monitor their environment. They are tactually more sensitive to vibrations and movement than children with normal hearing. The use of gestures emerges within normal time limits or even appears early in deaf children, and gestures are used longer compared to hearing children. Deaf children will use these gestures until some other mode of communication is learned and their gestures become more sophisticated over time. Deaf children also lack normal stress, intonation patterns, and pitch in their speech (Miller, 1988). If any of these behaviors or delays in development are noted, a hearing loss may be present, and an audiological assessment should be completed immediately.

Prior to a diagnosis of deafness, hearing parents typically suspect something is wrong based on the behaviors of their child. According to Altshuler (1974), parents begin suspecting a problem in infants between six and twelve months of age. Parents may notice 
that their child does not respond to loud noises, no longer babbles or vocalizes, uses gestures rather than speech, or has poor speech and language development as compared to typical peers or siblings. Parents then may try to convince others that their child is different. Often, doctors and other professionals tell parents that they are just overanxious, further delaying the diagnosis (Adams, 1997; Seabrook \& Rodda, 1991). According to Moore, Josephson, and Mauk (1991, p.193), 36\% of the parents they surveyed were told by professionals that there was nothing wrong with their child's hearing and/or not to worry. Physicians who identify infants with a hearing loss should learn more about deafness and its consequences beyond the diagnosis, as well as the difficulties parents face when dealing with deafness (Altshuler, 1974).

\section{The Diagnosis of a Hearing Loss}

The next step in the identification of a hearing loss is the diagnosis. Approximately 5,000 infants are born every year who have a hearing loss (Moore, Josephson, \& Mauk, 1991). According to Marschark (1997), more than $90 \%$ of these deaf children are born into hearing families. For the most part, hearing parents do not detect their child's hearing loss at birth. Hearing loss is generally not detected until a number of the behaviors previously described are observed. Typically, deafness is not diagnosed until a deaf child is between the ages of two and three, with the exception of deaf children with deaf parents. Generally, deaf mothers of deaf babies will be able to detect their child's deafness by six months of age based on their child's interactions and behaviors (Marschark, 1997). A deaf child will have more opportunities to develop language the earlier the diagnosis is made (Seabrook \& Rodda, 1991). According to Desselle (1994), deaf children of hearing parents experience language delays because their deafness is not detected early enough to provide appropriate interventions in language development.

In order to determine which sounds a child can hear, a complete audiological assessment is done. This assessment will also identify how loud sounds need to be for the 
child to hear, and how well, if at all, the child can hear speech. There are two general types of audiological testing. One type , called physiological and electrophysiological testing, requires no response from the child. The second type of test requires a response from the child and is known as behavioral testing (Copmann, 1996). Specialized tests are used to detect hearing loss at birth (Adam, 1993). High-risk registers list babies who have an increased chance for problems. Because of these specialized tests and high-risk registers, deafness is now often being identified at a younger age (Adam, 1993).

The first type of test that may be used in an audiological assessment is the test that does not require a response from the child being tested. These are physiological and electrophysiological tests that are considered to be objective. There are two types of physiological and one type of electrophysiological tests. The first type of physiological test is impedance testing, which evaluates the functioning of the middle ear. The second type of physiological tests is otoacoustic emissions testing, which assesses the function of the inner ear, specifically the cochlea. The Auditory Brainstem Response (ABR) is an electrophysiological test which measures the response of the child's brain to sound through the measurement of the electrical activity of the brain (Copmann, 1996).

The second method in assessing hearing loss, behavioral testing, requires the child to respond to tones and speech. These tests are conducted in a sound-treated booth. There are four types of behavioral testing. The first two types are pure-tone tests which measure the child's ability to hear tones in the range of speech, through air conduction and through bone conduction. Speech reception threshold testing determines how loud speech must be for the child to hear it. The fourth type of test is word recognition or word discrimination testing, which measures how clearly the child can hear speech (Copmann, 1996).

\section{Classification of a Hearing Loss}

There are four parameters used when identifying a hearing loss. Based on the results of the audiological assessment, the type of hearing loss can be determined. The 
second parameter is the cause of the hearing loss which may be determined by the type of hearing loss. The third parameter is age of onset of the hearing loss. This determination is made in relationship to the development of speech and language. Finally, the degree or amount of hearing loss is determined, based on the audiological assessment.

There are four types of hearing loss. They are classified based on the part of the ear affected by the hearing loss: conductive; sensorineural; mixed; and central auditory. The causes of hearing loss may differ depending on the type of hearing loss, and in some instances, the cause of hearing loss is unknown.

"A conductive hearing loss results when the difficulty originates in the outer ear or middle ear and prohibits sound from transmitted to the inner ear (Epstein, 1996). With this type of hearing loss, the inner ear has normal functioning. The causes of this type of hearing loss include a blockage in the outer ear, otitis media (severe ear infection), a perforation of the tympanic membrane, or congenital malformations of the external ear (Shames \& Wiig, 1982). Conductive hearing losses are identified through poor air conduction test results, while bone conduction tests reveal normal hearing. A conductive hearing loss can often be corrected by surgical or medical methods, restoring normal hearing permanently (Epstein, 1996).

The second type of hearing loss is a sensorineural hearing loss which results when there is a problem with the cochlea or the auditory nerve (Ballantyne, 1977). The causes of this type of hearing loss include viral and bacterial infections, excessive exposure to noise, drug toxicity, head trauma, congenital abnormality, pre-mature birth, Rh factor incompatibility, and heredity (Marschark, 1997). Air and bone conduction thresholds are the same with a sensorineural hearing loss (Shames \& Wiig, 1982). This type of hearing loss cannot typically be corrected by current medical or surgical methods (Epstein, 1996).

A third type of hearing loss is known as a mixed hearing loss. It involves some degree of both a conductive and a sensorineural hearing loss (Newby, 1979). The 
conductive component of a mixed hearing loss may be medically or surgically treatable depending on the cause and severity of the hearing loss (Epstein, 1996).

The fourth type of hearing impairment is a central auditory disorder which is caused by any problem with the neural pathways from the brain stem to and including the cortex (Newby, 1979). According to Shames \& Wiig (1982), "a central auditory dysfunction manifests itself in decreased auditory comprehension" (p. 309). Air and bone conduction thresholds are within normal limits, although speech is unrecognizable or cannot be interpreted by the listener (Shames \& Wiig, 1982).

Hearing loss is also classified based on the age of onset of the hearing loss. Very often age of onset is compared to speech and language development. A prelingual hearing loss occurs prior to the development of speech and language (Epstein, 1996).

Communication, psychosocial, and educational delays are apparent in children who are prelingually deaf (Moore, Josephson, \& Mauk, 1991). A postlingual hearing loss occurs after the development of speech and language, which could be between anytime from age two through six. Typically, the longer a child has hearing, the greater his or her ability to maintain that knowledge of the previously developed language (Epstein, 1996).

Finally, hearing loss can be classified by the degree of hearing loss. Normal hearing ranges from $0 \mathrm{~dB}$ to a $25 \mathrm{~dB}$ hearing loss. Greater degrees of hearing loss can be divided into five categories. A mild hearing loss is classified by a $26-40 \mathrm{~dB}$ loss. A moderate hearing loss is classified by a $41-55 \mathrm{~dB}$ loss. A severe hearing loss is classified by a 56-70 dB loss. A severe-profound hearing loss is measured at 71-90 dB and a profound hearing loss is classified by a 91 and above dB loss (Marschark, 1997). The amount of hearing an individual has left is referred to as residual hearing (Copmann, 1996). According to Chasen \& Zuckermen (1976), more than $50 \%$ of the deaf population has a profound hearing loss. 
For the purposes of this research study, all four parameters will not be analyzed. The type of hearing loss will not be analyzed because all of the participants in this study have the same type of hearing loss: sensori-neural. The cause of hearing loss will also not be analyzed since the majority of participants have a hearing loss of unknown cause. The age hearing loss was detected and the degree of hearing loss will be analyzed.

The Grieving Process

'Learning that one's child is deaf can be an intensely stressful event. It has been described as the loss or death of parent's dream of a normal child" (Kampfe, 1989, p. 255). A family's ability to adapt to their child's diagnosis of deafness significantly impacts the child's development. Most parents of newly diagnosed deaf children progress through similar stages which include shock, denial, anger, and finally acceptance (Simpson, 1982; Kampfe, 1989).

Even though most parents suspect a hearing loss, initially, they experience shock when their suspicions are confirmed. During this stage, most information imparted by physicians and others is not "heard" by the parents (Seabrook \& Rodda, 1991; Kampfe, 1989). Once they overcome the shock, parents usually become depressed and go through a stage of denial. They feel that the diagnosis was mistaken (Altshuler, 1974; Marschark, 1997). This period of denial may last from a few months to several years and thus impacts parent-child interactions, especially language development, because without specialized communication the deaf child is not exposed to sufficient language to support further communication development (Adams, 1997). Next, parents proceed to a stage of anger which further delays the child's development of language since they can not access it adequately (Marschark, 1997). The last stage is one of acceptance, and not all parents reach this stage. Only after a child's hearing loss is truly accepted can parents begin to appreciate their child for his or her unique characteristics (Marschark, 1997). It is also at this time that parents can make decisions that will assist their child in his or her cognitive 
and linguistic development. These decisions include what mode of communication to use, type of amplification device to use, and participation in an early intervention program.

\section{Section Three: Cognitive and Language Development}

The third section of the review of literature presents an overview of cognition and language development in children. A discussion of the critical age for language acquisition, as well as an overview of the stages of language development in hearing children, will also be included in this section. This section concludes with a description of the language acquisition process of deaf children with deaf parents and deaf children with hearing parents.

Cognition

Over time there has been a change in beliefs regarding the intellectual ability of deaf people. Until the 1950 's, deaf people were thought to be intellectually inferior to hearing people. At that time, level of intelligence was determined through psychometric testing, which was heavily dependent on paper-pencil group tests. Between 1950 and approximately 1965 , it was thought that deaf people were "cognitively concrete" (Quigley

\& Kretschmer, 1982, p. 57), meaning that deaf people could not process abstract thoughts. Since then, it has been found that deaf people are intellectually equal to hearing people (Heiling, 1995; Zwiebel, 1987; Quigley \& Kretschmer, 1982; Sisco \& Anderson, 1978). According to Altsher (1974), deafness, without additional handicapping conditions, does not limit intellectual ability.

The procedures used to measure actual intellectual ability in deaf children are difficult because many of the intelligence tests currently used are language-based. These instruments require some type of linguistic communication, even if the test questions do not, which creates a disadvantage for deaf individuals (Heiling, 1995). In order to more accurately measure a deaf child's ability, non-verbal tests have been utilized. When 
intelligence tests are administered using non-verbal instructions and are not dependent on verbal responses, deaf children typically score within the normal range of intellectual ability (Meadow, 1980). Therefore, Sisco \& Anderson (1978) suggest that the best measures of intellectual abilities of deaf persons are performance scale or non-verbal intelligence tests. On visual-spatial tests, deaf children with deaf parents who use sign language as their first language score as well or better than hearing children (Heiling, 1995).

According to Menyuk (1976), “cognitive and linguistic development is an unfolding process that begins at birth" (p. 52). Christensen (1990) stated that thought does not depend on the acquisition of a linguistic system. In other words, deprivation of an accessible language should not hinder the development of intellectual ability in deaf children. According to Fromkin (1988), language acquisition is not dependent on the ability to use and hear sounds, but rather on cognitive ability. Unfortunately, deaf children often lack the opportunity to acquire information in the same manner hearing children acquire information. They also lose the opportunities for acquisition of knowledge through incidental learning. Research indicates the cognitive capacities for learning, thinking, remembering, and language are not distributed differently between deaf children and hearing children (Nelson, Loncke, \& Camarata, 1993; Liddell, 1983; Quigley \& Kretschmer, 1982). These authors further state that the deficits in language, thinking, or academics for many deaf children can most likely be the result of limited learning opportunities. In other words, the academic deficits faced by deaf children may be related to the lack of access to language rather than lack of intellectual ability. If access to language is the issue, deaf children exposed to language from birth through a visual channel should perform intellectual and academic tasks equal to hearing children exposed to language from birth through an auditory channel. In a study by Kusche, Greenberg, \& Garfield (1983), deaf children with deaf parents scored higher on non-verbal intelligence tests than deaf children with hearing parents. 
The Piagetian model of cognitive development suggests that thought precedes language and that they grow independent of each other (Tomlinson -Keasey \& Kelly, 1974). This model traces the development of thought and cognition through four stages. The first is the sensory motor stage, during which time the child coordinates sensory experiences with object concepts. The second stage is the pre-operational stage, when the child acquires a symbol system. The third stage is the concrete operational period, during which the child starts to make simple transformations of concrete words. The final stage, the formal operational period, is when abstract thought emerges. This stage occurs at approximately age twelve (Tomlinson-Keasey, 1974). Heiling (1995) suggests that, during the sensory motor stage of development and the majority of the pre-operational stage of development, deaf children generally develop normally.

It is not until the later stages of development that delays appear in deaf children. In a study by Meadow (1980), concepts were learned by deaf children in the same manner and sequence as hearing children, but occurred at a later age. The concepts of sameness and symmetry show little delays, while opposition presents difficulty for deaf children. Tasks involving classification skills are easier than understanding analogies for deaf children. The later stages of development are more heavily dependent on language than the early stages; therefore, children with language delays begin to fall behind in the later stages of cognitive development.

\section{Critical Period}

Delays for deaf children are evident in the area of language. According to Weisel (1988), the first few years are considered critical in the development of children. There appears to be an optimum, or critical, period for the development of language in children with normal hearing. Research indicates that basic language skills develop during the first few years of life, and that the critical period for learning language is generally the first two to three years of life (Marschark, 1997; Brasel \& Quigley, 1977). Moores (1982) adds that 
language development may peak at approximately age three and be on a steady decline thereafter. Wolkomoir (1992), states that there is a risk of permanent linguistic impairment if language is not learned during the first five years of childhood, prior to the brain's neural connections being locked into place. It is during this time, Brasel \& Quigley (1977) suggest, that the most rapid development of verbal language occurs.

\section{Normal Language Development}

Language is a necessary tool in the development of children. It is a symbol system and is separate from the physical action of speech (Tomlinson-Keasey \& Kelly, 1974). Verbal language is used to describe thought and to transmit those thoughts to others. It is also used to explore the dreams and experiences of other individuals (Christensen, 1990; Rogers, 1989; Altshuler, 1974). Language development in hearing children develops naturally. Children need to have an abundance of experience in conversations with adults in order to learn language, and their language emerges from the routines of their daily lives (Schirmer, 1994). These experiences and routines are facilitated by the parent or caregiver.

For children with normal hearing, the information, experiences, and thoughts they receive through the spoken language of their primary care-givers are critically important to their language development (Swisher \& Thompson, 1985; Brasel \& Quigley, 1977). Language plays an integral role in parent-child relationships from birth, or even prior to birth (Marschark, 1997). Parents typically bombard their child with language from birth. Schirmer (1994) \& Owens (1988) indicated that mothers and their children begin to have interactions which resemble conversations almost immediately after birth. Language is an interactive process.

Hearing children progress through specific stages of language development. Infants as young as four weeks of age can discriminate among forty consonant sounds. Cooing in babies occurs during the first few months after birth. At three to four months of age, a baby will begin to babble, and be able to use six to seven vowels and four to five consonant 
sounds. Infants also begin to smile at this age. An infant typically laughs out loud by age four to five months. At age six to seven months, an infant will begin playing with language, especially at bedtime and in the morning. Infants nine to twelve months of age start internalizing language. They are able to recognize their names and the word "no". During children's first year of life, language is developing and, before their first words are spoken, a backlog of information has been stored (Adam, 1993). By their first birthday, children understand more than they can tell you. They are able say several words and use those words to gain attention. At this stage, it is important that parents read to their children as much as possible and concentrate on vocabulary development (Miller, 1988).

Language evolves rapidly during the second year of childhood (Altshuler, 1974). Children at approximately eighteen months of age have an expressive vocabulary of at least 25 to 100 words. Two-word utterances emerge at this age and are used to convey meaning. By age two, hearing children have an expressive vocabulary of at least 150 to 300 words and a receptive vocabulary of approximately 600 words. They ask many questions and typically utter three to five-word sentences (Miller, 1988). According to Brownlee (1998), the average three-year-old child produces ninety percent of his or her sentences grammatically correct.

Children by age 30 months know their full name and seldom use less than twoword utterances. More verbs emerge along with the use of pronouns at this age. The expressive vocabulary is approximately 500 word while the receptive vocabulary is approximately 1,000 words. By the age of three, children are able to talk about different themes in a picture, and have increased their expressive vocabulary to 1,000 words and their receptive vocabulary to almost 2,500 words. By this age, children use more modifiers and use pronouns more accurately (Miller, 1988).

The time between three-and-a-half and four years of age is extremely important for language development. By this age, the basic rules of language have been acquired by 
children and they have a solid language foundation (Miller, 1988; Meadow, 1968). They use adverbs, tell stories, and express their feelings. Expressive vocabulary of a children this age is comprised of 2,000 words, while their receptive vocabulary includes over 4,000 words (Miller, 1988).

By the age of five, children typically speak like an adult. They have a 2,500 to 3,000 word expressive vocabulary and a receptive vocabulary of more than 10,000 words. The growth in their expressive and receptive language skills continues to increase and, by their sixth birthday, children have an expressive vocabulary of 3,000 to 3,500 words and a receptive vocabulary of 15,000 to 20,000 words. Children at this age use at least six-word utterances and are able to explain the differences between objects. Six year old children usually have good pronunciation and grammatical usage (Miller, 1988). "By the age of six, and certainly by the age of twelve, most children have mastered fully the grammar of their native language (Maller, Singleton \& Supalla, 1997). According to Geer \& Schick (1988), a critical factor in language development, despite the language or mode of communication, is constant language stimulation through elementary school. In other words, language stimulation must be consistent whether oral communication or some type of sign language system is being utilized.

In children with normal hearing, the verbal language acquired during early childhood provides a foundation for later language development and learning (Brasel \& Quigley, 1977). A language-rich environment is imperative in order to capitalize on this optimal period for language development (Adam, 1993).

\section{Deaf Children of Deaf Parents}

Deaf children of deaf parents provide researchers a unique view of natural language development of deaf children. Typically, deaf parents communicate with their children using sign language in much the same way hearing parents communicate with their hearing children through spoken language. Therefore, deaf children with deaf parents and deaf 
children with hearing parents have been compared in the areas of academic achievement and communication skills.

According to Desselle (1994), deaf children of deaf parents do not appear to have language delays. The language acquisition of deaf children of deaf parents occurs naturally and acquisition of sign language is just as effortless as the acquisition of spoken language in hearing children with hearing parents, occurring in the same systematic, regular, and productive manner (Bellugi \& Klima, 1972). Furthermore, the milestones of language development in hearing children of hearing parents and deaf children of deaf parents appear to be the same, in spite of their different modalities (McEntee, 1994; Bellugi \& Klima, 1972). Specifically, "deaf children of deaf parents babble with their hands the way hearing children babble with their voices" (Liddell, 1993, p. 38). They string signs together similarly to the way hearing children string spoken words together (Liddell, 1983).

Deaf children of deaf parents do not experience language barriers. Therefore, they are not cognitively and linguistically delayed when they attend school. The research indicates that deaf children raised by deaf parents score higher on achievement and intelligence tests, and are more likely to succeed academically, than deaf children of hearing parents (Marschark, 1997; Ritter-Brinton \& Stewart, 1992; Mueller-Vollmer, 1990; Geers \& Schick, 1988; Weisel, 1988; Parasnis, 1983; Sisco \& Anderson, 1978).

Deaf children of deaf parents differ from deaf children of hearing parents in two ways. First, deaf parents are less traumatized by the birth of a deaf child. Second, deaf parents have a method of communicating with their deaf child from birth (Parasnis, 1983; Messerly \& Aram, 1980; Meadow, 1968).

Parasnis (1983) and Vernon \& Koh (1970) found that deaf parents often had less education than hearing parents. However, because deaf parents were able to communicate with their deaf children through sign language, their children received much more benefit educationally. These benefits were in the development of basic language competence and 
cognitive development (Parasnis, 1983 and Vernon \& Koh, 1970). In another study by Weisel (1988), the results also suggested that the difference between deaf children of deaf parents and deaf children of hearing parents may be attributed to environmental factors such as early and continuous exposure to sign language. Knowledge of the factors that contribute to the better academic performance of deaf children of deaf parents can lead to improved intervention strategies which would benefit deaf children of hearing parents (Weisel, 1988).

\section{Language Development of Deaf Children}

Unlike deaf children of deaf parents, deaf children of hearing parents, generally, are not exposed to sign language or even a rich oral communication environment at birth. Delays in the identification of a hearing loss impact the language development. "Research shows that deaf children born to the majority of hearing parents are linguistically disadvantaged" (McEntee, 1994, p. 5). Language delays in deaf children are typically the result of a "lack of access to a language model" and not typically associated with problems in cognitive or neurological development (Spencer, 1996, p. 867; Meadow, 1980; Chasen \& Zuckerman, 1976; Tomlinson-Keasey \& Kelly, 1974; Meadow, 1968). The lack of access to language is caused by an impaired auditory channel which limits natural development of language.

Hearing children receive input through five sensory pathways: vision, hearing, smell, taste, and touch. Deaf children are limited to four sensory pathways. According to Ross \& Giolas (1978), children will learn language if their functioning sensory pathways are continuously stimulated. Bellugi \& Klima (1972) state sign and speech's basic difference is in the organs which perceive them: the eye and the ear. Deaf people analyze language through sight and cannot communicate unless they can see each other, while hearing people analyze language through sound. Therefore, language input needs to be channeled through a deaf child's four available sensory pathways. 
Even after a hearing loss is identified, it takes a long time for deaf children to learn to lip read effectively and/or be able to take advantage of their residual hearing. During this time, deaf children do not have complete access to language. They only receive language input that is addressed to them directly, in face-to-face interactions (Taeschner, Devescovi, \& Volterra, 1988). According to Quigley \& Kretschmer (1982), from infancy to early adulthood, the establishment of a fluent system of communication, which can be integrated as a language foundation, should be the primary goal of parents with a deaf child. This internalized language can then be used as a foundation on which secondary systems, such as reading and writing, can be developed (Quigley \& Kretschmer, 1982).

The research indicates that spoken language used with deaf children differs from spoken language used with hearing children. Spoken language used with deaf children is often simpler in form as well as content (Taeschner, Devescovi, \& Volterra, 1988). Deaf children also process language differently than hearing children. Moores, Weiss \& Goodwin (1978) found that deaf children also process English sentences incorrectly and that most errors can be attributed to three rules: the reversal of noun phrases, the treating of passive sentences as active, and the processing of negative sentences as positives.

A child's expressive language, oral or sign, is the basis for reading and writing. Schirmer (1994) found deaf children's written language development is linked to their spoken and sign language development. Furthermore, reading development is also an important aspect of written language development. Research conducted by Rodda, Cumming \& Fewer (1993) identified four major weaknesses in the written language of deaf students. The first major weakness is the linguistically-deprived environment in which deaf children grow up. Pedagogical weakness is the second contribution to the poor writing skills of deaf children, which includes "inadequate communication skills, lowered expectations, inability to motivate adolescents, inordinate emphasis on classroom communication to foster language skills, and emphasis on correction of individual unrelated 
sentences on the part of teachers" (Rodda, Cumming, \& Fewer, 1993, p. 344). The third weakness is limited vocabulary, which leads to increased grammatical errors. Finally, there is concern that the linguistic differences in sign language used in late childhood may limit the development of English language skills (Rodda, Cumming, \& Fewer, 1993).

Deaf children need to develop language at the same rate as hearing children. "By opening communication and enhancing the development of language on its age-specific schedule, and by coming to accept only the realistic and not the excessive limitations that come out of personal fantasies about the handicapped, parents can enable the deaf child to grow to maturity and intelligence, as a productive, responsible, and reasonably welladjusted adult" (Altshuler, 1974, p. 375). According to Marschark (1997), as long as deaf children have equal opportunities, such as early detection of hearing loss, a language-rich environment, and access to incidental language, they could be as happy, smart, and successful as hearing children.

\section{Section Four: Communication}

Communication is the method used to express and receive information. It can be conveyed through speech, vision, gestures, sign language, hearing, body language, touch, and even taste. Regardless of the method used to communicate, it is important to the natural development of language in children. Approximately $88-90 \%$ of the deaf population with hearing parents have no communication system at home other than informal gestures (Meyers \& Bartee, 1992). Williams (1994) stated that parents and children must develop a shared language and communication system for there to be meaningful interaction. Furthermore, Moores, Weiss \& Goodwin (1978) indicated that deprivation of effective communication during a child's first five years of life has immense implications for problems in later pyschoeducational development. Finally, according to Menyuk (1976, p. 
252), normal development is dependent on the early establishment of a communication system with free access to age- appropriate experiences.

Deaf children use a formalized communication system once they enter a schoolbased program. The research shows that most deaf children will use some type of formal communication system at school, but have still no method of meaningful communication at home (Meyers \& Bartee, 1992). Therefore, learning and meaningful interaction basically stop once the deaf child leaves the school setting. All the information children receive through incidental language, in addition to direct language, is lost when there is no viable communication system within the home. Research has also shown that typical teenage problems may become worse with deaf adolescents who do not have a satisfactory method of communication with their parents. Often parents give up the role of protector which results in a deaf teenager with little guidance from his or her parents (Charlson, Strong \& Gold, 1992).

Children without a method of communication begin to feel isolated. Research has shown that young deaf children are often isolated from meaningful interactive experiences, particularly during the earliest years of their life. This isolation is often the direct result of communication barriers imposed by their hearing loss (Williams, 1994; Kluwin, Gaustad \& Gonter, 1991). The results of a study by Charlson, Strong \& Gold (1992) indicated that even successful deaf adolescents experience feelings of isolation. This isolation is almost always attributed to communication difficulties in the home.

Not only do deaf children experience language deficits and feel isolated, this lack of communication can effect their academic achievement. Research has shown that lack of a rich communication environment during early childhood and the deficient communication skills of the family have directly effect the academic achievement of deaf children (Meyers \& Bartee, 1992; Greenberg, 1980). The Commission on Education of the Deaf "emphasized the importance of helping parents achieve effective communication with their 
deaf children" (Ritter-Brinton \& Stewart, 1992, p. 1992). Any type of communication will be beneficial. Parents should be informed of every method of communication and encouraged to use any method that will assist their child in developing a language base. A study by Charlson, Strong \& Gold (1992) indicated that the need for good communication should be the most constant message given to hearing parents of deaf children. Language development and enriching experiences are also dependent on the ability of the extended family to communicate with the deaf child using the child's mode of communication (Williams, 1994).

Parents must decide which mode of communication to use with their child. Spoken language and sign language seem to activate the same areas of the brain, the posterior temporal occipital area, but sign language stimulates the occipital area more than spoken language. According to a study by Moores, Weiss \& Goodwin (1978, p. 930), "it appears that a child who develops proficiency in one mode will be likely to develop adequate skills in the others." Which method of communication to use with deaf children has been an area of contention for more than 200 years. Research has shown that the largest single influence on the mode of communication a mother chooses is related to the child's degree of hearing loss (Kluwin, Gaustad \& Gonter, 1991).

Sign Language Communication

American Sign Language (ASL) is a distinctive language which emerged from the blending of the methodical signs of the Abbe de l'Epee and the sign language that existed on Martha's Vineyard. Various artificial hybrids combining English and ASL have been also developed. These hybrids were developed to assist children in the acquisition of reading and writing (Marschark, 1997). These signed languages exist along a continuum between ASL and English.

Just as there is no universal spoken language, there is no universal sign language. ASL is a specific language used throughout the United States and parts of Canada. British 
Sign Language and Italian Sign Language are as different from one another as are their spoken languages. ASL is most similar to French Sign Language (Marschark, 1997).

ASL has its own distinct grammar, vocabulary, and syntax which differs from that of spoken English (Gallimore \& Woodruff, 1996; Heiling, 1995; Liddell, 1983; Quigley \& Kretschmer, 1982). ASL is a visual language and continues to evolve, but since the 1960's, its use has increased (Marschark, 1997).

Pidgin Signed English (PSE) was developed naturally among deaf and hearing individuals. It is a hybrid sign language that is a mixture of standard English and ASL. Signing occurs in English word order while retaining and using the literal meaning of ASL signs (Marschark, 1997; Gallimore \& Woodruff, 1996).

Manually Coded English (MCE), another hybrid sign language, is simply a translation of spoken English into manual signs (Schwartz, 1996). There are three types of MCE. Signed English is similar to PSE in that signing occurs in English word order and uses ASL signs. However, Signed English also uses fourteen markers combined with signs to express English structure (Marschark, 1997; Schwartz, 1996). These markers indicate elements of grammar such as past tense, plurals, possessives, and pronouns (Schwartz, 1996). Seeing Essential English (SEE 1) approximates spoken English. This system uses ASL signs supplemented by invented signs to represent root words and the inflectional system of English (Quigley \& Kretschmer, 1982). The combinations do not make conceptual sense, but do make spelling sense (Marschark, 1997). Signing Exact English (SEE 2) uses the same rules as SEE 1, but root determination differs (Quigley \& Kretschmer, 1982). SEE 2 retains the use of ASL signs whenever possible (Schwartz, 1996). Fingerspelling is another method of communication used with deaf children. It uses 26 handshapes to represent the 26 letters of written English. The Rochester Method uses fingerspelling to manually spell every word in the conversation, while the hand is held close to the mouth in order to supplement the process with speechreading. Most often it is 
used as a supplement when a conversational sign is unknown or obscure (Marschark, 1997).

Total Communication (TC) is a philosophy of communication. TC uses a sign language system, gestures, fingerspelling, speech, speechreading, and amplification during the instruction of deaf children (Bodner-Johnson, 1996; Liddell, 1983; Greenberg, 1980; Chasen \& Zuckerman, 1976). According to Greenberg (1980), TC proponents suggest that the communication environment is richest when sign language is used in conjunction with speech. The TC approach allows children to receive information in the manner that is best for them.

As described, there are various types of sign language systems that can be utilized with deaf children. Much of the research indicates that some type of sign language should be used. According to Tomlinson-Keasey \& Kelly (1974), deaf children of hearing parents can not use the auditory mode to integrate information, therefore, the natural symbol system among deaf children needs to be gestural. Unfortunately, hearing families are not well-versed with a gestural language and are often hesitant to encourage its use (Tomlinson-Keasey \& Kelly, 1974). If a sign language system is not established as early as possible, the child is at a high risk for difficult and delayed language acquisition. A deaf child's language acquisition may be negatively affected by his or her parents' lack of fluent signing ability (Spencer, 1992). Finally, Moores, Weiss \& Goodwin (1978) also state any delay in the use of sign language can be educationally harmful for deaf children. Needless to say, those who advocate oral communication do not agree with this research.

As previously discussed, sign language acquisition occurs quite naturally for deaf children when it is presented to them in a natural, consistent environment. Actually, signs often emerge prior to spoken language since hand movements naturally develop prior to vocal movements (Marschark, 1997; McEntee, 1994). The research indicates that deaf children exposed to sign language as early as possible will follow the same developmental 
language stages as hearing children exposed to spoken language (Marschark, 1997;

Schirmer, 1994; Geers \& Schick, 1988; Taeschner, Devescovi \& Volterra; 1988; Quigley \& Kretschmer, 1982; Altshuler, 1974). According to Spencer (1992), deaf infants acquire their first expressive signs at the same age hearing children acquire their first expressive words, even with mothers who have limited sign language skills. In a study by Spencer (1996), deaf children of deaf parents use expressive signs at or prior to one year of age, and midway through two years of age they are able to produce two-sign combinations.

It is important that parents become involved and learn sign language if it is the mode of communication they decide to use with their child so that their child can experience language as early as possible (Brownlee, 1998). According to Marschark, (1997), “over $80 \%$ of American school children with severe to profound hearing losses now receive some kind of sign language education in school" (p. 48). Parasnis (1983) stated that deaf children of hearing parents typically were not exposed to sign language until they attended school. Marschark (1997) goes on to say that "fewer than half of the children who use sign language in school also sign when they are with their families, and only a small fraction of those are able to carry on normal, everyday conversations with their parents" (p. 47). Therefore, it is important for hearing parents to be taught sign language so that exposure to language can occur in the home as well as in school. Unfortunately, most parents who choose sign language for their deaf child's mode of communication at school do not learn sign language or become involved with the educational programming (Nicholas, 1993). In a study by Howse \& Fitch (1972), deaf preschool children, whose hearing parents learned sign language, responded more accurately to picture cues than deaf children whose parents did not learn sign language.

Sign language is a natural, easy method of communication for deaf children. Research indicates that the earlier parents begin using sign language, the more likely the deaf child will grasp the concepts of language and communication, as well as create an 
adequate language foundation for future learning (Desselle, 1994; Geers \& Schick, 1988).

Parents are often concerned that early use of sign language will hinder later English skill development, such as speech, reading, and writing. Research shows that sign language knowledge does not hinder the learning of English or other symbol systems (Geers \& Schick, 1988; Tomlinson-Keasey \& Kelly, 1974).

Parents generally want their children to be like them. Hearing parents, therefore, strive for their deaf children to use speech as their method of communication. According to Meadow (1968), many professionals involved with parents of newly identified deaf children warn parents not to use sign language because of their belief that the children will not be motivated to learn speech or speechreading. Marschark (1997) also stated that some parents may delay the learning and use of sign language, hoping that the child will develop better speech skills. Hill (1993) indicated that a child's ability to learn a second language was based on their competence in their first language. Therefore, speech should be taught after the deaf child is fluent in his or her natural sign language. Research studies have shown that speech acquisition is not impeded or negatively correlated with early use of sign language (Marschark, 1997; Musselman \& Kircaali-Iftar, 1996; Quigley \& Kretschmer, 1982; Chasen \& Zuckerman, 1976; Altshuler, 1974; Vernon \& Koh, 1971; Stuckless \& Birch, 1966).

Although speech is an important aspect of communication in the hearing world, other language abilities, specifically in reading and writing, are imperative for school success. As noted, sign language can be used as a base on which other aspects of language, specifically reading and writing, can be taught. Research shows that deaf children exposed to sign language at an early age exhibit better receptive and expressive language skills than deaf children exposed to an oral-only language environment (RitterBrinton \& Stewart, 1992; Mueller-Vollmer, 1990; Geers \& Schick, 1988; Musselman, Lindsay \& Wilson, 1988; Watkins \& Clark, 1988; Greenberg, 1983; Parasnis, 1983; 
Greenberg, 1980; Altshuler, 1974; Vernon \& Koh, 1971; Vernon \& Koh, 1970; Stuckless \& Birch, 1966). Research also indicates that deaf children who experience early exposure to sign language demonstrate higher academic achievement than deaf children from oralonly language environments (Marschark, 1997; Kusche, Greenberg \& Garfield, 1983; Chasen \& Zuckerman, 1976; Altshuler, 1974; Vernon \& Koh, 1971; Vernon \& Koh, 1970). Specifically, Vernon \& Koh (1970) found that the academic achievement of children who used sign language was 1.2 to 1.6 grade years higher than children who used oral-only communication. In addition, Meyers \& Bartee (1992) found that the better the signing skills of the family, the better the academic achievement of the deaf child. LuetkeStahlman \& Milburn (1996) found that deaf/hard of hearing students using SEE 1 achieved closer to their actual grade level than those students using other modes of communication on the Stanford 9, reading comprehension and math computation. In a study by Andrews, et. al. (1997), deaf students who attended a bilingual-bicultural program from preschool through first grade achieved at grade level on the Stanford 9. Finally, Zwiebel (1987, p. 19) found gains in cognitive development in those students exposed to manual communication. This study also indicated that children exposed to sign language scored higher on intelligence tests than those not exposed to sign language.

This researcher believed a great deal more literature on the various types of sign languages and their relation to academic achievement would be available. Various searches were unsuccessful in locating information on the specific types of sign languages and their relation to the academic achievement of those deaf students who employ their use.

\section{Oral Communication}

The oral method of communication uses speech and speechreading for communication purposes, with the additional benefit of amplification and residual hearing (Gatty, 1996; Greenberg, 1980). Oral communication requires the use of spoken language only; manual communication is not required (Gatty, 1996). According to Liddell (1983) 
and Chasen \& Zuckerman (1976), those who supported oral-only communication (oralists) feel that the use of sign language would inhibit the deaf child's ability to speak or speechread.

Since only $30 \%$ of speech is visible through speechreading, deaf children need to learn methods to supplement the gaps (Gatty, 1996). One of these methods is known as Cued Speech, which is considered a variation of oral communication. Eight handshapes are used to manually support spoken English. These handshapes represent phonetic elements of speech typically not visible through speechreading. The eight handshapes are combined to show exact pronunciation of words (Williams-Scott \& Kipila, 1996; Quigley \& Kretschmer, 1982).

Oral communication requires intensive programming for deaf/hard of hearing students to achieve success. According to Quigley \& Kretschmer (1982), comprehensive oral programs exist at only three major United States schools for the deaf: Central Institute for the Deaf, St. Louis, Missouri; Clark School for the Deaf, Northampton Massachusetts; and St. Joseph's Institute for the Deaf, St. Louis, Missouri. Successful oral programs follow a specific curriculum that stresses strong academics and expects graduates to show high academic achievement (Gatty, 1996). The reasons for the success of these residential programs are that they are selective in student admission and provide a full-service, fulltime program for students. The comprehensive services necessary to achieve successful oral communication may not be provided in a typical public school program since students attend only during the day and programs must admit all students (Quigley \& Kretschmer, 1982).

Deaf children miss a great deal of information during daily oral conversations and most hearing parents of deaf children use only oral communication with their deaf children. "In the 1960's, about $90 \%$ of hearing parents used only spoken language with their deaf children, while the remainder used one or more of the forms of manual communication..." 
(Marschark, 1997, p. 47). The same remains true today. Successful oral communication is not simply using speech to communicate with a deaf child. It is labor intensive and requires specialized training. The research with certain types of deaf children shows that, when oral communication is actively and consistently pursued, impressive results can be obtained. These students typically have above average intelligence, have literate and highly motivated parents, and are involved with professionals committed and highly trained in the use of oral methods of communication (Quigley \& Kretschmer, 1982). Success of oral communication programs also depend on the child's use of his or her hearing aids and ability to understand sounds (Nicholas, 1993).

\section{Section Five: Amplification}

Hearing aids are simple devices consisting of a microphone, a receiver/amplifier with volume control, a miniature speaker, a battery, and an earmold. There are various types of amplification devices that differ in style, model, and color, but all hearing aids basically function in the same manner. "Amplified sound picked up by the microphone passes from the receiver to the speaker, through a tube, and into the plastic earmold, which is custom-molded for each user to ensure a snug fit" (Marschark, 1997, p. 37). The hearing aid makes all sounds, not only speech, louder. Hearing aids do not clarify speech or make it understandable to the receiver and too much amplification may cause further damage to the hearing mechanism. However, hearing aids can be very beneficial for a child with residual hearing (Marschark, 1997).

There are a variety of amplification devices. They include conventional hearing aids, FM systems, bone conduction hearing aids, tactile hearing aids, and cochlear implants. One type of hearing aid is known as a conventional hearing aid. This type can be worn ear-level (behind-the-ear) or body level. The ear-level aids allow for binaural 
amplification, while the body-level aids allow for greater amplification (Roush \& Gravel, 1994).

Another type of amplification device is an FM system, or auditory trainers. It consists of a microphone/transmitter, worn by the speaker, one or more receivers, worn by the deaf person, and an antenna for each receiver. FM systems are used to counteract the effects of noise and distance (Roush \& Gravel, 1994; Adam, 1993). FM systems greatly reduce "the degradation created by a noisy environment by improving the signal-to-noise ratio and by making speech significantly louder than the noise in the background" (Adam, 1993, p. 47).

Bone conduction devices are also a type of amplification device. They may be used when external ear anomalies prevent the use of typical types of hearing aids. The amplified sound is converted to vibrotactile stimuli and then transmitted directly into the inner ear via a bone conduction device on the head (Roush \& Gravel, 1994).

An alternative amplification device for deaf children with no residual hearing is a tactile aid, which receives acoustic information and decodes it on the child's wrist, arm, leg, back, sternum or stomach. Unfortunately these devices detect all sounds, not only speech (Roush \& Gravel, 1994).

The last type of amplification device to be discussed is the cochlear implant. This device is comprised of electrodes that are surgically implanted into the cochlea. "The cochlear implant, which consists of a magnet, a receiver-stimulator, and a banded array of 22 electrodes, is surgically implanted in the child's mastoid bone, just behind the ear" (Roush \& Gravel, 1994, p. 75). A microphone, worn externally, connects to a speech processor via a cable which can be harnessed around the child's waist. Cochlear implants are typically used with prelingually deaf children who are at least 24 months of age, and who do not benefit from amplification devices such as FM systems or hearing aids. Students who receive cochlear implants must participate in extensive training in order to use 
and benefit from the device (Marschark, 1997; Roush \& Gravel, 1994; Adam, 1993). According to Adam (1993), success of the cochlear implant is dependent on the family's involvement and commitment to oral education.

One of the amplification devices just discussed must be used with deaf children as early as possible. Adam (1993) stated that amplification should be used as soon as an earmold can be made for the infant. As previously described, hearing loss is typically not diagnosed for several years and the use of amplification should not be delayed once a hearing loss is diagnosed. According to Moore, Josephson \& Mauk (1991), the average delay between parents' initial suspicion of hearing loss and the initiation of amplification was more than 16 months. On average, the child is past the age of three before being fitted for amplification (Moore, Josephson \& Mauk, 1991).

Delays in the use of amplification may further hinder language development in deaf children. Ross \& Giolas (1978) state that for maximum development of speech and language through audition, early amplification is necessary. Ross \& Giolas (1978) specifically indicated, "one reason for early management is that a delay in stimulating the auditory pathways may produce auditory sensory deprivation effects, with a consequent reduction in the speech and language development mediated auditorily" (p. 266).

\section{Section Six: Placement Options}

Educators and parents of deaf/hard of hearing children agree that education of deaf/hard of hearing children is very different from that of other children, whether they are disabled or not. Specifically, these differences are manifested as limited language skills and specialized communication needs (Brill, MacNeil \& Newman, 1986). There are a variety of educational placement options which consider these differences in programming. They range from residential programs, which are separate, specialized schools for deaf students, to local public school programs, where deaf/hard of hearing children are educated along 
with hearing students. Whichever program parents select, parent involvement is essential. According to Morgan-Redshaw, Wilgosh \& Bibby (1989), all aspects of educational planning must include parents as active participants. Selection of a school program are affected by family decisions about the mode of communication to be used in the home, the use of hearing aids, and speech training (Meadow-Orlans \& Sass-Lehrer, 1995).

Residential programs are separate schools and facilities that were established because of the low incidence of deafness in individual communities and the special communication and educational needs of deaf children (Moores, 1992). These schools allow students to be grouped homogeneously from a large geographic region and provide qualified personnel to deliver appropriate services (Brill, MacNeil \& Newman, 1986). Deaf house-parents are typically employed to supervise students after school hours and serve as communication models. According to Moores (1992, p. 11), "programs for the handicapped (the blind, the retarded, and the deaf) that were developed in the early and middle nineteenth century essentially reflected an optimistic view of the potential benefits of education and training." The first residential schools for the deaf were built in cities, while later schools for the deaf were built in rural areas. Often, schools for the blind shared location sites and administrative staff with the schools for the deaf (Moores, 1992).

Parents select residential programs for specific reasons. Traditionally, deaf parents choose to send their deaf children to residential programs because of the cultural aspect. Residential programs employ more deaf adults than typical public school programs. These individuals serve as role models for deaf children and their fluent use of sign language benefits the deaf child (Marschark, 1997). In a study by Bernstein \& Martin (1992), approximately $71 \%$ of the parents surveyed moved their children to a residential school because they felt that the public school program was not adequate. These parents believed that their child would receive an optimal education in a residential program, and would have increased opportunities for free, easy communication. In a study by Charlson, Strong \& 
Gold (1992), deaf students in residential schools felt better able to communicate with their teachers and peers, as well as having greater opportunities to participate in extra-curricular activities than did students in a typical public school program.

There have been changes in residential school placements throughout history. Prior to 1945 , the majority of deaf students attended residential schools for the deaf. By 1960 , the majority of deaf students attended some type of day program, private or public. A day program is one in which students attend school during the day, but live at home. In 1979, approximately $30 \%$ of all deaf students attended a residential program, while $70 \%$ attended a day school program (Quigley \& Kretschmer, 1982). In 1984, 28\% of all deaf students attended residential schools, while $72 \%$ attended day schools. The percentage of students attending a residential program decreased again by 1994 to $21 \%$, while the percentage of deaf students attending a day program increased to $78 \%$ (Schildroth \& Hotto, 1996). In 1997 , only $20 \%$ of all deaf students in the United States attended a residential school, while approximately $80 \%$ attended some type of day school (Holden-Pitt \& Diaz, 1998).

Another option available to parents of deaf/hard of hearing children is a public school program in the deaf student's boundaried school district. This environment provides opportunities for deaf students to participate with hearing peers in a variety of curricular and extra-curricular activities, including advanced academic programming, a wide variety of competitive sports, and clubs or organizations within their local school district, which may or may not be available at a residential school. Options within this setting include self-contained classes and partial or full inclusion in general education classes with internal and/or external teacher and/or interpreter support (W. Gonsher, personal communication, September 10, 1998).

Local public school programs have also been selected by parents of deaf/hard of hearing children for a variety of reasons. Parents choose programs and special classes available through their local public school in order for their children to live at home and 
commute daily to school (Marschark, 1997; Bernstein \& Martin, 1992; Brill, MacNeil \& Newman, 1986). Local public school administrators also influence parental choice of school placement because administrators believe that the needs of all children with disabilities can be met at the local level. Also, local school education is less costly than residential placements, which appeals to legislators (Brill, MacNeil \& Newman, 1986). According to Moores (1992), it has only been since 1977 that a large number of deaf children have attended local public school programs.

The precedence for local public school education for deaf children dates back to the early nineteenth century. In England during that time, "there were several national movements to integrate deaf children into the public schools" (Moores, 1992, p. 14). These attempts failed because the curriculum was not modified to meet the needs of language delayed students. In addition, no specialized instructional support was provided for the deaf children(Moores, 1992).

There are a variety of local public school programs currently available to deaf/hard of hearing children in Broward County. Program placement is based on individual need and is determined through an Individual Education Plan (IEP) staffing. Programs include boundaried school placement or cluster school placement.

Deaf/hard of hearing students enrolled in their boundaried school may receive instruction from a general education teacher or from a general education teacher with the additional services of an itinerant teacher of deaf/hard of hearing children. Deaf/hard of hearing children enrolled in an itinerant program receive the majority of their instruction from a regular education teacher within a regular education class. Modifications and adaptations are made to the learning environment and/or curriculum based on student need. A certified teacher of deaf and hard of hearing students travels to several schools, providing specialized services to the deaf child on a regularly scheduled basis. Specialized services may include, but are not limited to, remediation, assistance with speechreading, and 
auditory training. The amount of time an itinerant teacher spends with the deaf child varies and is dependent on student need, but typically, does not exceed five hours per week. Interpreting and notetaking services are also available based on student need. Audiological services are provided on an as-needed basis. Most, students attending their boundaried school are able to access the general curriculum with minimal modifications and supports. (W. Gonsher, personal communication, September 10, 1998).

Deaf/hard of hearing students can also access a specialized day program. Broward County has developed these programs at specific sites throughout the district and are referred to as cluster programs. There is one centrally located high school and one middle school. Students attending the high school program receive their instruction through a Total Communication (TC) mode. Students attending the middle school have the opportunity of an oral program or a TC program. There are three elementary cluster programs which utilize either oral communication only or the sign language based approach. Finally, there is one preschool program centrally located which also provides both oral and sign language modes of communication.

A variety of options are available at these cluster sites. Students can be partially integrated into regular education classes where they follow the regular education curriculum, with necessary modifications and adaptations. An educational interpreter or a teacher of deaf/hard of hearing accompanies the students to class and interprets for the general education teacher, and hearing students, and voices for the deaf student within the general education classes. Students can also receive a portion of their instruction in a "selfcontained" class for deaf/hard of hearing students which follows the regular education curriculum, but is taught by a certified teacher of the deaf/hard of hearing. Deaf/hard of hearing students can also receive all of their instruction in a "self-contained" class taught by a teacher of the deaf/hard of hearing. Students in this type of program often follow a specialized curriculum which is dependent on student need and ability. Onsite audiological 
services and counseling from a certified counselor of deaf are also components of the cluster programs. Most students who attend cluster programs require specialized programming and all of the supports outlined (W. Gonsher, personal communication, September 10, 1998).

Historically, teachers of deaf/hard of hearing in Broward County have functioned as both classroom teachers and/or teacher/interpreters. Classroom teachers are responsible for delivery of the curriculum. Teachers/interpreters have been responsible for not only facilitating the communication between deaf student(s), the hearing students, and the general education teacher, but also to make modifications and adaptations within the general education class, along with tutoring the deaf student(s), as necessary. Certification programs for teachers of the deaf/hard of hearing usually require only one general class in sign language. Even though teacher/interpreters are responsible for facilitating communication, no additional certification is required.

Recently, Broward County has started hiring educational interpreters to replace teacher/interpreters. Educational interpreters are responsible for facilitating the communication between deaf student(s), the hearing students, and the general education teacher. They are also responsible for consulting with the general education and exceptional education teacher(s). Educational interpreters have completed a two-year interpreting training program and, additionally, must become certified interpreters within their first year of employment.

\section{Public Law 94-142 (PL 94-142)}

The passage of PL 94142 was an important turning point in the education of children with disabilities because the law impacted placement options for deaf/hard of hearing students. It was passed November 29, 1975 and was fully effective October 1, 1977. PL 94142, The Education for All Handicapped Children Act was amended in 1986 to include PL 99-457, to be discussed in a later section, and the 1990 Individuals with 
Disabilities Act (IDEA) (Brill, MacNeil \& Newman, 1986). IDEA is now used to describe the entire PL 94142 package (Marschark, 1997) and was re-authorized January, 1997. The amendments made to IDEA were incorporated under Section 101 (W. Gonsher, personal communication, September 10, 1998).

According to IDEA, it is the responsibility of the states and local school districts to ensure that all school-age handicapped students, through the age of twenty-one, receive a Free Appropriate Public Education (FAPE) in the least restrictive environment (Moores, 1992; Brill, MacNeil \& Newman, 1986; Quigley \& Kretschmer, 1982). This law states that a FAPE should occur with non-disabled peers to the greatest extent possible (Moores, 1992). IDEA ensures that all disabled children have the right to specifically designed instruction to meet their needs, in addition to related services necessary to benefit from such instruction (National Center for Law \& the Deaf, 1986). Related services include transportation, speech therapy, audiological services, counseling (Testut \& Baldwin, 1977).

According to the National Center for Law and the Deaf (1986), PL 94142 was designed to fulfill four major purposes. First, it was designed to ensure that all disabled students received a FAPE, which emphasizes exceptional education and related services provided to meet their individual needs. Second, the law was designed to ensure that the rights of disabled students, as well as their parents/guardians were protected. PL 94-142 was also designed to assist states and local school districts in paying for the education of their disabled students. Finally, this law was designed to ensure and assess program effectiveness.

\section{Section Seven: Early Intervention}

Early intervention programs are an integral aspect of deaf education. Early childhood education was established for deaf children based on an understanding that these 
children struggle with the acquisition of language. According to Bernstein \& Morrison (1992, p. 7), low academic achievement may begin with preschool programs since they are typically the first steps in the education of deaf children. It is especially critical that deaf children of hearing parents access early intervention programs so that their children can have an opportunity to be exposed to a natural, visual language as early as possible (Hill, 1993).

Preschool education for deaf children dates back to 1852 when the first early intervention program was established by David Bartlett in New York City. Hearing students as well as deaf children were admitted to the sign language based program. All modes of communication (hearing, speech, and sign) were used. The program did not survive even though it was successful (Lane, 1984). The Sarah Fuller Home for Little Children Who Cannot Hear was established in 1888 in Medford, Massachusetts to serve children before they were old enough to attend public school, but was closed in 1925 due to rising costs. At that time, a home visitation program developed in cooperation with the Horace Mann School for the Deaf in Boston. Trained teachers of the deaf/hard of hearing visited the homes of deaf children and taught the mothers how to work with their deaf children (Meadow, 1980). A study by Miller (1934) found preschool education to be a valuable experience for deaf children. Although superintendents of schools for the deaf favored admitting preschool students, they stated that it was a costly endeavor. Teachers reported that the preschool experience was a worthwhile experience for deaf/hard of hearing students, even if it was costly.

Education during the preschool years is very important for deaf/hard of hearing children because of critical issues related to language development. During the preschool years, the speed and diversity of language development is exciting. It is also a time for rapid lexical and relational concept acquisition (Owens, 1988). In order to provide young deaf children with a variety of social and educational experiences, intervention programs 
have been developed which also provide parents of these children with support and information (Marschark, 1997). In a study by Roush, Harrison \& Palsha (1991), a need was found for family-centered intervention programs. A major goal of most early intervention programs is to provide support to families, thereby reducing parental stress and improving the well-being of the entire family (Meadow-Orlans, 1994). Weisel (1988) added establishment of listening skills and language acquisition to the goals of early intervention programs.

During the last twenty years of early childhood special education, there has been a shift from focusing only on direct services related to the needs of the child to providing services to the family (Meadow-Orlans, 1994). Preschool and elementary programs differ in curricula, learning environment, and delivery of services. Typically, preschool programs focus on supporting and assisting the family rather than providing direct services to the deaf child. According to Moores (1982), early intervention programs provide a wide range of direct services including speech, language, and pre-academic training to the deaf child. Additionally, services to the families include counseling, transmission of factual information on deafness and its implications, and techniques and training in the child's preferred mode of communication. Once again, parents are important partners in this process of educating a deaf child and must be seen by the professional staff as valued members of the team (Morgan-Redshaw, 1989). Gatty (1994) stated that preschool programs should also introduce hearing parents of deaf children to deaf adults which would enable the deaf adults to have discussions with hearing parents of deaf children related to mode of communication and language modality.

Success at the preschool level is important to the language foundation for later academic achievement. Parents need to provide appropriate stimulation, with the assistance of preschool educators. In a study by Meadow-Orlans (1994), mothers reported less stress when they received support from professionals and also rated preschool programs as being 
helpful in this support. Research found that three-year-old deaf children enrolled in an early intervention program prior to sixteen months of age had higher academic achievement scores in language than those who enrolled after sixteen months of age (Weisel, 1988). Research has also shown that deaf children receiving early intervention prior to two-andone half years of age displayed significantly better communicative skills than did children who received similar interventions at a later age (Moore, Josephson \& Mauk, 1991). Finally, a study by Greenberg (1983) indicated that more mature communication patterns, lower stress, and higher quality of family interactions occurred when deaf children received intervention before the age of three.

There are a variety of early intervention programs, each providing different services. In some programs, deaf children are integrated into a full-service, hearing daycare center. All adults are trained to provide communication through oral methods and sign language. Hearing children are also encouraged to learn sign language to communicate with their deaf peers (Luetke-Stahlman, 1991).

The philosophy at Parent Infant Program at the Montreal Oral School for the Deaf is that parents are best able to provide a deaf infant with language and listening experiences through everyday activities in their own home. "Parents are encouraged to observe older children with similar abilities and hearing losses so that they can develop high yet realistic expectations for their children" (Bernstein, 1993).

The Mama Lere Training Program develops individual habilitation plans to address each family's unique needs for "emotional support, accurate, understandable information, and specific guidance to optimize their child's communicative development" (Fitzgerald \& Fischer, 1987, p. 3). This program also provides supportive counseling from the time of diagnosis throughout the child's growth and maturation. The program stresses the importance of having all individuals who interact with the deaf child involved in the information sharing process. Children are each assessed and individual intervention plans 
are developed. Finally, the program assists parents in understanding their rights and responsibilities (Fitzgerald \& Fischer, 1987).

The Visiting Infant and Parent program is located at the Clark School for the Deaf. It provides short-term assistance to families of deaf children, ages birth through five, with an evaluation process, intervention strategies, and parent education (Gatty, 1994)

The SKI*HI model was developed in Utah and provides in-home assistance on a weekly basis. This assistance includes modeling, support, and intervention in the areas of child development, communication needs, hearing aid usage, listening skills development, speech, and language (Clark, 1994).

There is also a variety of preschool programs within Broward County Public Schools. These programs include the Specialized Auditory and Language Training (SALT) program, the Preschool Learning Activities Classroom Experience (PLACE) program, and the Public Education Providing Preschool Evaluations and Remediation (PEPPER) program. Children must be eligible for exceptional education in order to access any of these programs. Children are referred to Broward County Public Schools by parents, local agencies, and audiologists, among others. Many students below the age of three are referred through a local agency, often the Children's Diagnostic \& Treatment Center. Appropriate Broward County school staff, as outlined in district policies and procedures, complete an evaluation of the child and meet with other school board staff and the child's parents to discuss the results of the evaluation. A determination is made as to whether or not the state criteria have been met and eligibility for services can be established. Students, ages three through five, are screened through a district-wide screening program, and indepth evaluations are completed for those students who fail the screening in one or more areas. All students referred for exceptional education must be screened in the areas of vision and hearing (SP \&P, 1992). 
The SALT program was designed specifically for deaf/hard of hearing children. The program emphasizes parent/child interaction, to help parents to foster their child's language growth. SALT provides direct education to students by certified teachers of deaf/hard of hearing and speech/language pathologists. A homebound program provides services to the families of eligible students between birth and age three. A teacher of deaf/hard of hearing makes weekly visits to the families to teach them how to provide language stimulation and auditory training to their deaf child, and to answer questions about deafness and its implications. Between the ages of three and five, deaf/hard of hearing students attend a school-based program five hours per day. The program focuses on language development and readiness skills. Students are provided with a specialized language-based curriculum and receive small group speech and language therapy, auditory training, and counseling. The program is designed to immerse students in language and to assist families with strategies to use at home to further enhance language development. The staff also provides consultative services, suggestions for home-centered activities, sign language instruction, and audiological services. Students who receive their instruction through Total Communication are grouped together for instructional purposes. Broward County also provides an integrated (SALT) program so that deaf/hard of hearing children who receive their instruction through oral communication have the opportunity to receive their education with hearing peers (SP \& P, 1996).

The PLACE program was designed for children with language disorders and/or developmental delays. Students ages three to five attend a school-based program for six hours per day. Teachers are certified in preschool education. It is a language-based program which emphasizes problem solving, discovery learning, and receptive/expressive language development. The program provides family education, support, and guidance through home visits. The program uses a multisensory approach to cognitive, pre- 
academic, and social development. Activity play is encouraged and a behavior management system is utilized (SP \& P, 1996).

The PEPPER program was designed for students with speech disorders. Students ages three to five attend a school-based program for a specified number of hours per week, as determined by an Individual Education Plan (IEP) committee. Speech/language pathologists or preschool certified teachers provide educational and consultative services. Children attend individual or group therapy for fluency, voice, speech intelligibility, or language therapy. The IEP committee determines the appropriate program at the time a child is initially found eligible for exceptional education services. Program placement is based on individual student need. Once the evaluation by the preschool team, which consists of a preschool teacher, speech/language pathologist, and a school psychologist, is completed, the team meets with the parent, discusses the results of the evaluation, and then decides if state criteria are met. If the child is found eligible for exceptional education services, an IEP is developed which documents the child's present level of performance, needs, and appropriate accommodations. Parents are an integral part of this committee and have the option of accessing the recommended Broward County program or seeking private preschools at their own expense (SP \& P, 1996).

Private preschools offer programs for all students for a set fee. These programs offer a language-based environment with typical peers. Activities are structured and centered around pre-academic skills development. They attempt to make necessary adaptations for students with special needs, but generally do not have specially trained staff (S. Daugherty, personal communication, Feb. 1, 1999).

\section{Public Law 99-457}

This law was passed in 1986 and provides for "interdisciplinary management of cases, improved early identification programs, individualized family service plans... and an interagency coordinating council on the state level to advise and assist in implementing the 
law" (Bernstein \& Morrison, 1992, p. 7). PL 99-457 requires early intervention through a family-centered approach (Roush, Harrison \& Palsha, 1991). Services are provided to families of all disabled children, including deaf/hard of hearing children, from birth to three years of age. Furthermore, PL $99-457$ provided revisions to PL 94142, Part B, to extend a Free and Appropriate Public Education (FAPE) to children between three and five years of age, along with providing assistance to their parents so they can be involved in their child's educational progress. If the local education agency cannot provide these services, this law requires the district to contract with an outside agency to provide the necessary services. Finally, a multidisciplinary team, including the parents, must develop a written Individual Family Service Plan (Sass-Lehrer \& Bodner-Johnson, 1989).

\section{Section Eight: Academic Achievement}

Academic achievement is an integral component of the educational process. Based on nonverbal tests of cognitive development, academic achievement in most deaf children is significantly below what would be expected (Marschark, 1997). According to Moores \& Sweet (1990), “an unacceptable(ly) large number of deaf adolescents continue to graduate from high school unable to express themselves in written English, or unable to comprehend simple printed materials" (p. 178). Geers and Schick (1988) reported that deaf children's comprehension of English syntax, spoken and signed production of English, as well as their spontaneous written expression, showed substantial deficits. Research has also indicated that profoundly deaf high school students rarely comprehended written text above a fourth-grade level (Furth, 1973). Previous research has also shown that deaf high school graduates had an average reading level of approximately third grade, with few attending college, and the majority performing unskilled, manual labor jobs (Greenwood-Logsdon, 1990). Rogers (1989, p.3) found that "beyond third or fourth grade, deaf children gain only two-tenths of a grade in comprehension for every year of formal education." As 
information in school becomes more abstract, the educational gaps between hearing and deaf children become greater (Goetzinger \& Rousely, 1959).

There are several determinants that influence academic achievement. Kluwin \& Stinson (1993) indicated that student traits, instructional quality, and environmental influences all impact the academic achievement of deaf students. Ritter-Brinton \& Stewart (1992) identified family factors associated with academic achievement. Family adaptation to the child's hearing loss and family expectations for achievement correlated with reading comprehension and mathematics achievement, as well as with social competence and overall academic performance. Walberg (1984) found that student traits, instructional quality, and environmental influences affected the achievement of deaf students. Student traits included intellectual ability and degree of hearing loss. Instructional quality was measured by the amount and quality of the instruction. Lastly, environmental influences included those in the home, family, and peer group (Walberg, 1984). Finally, Goetzinger \& Rousely (1959) found that preschool training had a positive influence over the future academic achievement of deaf children. According to Marschark (1997, p. 83), the "academic lives of young deaf children are enhanced by parents who are sensitive enough to their child's needs to pursue (1) early diagnosis of their children's hearing losses, (2) intervention and education programs for themselves and their children, and (3) communication instruction."

Academic achievement continues to be an important aspect of schooling. Many states require that students pass a test of minimum basic skills in order to receive a standard diploma. Deaf students are disproportionally effected by this because of their low academic performance. Specifically, in the State of Florida, standards required for a high school diploma are increasing. Students seeking a regular diploma in Broward County must maintain a 2.0 grade point average (G.P.A.), pass one credit of Algebra, and pass the High School Competency Test (HSCT). The mathematics section of the HSCT has recently 
become more algebra-based and contains more word problems than in the past. Since less than 10\% of the 1997-1998 graduating class of deaf/hard of hearing students in Broward County passed the HSCT, higher standards may result in a decreased number of deaf students who earn passing scores on this test and, consequently, a smaller percentage who graduate with a regular diploma (W. Gonsher, personal communication, September 10, 1998). Coursework required for a regular diploma includes four credits of English, three credits of math, three credits of science, three social studies credits, one-half credit of physical fitness, one-half credit of health, two credits of performing or practical arts, and nine elective credits. All coursework for a regular diploma must be completed within the regular education curriculum. In the past, students needed to function at approximately a fifth-grade level to fulfill the regular diploma requirements. Current standards require students to be functioning at least at an eighth-grade level in order to successfully earn a regular high school diploma.

Requirements for a special ESE diploma are very different. First, the curriculum is different and specialized. It is more vocationally and life-skill based. Students working toward a special diploma do not need to pass the HSCT. Students still must maintain a 2.0 G.P.A., but do not need to pass algebra. Coursework for a special diploma includes two English credits, two math credits, two credits in social studies, and two credits in science. Vocational courses may be used toward the social studies and science credits. Students also need one credit of reading, one-half credit of physical education, one-half credit of health, five vocational credits, and five elective credits. Typically, students working toward a special diploma function below the fifth-grade level in academic achievement testing. Unfortunately, most of the deaf/hard of hearing students in Broward County function below the fifth-grade level and therefore, regardless of their intellectual ability, graduate with a special diploma. 


\section{Chapter Summary}

Based on the review of literature presented in this chapter, research indicates that deaf children are at great risk for limited language development, and henceforth, limited academic success. The overview of the history of deaf education provides a basis for understanding the communication debate within the field of deaf education.

The deficits faced by deaf/hard of hearing children can be associated with the lack of early identification of the hearing loss, coupled with the lack of a language-rich environment. In addition, the lack of a comprehensive mode of communication used in both the home and at school adds to the deficits faced by deaf/hard of hearing students.

Different types of amplification devices and a wide variety of educational placements were also outlined. Deaf/hard of hearing students have a continuum of options from which to access educational services. With the requirements necessary for a high school diploma increasing, it is important that deaf/hard of hearing children be afforded opportunities which will enable them to perform as close to their ability level as possible. 


\section{CHAPTER III \\ METHODOLOGY}

\section{Introduction}

The review of literature identified the need for further research in identifying the early factors related to academic achievement in deaf/hard of hearing children, so that curricular and programmatic recommendations can be set forth. These recommendations will be aimed at reducing the gap between the intellectual ability and academic achievement of deaf/hard of hearing children.

The purpose of this chapter is to describe the methodology used to conduct this study. More specifically, this chapter describes: (1) the target population and the selected sample; (2) the data instruments used, (3) the research design, (4) the procedures followed to conduct this study, and (5) the method of data analysis.

\section{Population and Sample}

The target population for this study consisted of all deaf/hard of hearing students eligible students enrolled in Broward County Public Schools. These students have been previously found eligible through an Eligibility, Individual Education Plan, and Placement (EIP) committee based on criteria set by the State of Florida Department of Education as having a severe to profound, sensorineural, pre-lingual hearing loss. Criteria for eligibility were evidenced by a documented permanent or fluctuating hearing threshold of 25 decibels (dB) $\pm 5 \mathrm{~dB}$ or greater, unaided in the better ear; a high frequency threshold level of 25 decibels $(\mathrm{dB}) \pm 5 \mathrm{~dB}$ or greater, unaided in the better ear; or a unilateral hearing threshold level of $50 \mathrm{~dB} \pm 5 \mathrm{~dB}$, unaided. All thresholds were based on pure tone averages of 500 , 1,000 , and 2,000 Hertz (Hz) (SP \& P, 1996). Deafness is a low incidence handicapping condition. In the United States, approximately 4,000 children, or one tenth of one percent 
of all newborns, are born profoundly deaf (Epstein, 1996). An educationally significant, partial hearing loss is identified in an additional 10-15 percent of all newborns (Epstein, 1996).

Purposive sampling was used to select the participants in this study. Purposive sampling is a type of nonprobability sampling in which participants are selected based on the researcher's personal judgment as to which participants will be most useful to the study (Babbie, 1992).

The sample was identified through the Broward County Public Schools database of exceptional students, TERMS. In this database, all students who are eligible for deaf/hard of hearing programming must be coded $\mathrm{D}$ for deaf or $\mathrm{H}$ for hard of hearing. A search was conducted via TERMS to identify all students with a $\mathrm{D}$ or $\mathrm{H}$ code and a printout was attained. This printout provided the researcher with the name, address, and school location of all eligible deaf/hard of hearing students. The prospective sample size consisted of two hundred and twenty-eight participants, ranging in age from five to nineteen.

The majority of deaf/hard of hearing students at every level attended a cluster program $(n=163)$. At the elementary school level, there were slightly more males $(n=60)$ than females $(n=42)$. At the middle and high school levels, the genders were nearly equally distributed. The majority of boundaried school students were at the elementary and middle school levels. Nearly half of the prospective sample was at the elementary school level (see Table 1). 
Table 1

Number of students by Placement within School Level

\begin{tabular}{|c|c|c|c|c|c|c|c|c|c|}
\hline \multirow[t]{3}{*}{ Placement } & \multirow{2}{*}{\multicolumn{2}{|c|}{$\begin{array}{c}\text { Elementary } \\
\text { School }\end{array}$}} & \multicolumn{2}{|c|}{ Middle School } & \multicolumn{2}{|c|}{ High School } & \multicolumn{2}{|c|}{ Total } & \multirow[t]{3}{*}{ Total } \\
\hline & & & \multirow[t]{2}{*}{$\underline{\text { Males }}$} & \multirow[t]{2}{*}{ Females } & \multirow[t]{2}{*}{$\underline{\text { Males }}$} & \multirow[t]{2}{*}{ Females } & \multirow[t]{2}{*}{$\underline{\text { Males }}$} & \multirow[t]{2}{*}{ Females } & \\
\hline & $\underline{\text { Males }}$ & Females & & & & & & & \\
\hline Boundaried & 15 & 18 & 12 & 13 & 5 & 2 & 32 & 33 & 65 \\
\hline school & & & & & & & & & \\
\hline Cluster School & 45 & 24 & 23 & 21 & 23 & 27 & 91 & 72 & 163 \\
\hline Total & 60 & 42 & 35 & 34 & 28 & 29 & 123 & 105 & 228 \\
\hline
\end{tabular}

\section{Instruments}

Data were collected from parents and from the official school records of students enrolled in the Broward County Public Schools. Information from the parents was collected through the administration of a parent questionnaire developed by the researcher (See Appendix A). The questionnaire requested demographic information regarding the following: child's age at the time of diagnosis; age of initial amplification; age child began using language; child's participation in preschool programming; mode of communication used by the family; and language used by the family, if other than English.

Questionairre

The questionnaire contained eight items, each item presented as a question. The first question dealt with the age the child's hearing loss was detected. According to Marschark (1997), deafness is not typically diagnosed until a deaf child is between the ages of two and three. The research further shows educational delays with prelingually deaf/hard of hearing children (Moore, Josephson, \& Mauk, 1991).

The next question asked was the cause of the child's hearing loss. The causes of hearing loss include but are not limited to ear infections, damage to the tympanic 
membrane, various types of infections, or pre-mature birth. Very often the cause of hearing loss is not known.

The next question asked was the age at which the child began using amplification. "The early diagnosis of the hearing loss and providing of adequate amplification at an early stage are essential to the proper management of the hearing impaired child" (Ross \& Giolas, 1978, p. 34). Early use of amplification is imperative for deaf/hard of hearing children to succeed academically.

The fourth question was whether the child participated in a preschool program, the type of program it was, and the age at which the child began attending. Language experience should be the emphasis of preschool programs for deaf children and may influence the course of development (Musselman \& Kircaali-Iftar, 1996; Owens, 1988). Research has also shown that accelerated language growth is an advantage of early intervention programs (Watkins \& Clark, 1988). A description of the various preschool programs is provided in Chapter 2.

The questionnaire asked the parents what mode of communication was used in the home. An additional question asked what mode of communication was used by other family members. Previous research has found that meaningful interaction is very limited until parents and the child develop a shared language and communication system (Williams, 1994). Meyers \& Bartee (1992) noted a relationship between the communication skills of the family with the deaf child and his or her academic achievement. Williams (1994) further indicated that a deaf child's language experiences are also dependent on the ability of the extended family to communicate with the child in his or her mode of communication.

Another question asked the parents the age at which the child began using language, signed or orally, to communicate his or her wants and needs. Research indicates that the lower than average academic achievement of deaf/hard of hearing children may be the result of the lack of a rich communication environment during early childhood (Greenberg, 
1980). Therefore, it is important to surround a child with language, regardless of the mode of communication, as long as the child can use the mode of communication adopted. The final question asked about other languages spoken in the home.

Having developed the instrument, the next step involved determining the extent to which it was valid and reliable. According to Gay (1992 p. 155), validity "is the degree to which a test measures what it is suppose to measure." The nature of the instrument will determine the appropriate validation process to use (Gay, 1992). The parent questionnaire is considered to be valid for this study because the items correspond to each of the specific research questions of this study. Furthermore, the items contained within the parent questionnaire all relate to the reporting of factual information which could only be obtained from the parents of the participants of this study. The validity of the school records is considered adequate because the information collected was specific to each of the research questions. Finally, information from school records and parent questionnaires were matched for accuracy. The reliability of the instrument was determined by the completeness, accuracy, memory and honesty of the parental responses. Due to the nature of this study, it is believed that, if the instrument were completed a second time, the same information would be reported (P.A. Rendulic, personal communication, November 15, 1998).

\section{Students' School Files}

In addition, information from each student's school file was collected. Students' school records contained hearing case history forms, initial evaluation reports, reevaluation reports, and standardized scores from such tests as the Stanford Achievement Test - 9 (Stanford 9 ), widely used for students who are deaf and hard of hearing. This information was used to identify each child's mode of communication used in school, type and degree of hearing loss, intellectual ability as measured by tests such as the Hiskey-Nebraska Test of Learning Aptitude, and academic achievement results. 


\section{Intelligence Tests}

The intellectual ability scores were found in each student's initial evaluation report and are a measure of students' nonverbal intellectual ability. Nonverbal measures of intellectual ability measure cognitive abilities and aptitudes through the use of pictures, coded symbols, and figural illustrations ((Roid \& Miller, 1997) ). The use of nonverbal measures are essential to the evaluation process of deaf/hard of hearing children. On measures of intellectual ability, both mentally handicapped and deaf/hard of hearing students display low verbal ability. In addition, they demonstrate low adaptive behavior skills. When deaf/hard of hearing students display normal or above nonverbal ability, one may conclude that the deaf child's intellectual ability is not impaired (Braden, 1989). A variety of instruments were used to determine the student's ability, including the HiskeyNebraska Test of Learning Aptitude and the Comprehensive Test of Non-Verbal Intelligence (CTONI), the Leiter International Performance Scale, and the Weschler Intelligence Scale for Children-Third Edition (WISC-III).

The Hiskey-Nebraska Test of Learning Aptitude was developed in 1966. The authors of the Hiskey report internal consistency with coefficients of reliability from .546.889 among deaf children. The coefficients of reliability were found using the split-half method and the Spearman-Brown formula. For deaf children, ages three to ten, the coefficients of reliability were .947 . For deaf children ages eleven to seventeen, the coefficients of reliability were .918. Validity was not reported (Hiskey, 1966). These reliability coefficients are most likely higher than would be found using another method to establish reliability, e.g. Cronbachs Alpha, split-half reliability tens to underestimate reliability while the Spearman-Brown method overestimates it (Gay, 1992).

The Comprehensive Test of Non-Verbal Intelligence manual reports high reliability (all coefficients for the composite scores are equal to or above .93). Test-retest reliability, ranged from .87 - .94 for all age groups. The CTONI is considered valid because of its 
high correlation with the WISC-III Performance Scale (Hammell, Pearson, \& Wiederholt, 1997).

The reliability coefficients of the Leiter ranged from $.91-.93$. Test-retest reliability ranged from .90-.96 across ages. The authors report that the Leiter is a valid measure of non-verbal ability based on their research. The Leiter and the WISC-III are highly correlated, providing validity for the Leiter.

The WISC-III Performance scale is used and recommended by professionals in the field of deaf education. The performance section is a good instrument to use with deaf children and is an excellent supplement to the Hiskey (Vernon \& Alles, 1986).The test shows adequate reliability and validity (Braden, 1989). Reliability coefficients range from $.89-.94$. According to the authors, this test is a valid measure of intellectual functioning for children, and is appropriate for a wide variety of students, including those with disabilities (Wechsler, 1991).

The program monitor for the deaf/hard of hearing program determines which measure to use in Broward County Public Schools. The program monitor administers the Hiskey-Nebraska or the CTONI, while a school psychologist administers the Leiter or the WISC-III. All students referred for possible deaf/hard of hearing eligibility are administered a nonverbal test of ability (SP \& P, 1996).

Academic Achievement Tests

A variety of measures are used to determine the level of academic achievement among deaf children. Measures of academic achievement included the Stanford 9 , the Woodcock Johnson Psychoeducational Battery - Revised, Achievement (WJ-R), the Peabody Individual Achievement Test-Revised (PIAT-R) and the Wide Range Achievement Test 3 (WRAT3).

The Stanford 9 has eight levels of difficulty designed to measure the appropriate content for hearing students in specific grades. The test is used for both hearing and 
deaf/hard of hearing students, with students who are deaf and hard of hearing being assigned a level of the test based on the results of a screening instrument. There are also deaf and hard of hearing norms available which enable deaf and hard of hearing students to be compared with other deaf and hard of hearing students of the same age. Hearing students are administered the test based on their current grade level (Gallaudet Research Institute, 1996).

The screening instrument was designed because deaf and hard of hearing students typically develop reading and English language skills at a slower rate than hearing children. The screening instrument is administered based on the previous test scores, knowledge of the student, and consideration of the content covered on each test. There are separate screening tests used for mathematics and reading since many deaf and hard of hearing students perform at different levels in these areas. Screening tests are given by school personnel, who use those scores, along with tables developed by Gallaudet Research Institute, to determine the appropriate Stanford 9 test level to be administered (Gallaudet Research Institute, 1996).

The reliability scores for internal consistency reported are high for those subtests typically administered to deaf and hard of hearing students. The Cronbach's alpha scores of the subtests used for the purposes of this research study ranged from .79- .89 in the area of reading comprehension, $.81-.88$ in the area of mathematical problem solving, and .64 .86 in the area of language. The reliability scores of item discrimination analysis, which measure the relationship between the score on an individual item and the total test ranged from .65 - .91 for reading comprehension, .79 - .90 for mathematics, and $.32-.88$ for language. The Stanford 9 was also reported to be a valid measure of academic achievement. However, off-level testing, based on results of the screening instrument, creates a threat to the validity of the test (Holt, Traxler \& Allen, 1996). 
The reliability scores reported for the WJ-R, ages six through eighteen, ranged from .90 to .98 for reading, .85 to .98 for written language, and .93 to .96 for mathematics. Concurrent validity scores were also available for the WJ-R and the PIAT-R or the WRAT-R. In the area of reading, validity coefficients of .86 and .68 , for ages nine and seventeen respectively, were reported for the PIAT-R. In the area of mathematics, scores of .63 and .72 , for ages nine and seventeen respectively, were reported for the WRAT-R (Woodcock \& Mather, 1989)

The coefficient split-half reliability estimates for the PIAT-R were .92 and .94 in the areas of reading comprehension and mathematics, indicating a high degree of reliability. The Kuder-Richardson Reliability coefficients reported for reading comprehension and mathematics were both .94 , indicating a high degree of content homogeneity. The testretest reliability coefficients reported in the areas of reading comprehension and mathematics were .88 and .84 , further indicating a high degree of reliability (Markwardt, 1989).

The median coefficient alphas on the WRAT3 ranged from .92-.95, indicating a high degree of reliability. The correlational coefficients for the two versions of the test in the area of mathematics ranged from .82-.99. The test-retest reliability ranged from .91.98. These results indicate a high degree of reliability. The authors also report a strong degree of content validity (Wilkinson, 1993).

Deaf/hard of hearing students are given a measure of academic achievement during the initial evaluation, during a reevaluation, or during bi-annual testing. The Program Monitor for the deaf/hard of hearing program administers the PIAT-R and the WRAT3 at the time of the student's initial evaluation or during a reevaluation. Typically, students who attend their boundaried schools are administered these measures. Students who attend a cluster program are administered the STANFORD 9 or the WJ-R given by the ESE 
Specialist or classroom teacher (W. Gonsher, personal communication, September 10, 1998).

\section{Research Design}

A correlational method of statistical analysis was used to determine the relationship between variables. The first step was to identify variables which were hypothesized to be related to an expected outcome. This researcher identified eight factors which may be related to the academic achievement of deaf children. These eight factors were: the parental mode of communication, school mode of communication, age amplification was utilized, age deafness was detected, type of preschool program, age entered preschool, degree of hearing loss, and intellectual ability (Desselle, 1994; Nelson, Loncke \& Camarata, 1993; Ritter-Brinton \& Stewart, 1992; Watkins \& Clark, 1988; and Ross \& Giolas, 1978)

Academic achievement among deaf/hard of hearing children was the dependent variable in this study. It was hypothesized that mode of communication used by the parents of deaf/hard of hearing children, mode of communication used in school, age amplification was first used, participation in preschool, age of preschool participation, age hearing loss was detected, intellectual ability, degree of hearing loss, were all contributing factors to the differences in academic achievement among deaf/hard of hearing children. Due to the small sample size, the modes of communication used by parents and at school were grouped into the three categories of sign language (Signed English, Simultaneous Communication, Pidgin Signed English, or American Sign Language), oral only communication, or Other. The degree of hearing loss was defined as mild, moderate, severe, severe-profound, and profound. Intellectual ability was reported as the students' scores on a nonverbal test of intellectual ability. 


\section{Procedures}

Approval to conduct this study was obtained from the Research and Evaluation Department of the School Board of Broward County. A computer printout listing of the names of all eligible deaf/hard of hearing students in Broward County Public Schools between the ages of five and nineteen was provided through TERMS, the Broward County Public Schools student information database. This printout contained the names and addresses of all deaf/hard of hearing students eligible students in Broward County. A packet was sent to the parents of each identified deaf/hard of hearing student containing a letter that briefly explained the research study (see Appendix A) and asked the parents to complete the attached permission form (see Appendix B). The remaining form included a parent questionnaire (see Appendix C), which was to be returned to the researcher in a selfaddressed stamped envelope. Approximately three weeks after the first letter was sent, the researcher sent a follow-up letter to those parents who had not responded (see Appendix D).

After parent permission was received, the researcher collected information from each student's school files that included: initial evaluation reports, hearing case history forms, academic testing results, and subsequent re-evaluation reports.

\section{Data Analysis}

A variety of descriptive and inferential statistics were used to analyze the data. Descriptive statistics were used to present the characteristics of the students, such as age of onset, age of amplification, type of preschool program, age entered preschool, mode of communication used at home and school, degree of hearing loss, and intellectual ability at different points in the development of the child. Cross classification (crosstabs) analysis and Chi-square analysis were used to answer each of the subsidiary research questions. 


\section{CHAPTER IV}

\section{RESULTS}

\section{Introduction}

The purpose of this research study was to examine specific factors believed to relate to academic achievement of deaf/hard of hearing children. More specifically, this research sought to determine whether: (1) the deficits in the academic achievement of this group of students are reduced when students acquire a language base as early as possible; (2) there is a significant difference in achievement between those students whose families use oral communication only and those whose families use some type of sign language, including Total Communication. An additional purpose of this research was to determine if there is a significant difference in academic achievement of those deaf/hard of hearing students who used early amplification compared to those who did not utilize early use of amplification. This study also sought to determine whether providing early intervention programs that emphasize and enable parents to develop a language-rich environment had a significant impact on the academic achievement of deaf/hard of hearing children, and whether the age at which initial services were received influenced a deaf student's subsequent academic achievement. In order to answer the research questions posed in this study, parents were asked to complete a questionnaire developed by the researcher. The researcher collected additional data by reviewing and analyzing students' school records.

\section{Description of Sample}

A total of 228 permission forms and questionnaires were mailed to parents of eligible deaf/hard of hearing students. Twenty-four of the letters were returned due to inaccurate addresses. Of the remaining 204 , ninety-six parents returned the completed permission forms and questionnaires. Four parents did not grant consent to have 
information pertaining to their children used in this study. Only 61 of the students whose parents granted consent in this study, (27\% of the eligible participants), were included in this study because the remaining 31 students had incomplete school records.

The sample was nearly evenly divided between males $(n=33$ and females $(n=28)$. The majority of students $(n=47)$ were enrolled in a cluster program. Finally, the sample of 61 students was evenly divided across elementary, middle and high school. (see Table 2). Table 2

Number of students by Placement within School Level (Sample)

\begin{tabular}{ccccccccccc}
\hline Placement & \multicolumn{2}{c}{$\begin{array}{c}\text { Elementary } \\
\text { School }\end{array}$} & \multicolumn{2}{c}{ Middle School } & \multicolumn{2}{c}{ High School } & & \multicolumn{2}{c}{ Total } & \multicolumn{1}{c}{ Total } \\
$\begin{array}{c}\text { Moundaried } \\
\text { school }\end{array}$ & $\frac{\text { Males }}{3}$ & $\frac{\text { Females }}{4}$ & $\frac{\text { Males }}{1}$ & $\frac{\text { Females }}{3}$ & $\frac{\text { Males }}{1}$ & $\frac{\text { Females }}{2}$ & $\frac{\text { Males }}{5}$ & $\frac{\text { Females }}{9}$ & 14 \\
$\begin{array}{c}\text { Cluster } \\
\text { School } \\
\text { Total }\end{array}$ & 8 & 5 & 11 & 6 & 9 & 8 & 28 & 19 & 47 \\
\hline
\end{tabular}

Within the sample, the majority of parents of elementary and middle school students used oral communication at home. The majority of parents of high school students indicated that they used some type of sign language at home. There were no parents of students who attend their boundaried school who used any type of sign language with their children (see Table 3 ).

Table 3

Number of students by Placement within School Level within Parental Mode of Communication

\begin{tabular}{|c|c|c|c|c|c|c|c|c|c|c|c|c|}
\hline \multirow[t]{2}{*}{ Placement } & \multicolumn{3}{|c|}{ Elementary School } & \multicolumn{3}{|c|}{ Middle School } & \multicolumn{3}{|c|}{ High School } & \multicolumn{3}{|c|}{ Total } \\
\hline & Oral & $\underline{\text { Sign }}$ & Other & Oral & $\underline{\text { Sign }}$ & Other & Oral & $\underline{\text { Sign }}$ & Other & $\underline{\text { Oral }}$ & $\underline{\underline{\text { Sign }}}$ & Other \\
\hline Boundaried & & & & & & & & & & & & \\
\hline $\begin{array}{l}\text { School } \\
\text { Cluster }\end{array}$ & 7 & $\mathbf{0}$ & $\mathbf{0}$ & 4 & 0 & 0 & 3 & $\mathbf{0}$ & 0 & 14 & 0 & 0 \\
\hline School & 7 & 5 & 1 & 11 & 6 & 0 & 4 & 11 & 2 & 22 & 22 & 3 \\
\hline Total & 14 & 5 & 1 & 15 & 6 & 0 & 7 & 11 & 2 & 36 & 22 & 3 \\
\hline
\end{tabular}


Within the sample, the majority of cluster students in elementary school used oral communication at school. At the middle and high school levels, the majority of students used some type of sign language at school. There were no students who attended their boundaried school who used any type of sign language in school (see Table 4).

Table 4

Number of students by Placement within School Level within Mode of Communication used in school

\begin{tabular}{|c|c|c|c|c|c|c|c|c|}
\hline \multirow[t]{2}{*}{ Placement } & \multicolumn{2}{|c|}{ Elementary School } & \multicolumn{2}{|c|}{ Middle School } & \multicolumn{2}{|c|}{ High School } & \multicolumn{2}{|c|}{ Total } \\
\hline & Oral & $\underline{\text { Sign }}$ & Oral & $\underline{\text { Sign }}$ & Oral & $\underline{\text { Sign }}$ & Oral & $\underline{\text { Sign }}$ \\
\hline Boundaried School & 7 & 0 & 4 & 0 & 3 & 0 & 14 & 0 \\
\hline Cluster School & 7 & 6 & 3 & 14 & 2 & 15 & 12 & 35 \\
\hline Total & 14 & 6 & 7 & 14 & 5 & 15 & 26 & 35 \\
\hline
\end{tabular}

Severity of hearing loss was determined by audiograms administered by the school audiologist. All audiograms were as given within the 1997 - 1998 school year.

Furthermore, all participants had a sensorineural, bilateral hearing loss. Within the sample, the majority of students $(n=37)$ who had a severe-profound hearing loss or greater were enrolled in cluster programs. Those students who had a mild hearing loss were evenly distributed between a cluster program and their boundaried school (see Table 5).

Table 5

Number of students by Placement within Severity of Hearing Loss

\begin{tabular}{|c|c|c|c|c|c|c|}
\hline Placement & $\stackrel{\text { Mild }}{\text { Hearing }}$ & Moderate & $\frac{\text { Severe }}{\text { Hearing Loss }}$ & Severe-Profound & Profound & Total \\
\hline Boundaried & $\frac{\text { Heaming Loss }}{7}$ & $\frac{\text { neaning Luss }}{3}$ & $\frac{\text { mearing Luss }}{0}$ & $\frac{2}{2}$ & $\frac{n^{2}}{2}$ & 14 \\
\hline $\begin{array}{l}\text { School } \\
\text { Cluster } \\
\text { school }\end{array}$ & 6 & 5 & 3 & 26 & 7 & 47 \\
\hline Total & 13 & 8 & 3 & 28 & 9 & 61 \\
\hline
\end{tabular}




\section{$\underline{\text { Results }}$}

The results are presented according to each of the eight research questions. The researcher was limited to the reported grade-level scores of the academic achievement measures previously administered to the participants. The researcher calculated the difference between the participant's actual grade-level placement and his or her reported grade level achievement score reported in his or her school records. The researcher grouped the participants based on the difference between actual grade placement and reported achievement scores: participants who scored at or within one grade level below actual grade placement (one grade level), participants who scored between one and two grade levels below actual grade placement (two grade levels), and participants who scored three or more grade levels below actual grade level placement (three grade levels).

Research Question 1: What is the relationship between parental mode of communication and academic achievement in deaf/hard of hearing children?

A crosstabulation was completed to determine if there was a relationship between parental mode of communication and academic achievement in deaf/hard of hearing children. Of the parents who participated in this study, $51.7 \%$ used oral communication while $48.3 \%$ used some type of sign language to communicate with their deaf child. Due to the small sample size, the various types of sign languages were grouped together.

In the area of reading, the results of Pearson Chi-square analysis showed a significant relationship between parental mode of communication and reading achievement among deaf/hard of hearing children $\left(\chi^{2}=7.685, \mathrm{df}=2, \underline{\mathrm{p}}<.021\right)$. The results indicated that almost $47 \%$ of the deaf/hard of hearing students whose parents used oral communication achieved up to one grade below their actual grade level placement as compared to slightly more than $14 \%$ of the deaf/hard of hearing students whose parents used some type of sign language. Among deaf/hard of hearing students whose parents used oral communication, nearly $\mathbf{2 7 \%}$ achieved three or more grade levels below their actual 
grade placement compared to approximately $54 \%$ whose parents used some type of sign language (see Table 6).

Table 6

Difference between grade level achievement and actual grade level by parental mode of communication (reading achievement)

\begin{tabular}{|c|c|c|c|}
\hline $\begin{array}{c}\text { Difference between } \\
\text { achievement and actual }\end{array}$ & $\frac{\text { Parental use of oral }}{\text { communication }}$ & $\frac{\text { Parental use of sign }}{\underline{\text { language }}}$ & Total \\
\hline $\begin{array}{c}\text { count } \\
\text { one grade level }\end{array}$ & $\begin{array}{c}14 \\
46.7 \%\end{array}$ & $\begin{array}{c}4 \\
14.3 \%\end{array}$ & $\begin{array}{c}18 \\
31 \%\end{array}$ \\
\hline $\begin{array}{c}\text { count } \\
\text { two grade levels }\end{array}$ & $\begin{array}{c}8 \\
26.7 \%\end{array}$ & $\begin{array}{c}9 \\
32.1 \%\end{array}$ & $\begin{array}{c}17 \\
29.3 \%\end{array}$ \\
\hline $\begin{array}{c}\text { count } \\
\text { three or more grade } \\
\text { levels }\end{array}$ & $\begin{array}{c}8 \\
26.7 \%\end{array}$ & $\begin{array}{c}15 \\
53.6 \%\end{array}$ & $\begin{array}{c}23 \\
39.7 \%\end{array}$ \\
\hline $\begin{array}{l}\text { count } \\
\text { total }\end{array}$ & $\begin{array}{c}30 \\
100 \%\end{array}$ & $\begin{array}{c}28 \\
100 \%\end{array}$ & $\begin{array}{c}58 \\
100 \%\end{array}$ \\
\hline
\end{tabular}

In the area of written language, the results of Pearson Chi-square analysis showed no significant relationship between parental mode of communication and written language achievement among deaf/hard of hearing children $\left(\chi^{2}=2.701\right.$, df $\left.=2, \underline{p}>.259\right)$. Approximately $63 \%$ of the deaf/hard of hearing students whose parent used oral communication and $75 \%$ of the deaf/hard of hearing students whose parents used some type of sign language achieved three or more grade levels below their actual grade placement (see Table 7).

Previous research identified four major weaknesses contributing to written language deficiencies of deaf/hard of hearing children, regardless of their mode of communication. These weaknesses may be the result of a linguistically-deprived environment, pedagogical weaknesses, limited vocabulary, and linguistic differences within the various systems of 
communication (Rodda, Cumming \& Fewer, 1993). Even though this study showed no significant relationship between written language and parental mode of communication, $90 \%$ of the participants in this study scored at least two grade levels below their actual grade placement in writing, as determined by their obtained scores on the written language section of their academic achievement measure (STANFORD 9, WJ-R, or PIAT).

\section{Table 7}

Difference between grade level achievement and actual grade level by parental mode of communication (written language achievement)

\begin{tabular}{|c|c|c|c|}
\hline $\begin{array}{l}\frac{\text { Difference between }}{\text { achievement and actual }} \\
\text { grade placement }\end{array}$ & $\begin{array}{l}\text { Parental use of oral } \\
\text { communication }\end{array}$ & $\frac{\text { Parental use of sign }}{\text { language }}$ & Total \\
\hline $\begin{array}{c}\text { count } \\
\text { one grade level }\end{array}$ & $\begin{array}{c}5 \\
16.7 \%\end{array}$ & $\begin{array}{c}1 \\
3.7 \%\end{array}$ & $\begin{array}{c}6 \\
10.3 \%\end{array}$ \\
\hline $\begin{array}{c}\text { count } \\
\text { two grade levels }\end{array}$ & $\begin{array}{c}6 \\
20.0 \%\end{array}$ & $\begin{array}{c}6 \\
21.4 \%\end{array}$ & $\begin{array}{c}12 \\
20.7 \%\end{array}$ \\
\hline $\begin{array}{l}\text { count } \\
\text { three or more grade } \\
\text { levels }\end{array}$ & $\begin{array}{c}19 \\
63.3 \%\end{array}$ & $\begin{array}{c}21 \\
75.0 \%\end{array}$ & $\begin{array}{c}40 \\
69.0 \%\end{array}$ \\
\hline $\begin{array}{l}\text { count } \\
\text { total }\end{array}$ & $\begin{array}{c}30 \\
100 \%\end{array}$ & $\begin{array}{c}28 \\
100 \%\end{array}$ & $\begin{array}{c}58 \\
100 \%\end{array}$ \\
\hline
\end{tabular}

In the area of mathematics, the results of Pearson Chi-square analysis showed a significant relationship between parental mode of communication and math achievement among deaf/hard of hearing children $\left(\chi^{2}=7.101, \mathrm{df}=2, \underline{\mathrm{p}}<.029\right)$. The results indicated that almost $53 \%$ of the deaf/hard of hearing students whose parents used oral communication achieved up to one grade below their actual grade level placement, as compared to $25 \%$ of the deaf/hard of hearing students whose parents used some type of sign language. Among deaf/hard of hearing students whose parents used oral communication, nearly $27 \%$ achieved three or more grade levels below their actual grade 
placement, compared to approximately $61 \%$ whose parents used some type of sign language (see Table 8).

Table 8

Difference between grade level achievement and actual grade level by parental mode of communication (mathematics achievement)

\begin{tabular}{|c|c|c|c|}
\hline $\begin{array}{l}\begin{array}{c}\text { Difference between } \\
\text { achievement and actual }\end{array} \\
\text { grade placement }\end{array}$ & $\frac{\text { Parental use of oral }}{\text { communication }}$ & $\frac{\text { Parental use of sign }}{\underline{\text { language }}}$ & Total \\
\hline $\begin{array}{c}\text { count } \\
\text { one grade level }\end{array}$ & $\begin{array}{c}16 \\
53.3 \%\end{array}$ & $\begin{array}{c}7 \\
25.0 \%\end{array}$ & $\begin{array}{c}23 \\
39.7 \%\end{array}$ \\
\hline $\begin{array}{c}\text { count } \\
\text { two grade levels }\end{array}$ & $\begin{array}{c}6 \\
20.0 \%\end{array}$ & $\begin{array}{c}4 \\
14.3 \%\end{array}$ & $\begin{array}{c}10 \\
17.2 \%\end{array}$ \\
\hline $\begin{array}{c}\text { count } \\
\text { three or more grade } \\
\text { levels }\end{array}$ & $\begin{array}{c}8 \\
26.7 \%\end{array}$ & $\begin{array}{c}17 \\
60.7 \%\end{array}$ & $\begin{array}{c}25 \\
43.1 \%\end{array}$ \\
\hline $\begin{array}{l}\text { count } \\
\text { total }\end{array}$ & $\begin{array}{c}30 \\
100 \%\end{array}$ & $\begin{array}{c}28 \\
100 \%\end{array}$ & $\begin{array}{c}58 \\
100 \%\end{array}$ \\
\hline
\end{tabular}

Research Question 2: What is the relationship between mode of communication used in school and academic achievement in deaf/hard of hearing children?

A crosstabulation was completed to determine if there was a relationship between the mode of communication used in school and academic achievement among deaf/hard of hearing children. Of the students who participated in this study, approximately $39 \%$ used oral communication in school, while nearly $61 \%$ used some type of sign language in school.

In the area of reading, the results of Pearson Chi-square analysis showed a significant relationship between mode of communication used in school and reading achievement among deaf/hard of hearing children $\left(\chi^{2}=13.864\right.$, df $\left.=2, \underline{p}<.001\right)$. Just over $54 \%$ of the deaf/hard of hearing students who used oral communication in school 
achieved up to one grade level below their actual grade level placement, as compared to almost $30 \%$ who used some type of sign language in school. Among deaf/hard of hearing students who used oral communication in school, nearly $17 \%$ achieved three or more grade levels below their actual grade placement, compared to approximately $57 \%$ who used some type of sign language in school (see Table 9).

Table 9

Difference between grade level achievement and actual grade level by mode of communication used in school (reading achievement)

\begin{tabular}{|c|c|c|c|}
\hline $\begin{array}{c}\frac{\text { Difference between }}{\text { achievement and actual }} \\
\text { grade placement }\end{array}$ & $\begin{array}{l}\text { Oral communication } \\
\text { used in school }\end{array}$ & $\begin{array}{l}\text { Sign language } \\
\text { used in school }\end{array}$ & Total \\
\hline $\begin{array}{c}\text { count } \\
\text { one grade level }\end{array}$ & $\begin{array}{c}13 \\
54.2 \%\end{array}$ & $\begin{array}{c}5 \\
13.5 \%\end{array}$ & $\begin{array}{c}18 \\
29.5 \%\end{array}$ \\
\hline $\begin{array}{c}\text { count } \\
\text { two grade levels }\end{array}$ & $\begin{array}{c}7 \\
29.2 \%\end{array}$ & $\begin{array}{c}11 \\
29.7 \%\end{array}$ & $\begin{array}{c}18 \\
29.5 \%\end{array}$ \\
\hline $\begin{array}{l}\text { count } \\
\text { three or more grade } \\
\text { levels }\end{array}$ & $\begin{array}{c}4 \\
16.7 \%\end{array}$ & $\begin{array}{c}21 \\
56.8 \%\end{array}$ & $\begin{array}{c}25 \\
41.0 \%\end{array}$ \\
\hline $\begin{array}{l}\text { count } \\
\text { total }\end{array}$ & $\begin{array}{c}30 \\
100 \%\end{array}$ & $\begin{array}{c}28 \\
100 \%\end{array}$ & $\begin{array}{c}61 \\
100 \%\end{array}$ \\
\hline
\end{tabular}

In the area of written language, the results of Pearson Chi-square analysis showed no significant relationship between mode of communication used in school and written language achievement among deaf/hard of hearing children $\left(\chi^{2}=2.113, \mathrm{df}=2, \mathrm{p}>.348\right)$. The results indicated that approximately $63 \%$ of the deaf/hard of hearing students who used oral communication and $73 \%$ of the deaf/hard of hearing students who used some type of sign language in school achieved three or more grade levels below their actual grade placement (see Table 10). 
Table 10

Difference between grade level achievement and actual grade level by mode of communication used in school (written language achievement)

\begin{tabular}{|c|c|c|c|}
\hline $\begin{array}{l}\frac{\text { Difference between }}{\text { achievement and actual }} \\
\text { grade placement }\end{array}$ & $\frac{\text { Oral communication }}{\text { used in school }}$ & $\begin{array}{l}\text { Sign language } \\
\text { used in school }\end{array}$ & Total \\
\hline $\begin{array}{c}\text { count } \\
\text { one grade level }\end{array}$ & $\begin{array}{c}4 \\
16.7 \%\end{array}$ & $\begin{array}{c}2 \\
5.4 \%\end{array}$ & $\begin{array}{c}6 \\
9.8 \%\end{array}$ \\
\hline $\begin{array}{c}\text { count } \\
\text { two grade levels }\end{array}$ & $\begin{array}{c}56 \\
20.8 \%\end{array}$ & $\begin{array}{c}8 \\
21.6 \%\end{array}$ & $\begin{array}{c}13 \\
21.3 \%\end{array}$ \\
\hline $\begin{array}{c}\text { count } \\
\text { three or more grade } \\
\text { levels }\end{array}$ & $\begin{array}{c}15 \\
62.5 \%\end{array}$ & $\begin{array}{c}27 \\
73.0 \%\end{array}$ & $\begin{array}{c}42 \\
68.9 \%\end{array}$ \\
\hline $\begin{array}{l}\text { count } \\
\text { total }\end{array}$ & $\begin{array}{c}24 \\
100 \%\end{array}$ & $\begin{array}{c}37 \\
100 \%\end{array}$ & $\begin{array}{c}61 \\
100 \%\end{array}$ \\
\hline
\end{tabular}

In the area of mathematics, the results of Pearson Chi-square analysis showed a significant relationship between the mode of communication used in school and math achievement among deaf/hard of hearing children $\left(\chi^{2}=7.823\right.$, df $\left.=2, \underline{p}<.020\right)$. Just over $58 \%$ of the deaf/hard of hearing students who used oral communication in school achieved up to one grade level below their actual grade level placement, as compared to slightly more than $24 \%$ who used some type of sign language in school. Among deaf/hard of hearing students who used oral communication in school, $25 \%$ achieved three or more grade levels below their actual grade placement, compared to approximately $57 \%$ who used some type of sign language in school (see Table 11). 
Table 11

Difference between grade level achievement and actual grade level by mode of communication used in school (mathematics achievement)

\begin{tabular}{cccc}
\hline $\begin{array}{c}\text { Difference between } \\
\text { achievement and actual }\end{array}$ & Oral communication & Sign language & Total \\
\hline grade placement & used in school & used in school & \\
$\begin{array}{c}\text { count } \\
\text { one grade level }\end{array}$ & 14 & 9 & 23 \\
& $58.3 \%$ & $24.3 \%$ & $37.7 \%$ \\
count & 4 & & 10 \\
two grade levels & $16.7 \%$ & 7 & $18.0 \%$ \\
count & & $18.9 \%$ & \\
three or more grade & 6 & & 27 \\
levels & $25.0 \%$ & 21 & $44.3 \%$ \\
count & & $56.8 \%$ & \\
total & 24 & & 61 \\
\hline
\end{tabular}

Question 3: What is the relationship between age at which amplification was first used and academic achievement in deaf/hard of hearing children?

A correlational analysis was done to determine if there was a significant relationship between the age a child began using amplification and his or her academic achievement. $\mathrm{A}$ Pearson correlation (see Table 12) between the age a child began using amplification and academic achievement was not significant $(\mathrm{r}=.014, \underline{\mathrm{p}}>.918, \mathrm{n}=60 ; \mathrm{r}=.207, \underline{\mathrm{p}}>.113, \mathrm{n}$ $=60 ; \mathrm{r}=-.018, \mathrm{p}<.893, \mathrm{n}=60)$. 
Table 12

Relationship between age of amplification by difference between grade level achievement and actual grade level

Difference between achievement and actual grade level placement

Age of amplification

READING

WRITTEN

LANGUAGE

Pearson correlation

.014

.207

$-.018$

Level of significance

.918

.113

.893

n

60

60

60

Question 4: What is the relationship between the type of early intervention programs and academic achievement in deaf/hard of hearing children?

A crosstabulation was completed to determine if there was a relationship between the type of early intervention program deaf/hard of hearing students attended and their academic achievement. Of the students who participated in this study, $32.8 \%$ participated in a private preschool program, $44.3 \%$ participated in a preschool program through Broward County Public Schools, and $23.0 \%$ did not participate in any type of preschool program.

In the area of reading, the results of Pearson Chi-square analysis showed no significant relationship between type of preschool program and reading achievement among deaf/hard of hearing children $\left(\chi^{2}=1.461, \mathrm{df}=4, \underline{p}>.833\right)$. The results indicated that $45.0 \%$ of the deaf/hard of hearing students who participated in a private preschool program achieved three or more grade levels below their actual grade level placement. The results further indicated that, among deaf/hard of hearing students who participated in a preschool program through Broward County Schools, $37.0 \%$ achieved three or more grade levels below their actual grade level placement. Finally, $42.9 \%$ of the students who did not participate in any type of preschool program also achieved three or more grade levels below their actual grade placement (see Table 13). 
Table 13

Difference between grade level achievement and actual grade level by type of early intervention program (reading achievement)

\begin{tabular}{|c|c|c|c|c|}
\hline $\begin{array}{c}\text { Difference between } \\
\frac{\text { achievement and }}{\text { actual grade }} \\
\text { placement }\end{array}$ & Private preschool & $\begin{array}{c}\frac{\text { Broward County }}{\text { Public Schools }} \\
\text { preschool }\end{array}$ & No preschool & Total \\
\hline $\begin{array}{c}\text { count } \\
\text { one grade level }\end{array}$ & $\begin{array}{c}6 \\
30.0 \%\end{array}$ & $\begin{array}{c}7 \\
25.9 \%\end{array}$ & $\begin{array}{c}5 \\
35.7 \%\end{array}$ & $\begin{array}{c}18 \\
29.5 \%\end{array}$ \\
\hline $\begin{array}{c}\text { count } \\
\text { two grade levels }\end{array}$ & $\begin{array}{c}5 \\
25.0 \%\end{array}$ & $\begin{array}{c}10 \\
37.0 \%\end{array}$ & $\begin{array}{c}3 \\
21.4 \%\end{array}$ & $\begin{array}{c}18 \\
29.5\end{array}$ \\
\hline $\begin{array}{l}\text { count } \\
\text { three or more grade } \\
\text { levels }\end{array}$ & $\begin{array}{c}9 \\
45.0 \%\end{array}$ & $\begin{array}{c}10 \\
37.0 \%\end{array}$ & $\begin{array}{c}6 \\
42.9 \%\end{array}$ & $\begin{array}{c}25 \\
41.0 \%\end{array}$ \\
\hline $\begin{array}{l}\text { count } \\
\text { total }\end{array}$ & $\begin{array}{c}20 \\
100 \%\end{array}$ & $\begin{array}{c}27 \\
100 \%\end{array}$ & $\begin{array}{c}14 \\
100 \%\end{array}$ & $\begin{array}{c}61 \\
100 \%\end{array}$ \\
\hline
\end{tabular}

In the area of written language, the results of Pearson Chi-square analysis showed no significant relationship between the type of preschool program and written language achievement among deaf/hard of hearing children $\left(\chi^{2}=8.185, \mathrm{df}=4, \underline{p}>.085\right)$.

According to the data, $85 \%$ of the deaf/hard of hearing students who participated in a private preschool program achieved three or more grade levels below their actual grade level placement. The results further indicated that, among deaf/hard of hearing students who participated in a public preschool program through Broward County Schools, nearly $59 \%$ achieved three or more grade levels below their actual grade level placement. Finally, almost $79 \%$ of the students who did not participate in any type of preschool program also achieved three or more grade levels below their actual grade placement (see Table 14). 
Table 14

Difference between grade level achievement and actual grade level by type of early intervention program (written language achievement)

\begin{tabular}{|c|c|c|c|c|}
\hline$\frac{\frac{\text { Difference between }}{\text { achievement and }}}{\frac{\text { actual grade }}{\text { placement }}}$ & Private preschool & $\frac{\frac{\text { Broward County }}{\text { Public Schools }}}{\text { preschool }}$ & No preschool & Total \\
\hline $\begin{array}{c}\text { count } \\
\text { one grade level }\end{array}$ & $\begin{array}{c}2 \\
10.0 \%\end{array}$ & $\begin{array}{c}3 \\
11.1 \%\end{array}$ & $\begin{array}{c}1 \\
7.1 \%\end{array}$ & $\begin{array}{c}6 \\
9.8 \%\end{array}$ \\
\hline $\begin{array}{c}\text { count } \\
\text { two grade levels }\end{array}$ & $\begin{array}{c}1 \\
5.0 \%\end{array}$ & $\begin{array}{c}10 \\
37.0 \%\end{array}$ & $\begin{array}{c}2 \\
14.3 \%\end{array}$ & $\begin{array}{c}13 \\
21.3 \%\end{array}$ \\
\hline $\begin{array}{c}\text { count } \\
\text { three or more grade } \\
\text { levels }\end{array}$ & $\begin{array}{c}17 \\
85.0 \%\end{array}$ & $\begin{array}{c}14 \\
58.9 \%\end{array}$ & $\begin{array}{c}11 \\
78.6 \%\end{array}$ & $\begin{array}{c}42 \\
68.9 \%\end{array}$ \\
\hline $\begin{array}{l}\text { count } \\
\text { total }\end{array}$ & $\begin{array}{c}20 \\
100 \%\end{array}$ & $\begin{array}{c}27 \\
100 \%\end{array}$ & $\begin{array}{c}14 \\
100 \%\end{array}$ & $\begin{array}{c}61 \\
100 \%\end{array}$ \\
\hline
\end{tabular}

In the area of mathematics, the results of Pearson Chi-square analysis were not significant between type of preschool program and mathematics achievement among deaf/hard of hearing children $\left(\chi^{2}=1.749, \mathrm{df}=4, \underline{p}>.782\right)$. The results indicated that $35 \%$ of the deaf/hard of hearing students who participated in a private preschool program achieved three or more grade levels below their actual grade level placement. The results further indicated that, among deaf/hard of hearing students who participated in a preschool program through Broward County Schools, almost 52\% achieved three or more grade levels below their actual grade level placement. Finally, nearly $43 \%$ of the students who did not participate in any type of preschool program also achieved three or more grade levels below their actual grade placement (see Table 15). 
Table 15

Difference between grade level achievement and actual grade level by type of early intervention program (mathematics achievement)

\begin{tabular}{|c|c|c|c|c|}
\hline$\frac{\text { Difference between }}{\frac{\text { achievement and }}{\text { actual grade }}}$ & Private preschool & $\frac{\frac{\text { Broward County }}{\text { Public Schools }}}{\text { preschool }}$ & No preschool & Total \\
\hline $\begin{array}{c}\text { count } \\
\text { one grade level }\end{array}$ & $\begin{array}{c}9 \\
45.0 \%\end{array}$ & $\begin{array}{c}8 \\
29.6 \%\end{array}$ & $\begin{array}{c}6 \\
42.9 \%\end{array}$ & $\begin{array}{c}23 \\
37.7 \%\end{array}$ \\
\hline $\begin{array}{c}\text { count } \\
\text { two grade levels }\end{array}$ & $\begin{array}{c}4 \\
20.0 \%\end{array}$ & $\begin{array}{c}5 \\
18.5 \%\end{array}$ & $\begin{array}{c}2 \\
14.3 \%\end{array}$ & $\begin{array}{c}11 \\
18.0 \%\end{array}$ \\
\hline $\begin{array}{l}\text { count } \\
\text { three or more grade } \\
\text { levels }\end{array}$ & $\begin{array}{c}7 \\
35.0 \%\end{array}$ & $\begin{array}{c}14 \\
51.9 \%\end{array}$ & $\begin{array}{c}6 \\
42.9 \%\end{array}$ & $\begin{array}{c}27 \\
44.3 \%\end{array}$ \\
\hline $\begin{array}{l}\text { count } \\
\text { total }\end{array}$ & $\begin{array}{c}20 \\
100 \%\end{array}$ & $\begin{array}{c}27 \\
100 \%\end{array}$ & $\begin{array}{c}14 \\
100 \%\end{array}$ & $\begin{array}{c}61 \\
100 \%\end{array}$ \\
\hline
\end{tabular}

Question 5: What is the relationship between the age at which early intervention was provided and academic achievement in deaf/hard of hearing children?

A correlational analysis was used to determine if there was a significant relationship between the age of a student entering a preschool program and his or her academic achievement. The results of a Pearson correlation (see Table 16) suggest that the age of the student when entering a preschool program was not significantly related to academic achievement in reading, written language or mathematics $(r=-.068, \mathrm{p}>.651, \mathrm{n}=46 ; \mathrm{r}=$ $.157, \mathrm{p}>.296, \mathrm{n}=46 ; \mathrm{r}=.039, \mathrm{p}<.799, \mathrm{n}=46)$. 
Table 16

Relationship between age attended preschool program by difference between grade level achievement and actual grade level

Difference between achievement and actual grade level placement

Age entered preschool program

Pearson correlation

Level of significance $\underline{\text { READING }}$

$-.068$

.651

46
WRITTEN

LANGUAGE

.157

.296

46
MATHEMATICS

.039

.799

46

Question 6: What is the relationship between the age at which deafness was detected and academic achievement in deaf/hard of hearing children?

A correlational analysis was completed to determine the nature and extent of the relationship between the age a child's deafness was detected and his or her academic achievement. The results of a Pearson correlation (see Table 17) suggest that the age when deafness was first detected is not significantly related to achievement in reading, written language or mathematics $(r=-.232, p>.072, n=61 ; r=.183, p>.159, n=61 ; r=.221$, $\mathrm{p}>.087, \mathrm{n}=61)$.

Table 17

Relationship between age deafness detected by difference between grade level achievement and actual grade level

Difference between achievement and actual grade level placement

Age deafness detected

READING

$-.232$

.072

61

Pearson correlation

Level of significance n
WRITTEN

LANGUAGE
MATHEMATICS

61 
Question 7: What is the relationship between the students' intellectual ability and academic achievement in deaf/hard of hearing children?

A correlational analysis was completed to determine if there was a significant relationship between a student's measured intellectual ability and his or her academic achievement. The results of a Pearson correlation (see Table 18) suggest that intellectual ability was significantly related to academic achievement in reading $(r=-.327, \underline{p}>.010, n$ $=61$ ), while it was not significantly related to academic achievement in the areas of written language or mathematics $(r=-.237, \mathrm{p}>.066, \mathrm{n}=61 ; \mathrm{r}=-.133, \mathrm{p}>.308, \mathrm{n}=61)$.

Table 18

Relationship between intellectual ability by difference between grade level achievement and actual grade level

Difference between achievement and actual grade level placement

Intellectual ability

Pearson correlation

Level of significance

n
READING

$-.327$

.010

61
WRITTEN

LANGUAGE

$-.237$

.066

61
MATHEMATICS

$-.133$

.308

61

Question 8: What is the relationship between the child's degree of hearing loss and his or her academic achievement?

A crosstabulation was completed to determine if there was a significant relationship between the degree of hearing loss and the academic achievement among deaf/hard of hearing children. Of the students who participated in this study, just over $21 \%$ exhibited a mild hearing loss, nearly $13 \%$ had a moderate hearing loss, almost $5 \%$ had a severe hearing loss, nearly $46 \%$ had a severe to profound hearing loss, and approximately $15 \%$ had a profound hearing loss. 
In the area of reading, the results of a Pearson Chi-square analysis showed a significant relationship between degree of hearing loss and reading achievement among deaf/hard of hearing children $\left(\chi^{2}=15.980, \mathrm{df}=8, \underline{p}<.043\right)$. The results indicated that students with a mild hearing loss were almost evenly distributed among the levels of differences between achievement and actual grade level placement. The majority of students with a moderate hearing loss (75\%) achieved within one grade level of their actual grade level placement. Two of the three participants who had a severe hearing loss achieved at three or more grade levels below their actual grade level placement, while just over $57 \%$ of the participants who had a severe to profound hearing loss achieved three or more grade levels below their actual grade placement. Finally, students with a profound hearing loss were somewhat evenly distributed among the levels of differences between achievement and actual grade level placement (see Table 19).

Table 19

Difference between grade level achievement and actual grade level by degree of hearing loss (reading achievement)

\begin{tabular}{|c|c|c|c|c|c|c|}
\hline $\begin{array}{c}\frac{\text { Difference between }}{\text { achievement and actual }} \\
\text { grade placement }\end{array}$ & Mild & Moderate & Severe & $\begin{array}{l}\text { Severe to } \\
\text { Profound }\end{array}$ & Profound & Total \\
\hline $\begin{array}{c}\text { count } \\
\text { one grade level }\end{array}$ & $\begin{array}{c}5 \\
38.5 \%\end{array}$ & $\begin{array}{c}6 \\
75.0 \%\end{array}$ & $\begin{array}{c}1 \\
33.3 \%\end{array}$ & $\begin{array}{c}4 \\
14.3 \%\end{array}$ & $\begin{array}{c}2 \\
22.2 \%\end{array}$ & $\begin{array}{c}18 \\
29.5 \%\end{array}$ \\
\hline $\begin{array}{c}\text { count } \\
\text { two grade levels }\end{array}$ & $\begin{array}{c}4 \\
30.8 \%\end{array}$ & $\begin{array}{c}2 \\
25.0 \%\end{array}$ & $\ldots$ & $\begin{array}{c}8 \\
28.6 \%\end{array}$ & $\begin{array}{c}4 \\
44.4 \%\end{array}$ & $\begin{array}{c}18 \\
29.5 \%\end{array}$ \\
\hline $\begin{array}{c}\text { count } \\
\text { three or more grade levels }\end{array}$ & $\begin{array}{c}4 \\
30.8 \%\end{array}$ & - & $\begin{array}{l}2 \\
66.7 \%\end{array}$ & $\begin{array}{c}16 \\
57.1 \%\end{array}$ & $\begin{array}{c}3 \\
33.3 \%\end{array}$ & $\begin{array}{c}25 \\
41.0 \%\end{array}$ \\
\hline $\begin{array}{l}\text { count } \\
\text { total } \\
\end{array}$ & $\begin{array}{c}13 \\
100.0 \%\end{array}$ & $\begin{array}{c}8 \\
100.0 \%\end{array}$ & $\begin{array}{c}3 \\
100.0 \%\end{array}$ & $\begin{array}{c}28 \\
100.0 \%\end{array}$ & $\begin{array}{c}9 \\
100.0 \%\end{array}$ & $\begin{array}{c}61 \\
100.0 \%\end{array}$ \\
\hline
\end{tabular}

In the area of written language, the results of Pearson Chi-square analysis showed no significant relationship between the degree of the student's hearing loss and written 
language achievement among deaf/hard of hearing children $\left(\chi^{2}=3.832, \mathrm{df}=8, \underline{p}>.872\right)$.

The results indicated that the majority of the participants across all degrees of hearing loss achieved three or more grade levels below their actual grade placement (Table 20).

Table 20

Difference between grade level achievement and actual grade level by degree of hearing loss (written language achievement)

\begin{tabular}{|c|c|c|c|c|c|c|}
\hline $\begin{array}{c}\text { Difference between } \\
\text { achievement and actual } \\
\text { grade placement }\end{array}$ & Mild & Moderate & $\underline{\text { Severe }}$ & $\begin{array}{l}\text { Severe to } \\
\text { Profound }\end{array}$ & Profound & Total \\
\hline $\begin{array}{c}\text { count } \\
\text { one grade level }\end{array}$ & $\begin{array}{c}1 \\
7.7 \%\end{array}$ & $\begin{array}{c}1 \\
12.5 \%\end{array}$ & - & $\begin{array}{c}2 \\
7.1 \%\end{array}$ & $\begin{array}{c}2 \\
22.2 \%\end{array}$ & $\begin{array}{c}6 \\
9.8 \%\end{array}$ \\
\hline $\begin{array}{c}\text { count } \\
\text { two grade levels }\end{array}$ & $\begin{array}{c}3 \\
23.1 \%\end{array}$ & $\begin{array}{c}2 \\
25.0 \%\end{array}$ & 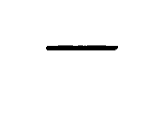 & $\begin{array}{c}7 \\
25.0 \%\end{array}$ & $\begin{array}{c}1 \\
11.1 \%\end{array}$ & $\begin{array}{c}13 \\
21.3 \%\end{array}$ \\
\hline $\begin{array}{c}\text { count } \\
\text { three or more grade } \\
\text { levels }\end{array}$ & $\begin{array}{c}9 \\
69.2 \%\end{array}$ & $\begin{array}{c}5 \\
62.5 \%\end{array}$ & $\begin{array}{c}3 \\
100.0 \%\end{array}$ & $\begin{array}{c}19 \\
67.9 \%\end{array}$ & $\begin{array}{c}6 \\
66.7 \%\end{array}$ & $\begin{array}{c}42 \\
68.9 \%\end{array}$ \\
\hline $\begin{array}{l}\text { count } \\
\text { total }\end{array}$ & $\begin{array}{c}13 \\
100.0 \%\end{array}$ & $\begin{array}{c}8 \\
100.0 \%\end{array}$ & $\begin{array}{c}3 \\
100.0 \%\end{array}$ & $\begin{array}{c}28 \\
100.0 \%\end{array}$ & $\begin{array}{c}9 \\
100.0 \%\end{array}$ & $\begin{array}{c}61 \\
100.0 \%\end{array}$ \\
\hline
\end{tabular}

In the area of mathematics, the results of a Pearson Chi-square analysis showed a significant relationship between degree of hearing loss and math achievement among deaf/hard of hearing children $\left(\chi^{2}=26.873, \mathrm{df}=8, \underline{p}<.001\right)$. The results indicated that the majority of students with a mild hearing loss achieved at or within one year of their actual grade level placement. All of the participants with a moderate hearing loss also achieved at or within one year of their actual grade level placement, while all the participants with a severe hearing loss achieved three or more grade levels below their actual grade level placement. Finally, the majority of students with a severe-profound or 
profound hearing loss also achieved three or more grade levels below their actual grade level placement (Table 21).

Table 21

Difference between grade level achievement and actual grade level by degree of hearing loss (mathematics achievement)

\begin{tabular}{|c|c|c|c|c|c|c|}
\hline $\begin{array}{c}\text { Difference between } \\
\frac{\text { achievement and actual }}{\text { grade placement }}\end{array}$ & Mild & Moderate & Severe & $\begin{array}{l}\text { Severe to } \\
\text { Profound }\end{array}$ & Profound & Total \\
\hline $\begin{array}{c}\text { count } \\
\text { one grade level }\end{array}$ & $\begin{array}{c}7 \\
53.8 \%\end{array}$ & $\begin{array}{c}8 \\
100.0 \%\end{array}$ & - & $\begin{array}{c}5 \\
17.9 \%\end{array}$ & $\begin{array}{c}3 \\
33.3 \%\end{array}$ & $\begin{array}{c}23 \\
37.7 \%\end{array}$ \\
\hline $\begin{array}{c}\text { count } \\
\text { two grade levels }\end{array}$ & $\begin{array}{c}4 \\
30.8 \%\end{array}$ & 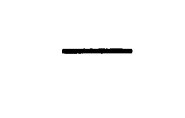 & 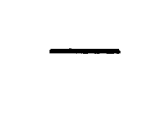 & $\begin{array}{c}6 \\
21.4 \%\end{array}$ & $\begin{array}{c}1 \\
11.1 \%\end{array}$ & $\begin{array}{c}11 \\
18.0 \%\end{array}$ \\
\hline $\begin{array}{c}\text { count } \\
\text { three or more grade } \\
\text { levels }\end{array}$ & $\begin{array}{c}2 \\
15.4 \%\end{array}$ & - & $\begin{array}{c}3 \\
100.0 \%\end{array}$ & $\begin{array}{c}17 \\
60.7 \%\end{array}$ & $\begin{array}{c}5 \\
55.6 \%\end{array}$ & $\begin{array}{c}27 \\
44.3 \%\end{array}$ \\
\hline $\begin{array}{l}\text { count } \\
\text { total }\end{array}$ & $\begin{array}{c}13 \\
100.0 \%\end{array}$ & $\begin{array}{c}8 \\
100.0 \%\end{array}$ & $\begin{array}{c}3 \\
100.0 \%\end{array}$ & $\begin{array}{c}28 \\
100.0 \%\end{array}$ & $\begin{array}{c}9 \\
100.0 \%\end{array}$ & $\begin{array}{c}61 \\
100.0 \%\end{array}$ \\
\hline
\end{tabular}

Additional analyses were completed to determine if a significant relationship existed between academic achievement and parental mode of communication/mode of communication used at school, with degree of hearing loss as a modulating factor. Degree of hearing loss was grouped into two groups due to the small sample size. The first group included all students who had a mild or moderate hearing loss. The second group consisted of the students who had a severe, severe-profound, or profound hearing loss. No significant relationship was found when parental mode of communication was correlated with degree of hearing loss in any area of academic achievement. A significant relationship was found between reading achievement and mode of communication used in school for those participants who had a severe to profound hearing loss $(\mathrm{p}>.011, \mathrm{n}=40)$. A Cramer's V analysis indicates nearly $47 \%$ of the relationship can be explained by the 
participants' mode of communication used at school, coupled with their severe to profound hearing loss. The researcher was unable to complete further analyses, such as degree of hearing loss correlated with educational placement (boundaried or cluster) with academic achievement, or degree of hearing loss correlated with age deafness was detected with academic achievement, degree of hearing loss correlated with intellectual ability with academic achievement, due to the small sample size.

\section{Chapter Summary}

The results show that parental mode of communication and mode of communication used in school were significantly related in the areas of reading and mathematics. Intellectual ability was also significantly related to academic achievement in the area of reading. Finally, the degree of hearing loss and reading achievement were also found to be significantly related. 


\section{CHAPTER V \\ DISCUSSION}

Introduction

The purpose of this research study was to identify the early factors that influence academic achievement among deaf/hard of hearing children. In particular, this research investigated the relationship between academic achievement and several specific factors, including parental mode of communication, mode of communication used in school, age at which amplification was first used, type of preschool program, age entered a preschool program, age hearing loss was detected, intellectual ability, and degree of hearing loss. In order to answer the research questions of interest, a parent questionnaire and permission form were sent to all eligible deaf/hard of hearing students in Broward County. School records were analyzed for those students whose parents returned the permission form and questionnaire.

This chapter presents a summary of the significant findings, an interpretation of the findings, implications and recommendations, and finally, several recommendations for further research.

\section{Summary of Significant Findings}

A summary of the early factors influencing academic achievement is found in Table 22. 
Table 22

Early factors influencing academic achievement

\begin{tabular}{|c|c|c|c|}
\hline Early Factors & Reading & Written Language & Mathematics \\
\hline $\begin{array}{l}\text { Parental mode of } \\
\text { communication }\end{array}$ & Significant & Not Significant & Significant \\
\hline $\begin{array}{l}\text { School mode of } \\
\text { communication }\end{array}$ & Significant & Not Significant & Significant \\
\hline $\begin{array}{c}\text { Age amplification first } \\
\text { used }\end{array}$ & Not Significant & Not Significant & Not Significant \\
\hline $\begin{array}{c}\text { Type of preschool } \\
\text { program }\end{array}$ & Not Significant & Not Significant & Not Significant \\
\hline $\begin{array}{c}\text { Age enter preschool } \\
\text { program }\end{array}$ & Not Significant & Not Significant & Not Significant \\
\hline Age deafness detected & Not Significant & Not Significant & Not Significan \\
\hline Intellectual ability & Significant & Not Significant & Not Significan \\
\hline Degree of hearing loss & Significant & Not Significant & Significant \\
\hline
\end{tabular}

The results of this research study indicated that there was a significant relationship between parental mode of communication and academic achievement in the areas of reading and mathematics. The results suggest that deaf/hard of hearing children whose parents use oral communication are performing closer to actual grade level equivalents on tests measuring reading and math achievement than do deaf/hard of hearing students whose parents are using some type of sign language at home. These results are contrary to previous research studies. According to Desselle (1994), deaf children of deaf parents, whose native language is American Sign Language, do not exhibit any language delays. These children progress through the stages of language development at the same rate as hearing children exposed to verbal communication (Marschark, 1997; McEntee, 1994; Schirmer, 1994; Geers \& Schick, 1988; Taeschner, Devescovi \& Volterra, 1988; Quigley 
\& Kretschmer, 1982; Altshuler, 1974; Bellugi \& Klima, 1972). The lack of delays in language development may be exhibited in higher academic achievement in subject areas, such as reading and mathematics, which require language.

There were more students whose parents use oral communication participating in this study than students whose parents use sign language. The results of this research study may have been influenced by this discrepancy. In addition, historically within Broward County students who use oral communication at school and with their parents score closer to actual grade level placement on tests of academic achievement than do students for whom this is not the case. This may be the direct result of these students having less severe needs than those students who are encouraged to utilize some type of sign language at school and with their parents. Also, students who use oral communication typically have less severe hearing losses. In some instances, students in the cluster schools may have additional handicapping conditions even though they have not been evaluated for additional eligibilities. Finally, these results may also be related to the differences between the various types of sign languages used by the participants of this study. Students who utilize American Sign Language are learning a complete, natural language. Students who use other types of sign language do not have the benefit of learning a true language. These factors, which may be specific to deaf/hard of hearing students in Broward County Public Schools, all may have contributed to the results of this study, which showed that students whose parents use oral communication scored closer to their actual grade level placement in reading and math than those students whose parents used some type of sign language.

A significant relationship was also found between the mode of communication used at school and academic achievement among deaf/hard of hearing children in the areas of reading and mathematics. The results suggest that deaf/hard of hearing children who receive their instruction in school through oral communication are performing closer to actual grade level in tests measuring reading and math achievement than deaf/hard of 
hearing students who receive their instruction through sign language. Based on this researcher's experience as a teacher in this district, teachers of deaf/hard of hearing students in Broward County do not have specific or extensive training in the signing system used within their classroom. Therefore, they are less able to teach in a fluent mode of signed communication. The instructional implication is that programs are only as good as their teachers, and if teachers are unable to communicate fluently, the instruction will suffer. Further, the same factors discussed for the findings regarding parental mode of communication may have contributed to these results. In addition, Broward County has historically encouraged all deaf/hard of hearing students to begin their school program using an oral communication approach unless they have a severe or greater hearing loss, additional disabilities, or deaf parents. The number of students who begin a preschool program using oral communication who then switch to the use of Total Communication, may be referred to as "oral failures". The needs of these students are not addressed in Broward County. This information is not quantifiable but may be useful in analyzing low academic achievement among deaf children. Thus the mode of communication is often selected for deaf/hard of hearing children based on these specific characteristics related to degree of hearing loss rather than individual student need or research based literature.

There was no significant relationship between age of amplification and academic achievement among deaf/hard of hearing children. Previous research only indicated that early amplification was necessary for maximum development of language (Ross \& Giolas, 1978), while this research study found no significant relationship between the age of amplification and academic achievement among deaf/hard of hearing children. In Broward County, all deaf/hard of hearing students who would benefit from amplification and are enrolled in school are fitted with amplification devices upon entering a preschool program. Therefore, there was very little variation among the ages amplification was first used among the participants within this study. 
This research study showed no significant relationship between the type of preschool program and academic achievement among deaf/hard of hearing children. These results may be misleading due the inherent characteristics of preschool programs. Generally, most preschool programs are very language-based and offer a structured environment for learning language. There may be factors inhibiting language development for these students other than type of preschool. The participants in this study ranged in age from five through nineteen. Participants may have entered kindergarten achieving close to or at grade level, but their language abilities may not have grown at the same rate as their hearing peers, prohibiting them from achieving academically as well as would be expected based on their ability measures. Based on this researcher's experience, the curriculum accessed by deaf/hard of hearing students is not always equivalent to that offered within general education classes. Since deaf/hard of hearing children often initially enter school with little or no language, much of the curriculum used is for the purpose of teaching language. Children who access general education classes usually already use language, therefore, that curriculum focuses on the development of academic skills. Due to the differentiated curriculum, teachers may have lower expectations for their deaf/hard of hearing students. In addition, continuity of the curriculum is absent from this program. Continuity of the curriculum is achieved when the content is repeated at increasing levels of complexity at consecutive levels. Continuity has also been referred to as the spiral curriculum (Oliva, 1992).

Previous research indicated that students enrolled in a preschool program prior to sixteen months of age scored higher on academic achievement tests in the area of language than students enrolled after age sixteen months (Weisel, 1988). However, this research study found no significant relationship between the age a child entered preschool and his or her academic achievement. Once again, these participants may have entered kindergarten achieving close to or at grade level, but their language abilities may not have grown at the 
same rate as their hearing peers, therefore prohibiting them from achieving academically as well as would be expected based on their ability measures. Additionally, this research study found no significant relationships between the type of preschool program and academic achievement. The lack of significance could be due to the majority of participants in this study attending some type of preschool program, public or private. Both types of programs do offer some type of language-based curriculum, as well as structured activities.

According to Seabrook \& Rodda (1991) and Desselle (1994), the identification of a hearing loss and language ability are related in that the earlier a child is diagnosed, the more opportunities he or she has in developing language. This research study showed no such relationship. The majority of participants involved in this study were identified by age three by the Broward County Public Schools. Since previous research, as stated in Chapter 2, suggests that learning language occurs earlier than age three, the majority of these deaf/hard of hearing children were already suffering from language delays by the time they attended a preschool program. In other words, there is not sufficient variation among the participants in the age they began attending a preschool program. Therefore it can be assumed that all families received the same services and the same information. However, even though students may have been identified, families may not have been receiving services to assist in the educational aspects of the students' lives. It has been the experience of this researcher that parents of newly identified deaf/hard of hearing students receive very little information on how the child's mode of communication may affect their learning. It has been suggested by some that parents receive more than enough information when their child becomes eligible for an exceptional program and the debate over mode of communication would only add conflict and stress to the situation. This delay in information sharing may have also affected the results of this study.

Previous research indicated that deafness alone does not limit intellectual ability (Altsher, 1974). This research study demonstrated a significant relationship between 
intellectual ability and reading achievement among deaf/hard of hearing children. There was no significant relationship between intellectual ability and written language or mathematics achievement among deaf/hard of hearing children. In other words, students who have more intellectual ability as measured by nonverbal IQ did not necessarily perform better on written and mathematics achievement tests than those students with less intellectual ability. However, academic achievement is measured through standardized tests. It has been this researcher's experience that deaf/hard of hearing students do not receive any instruction in study skills or test taking skills. Unlike students in general education, deaf/hard of hearing students who attend a cluster program have minimal experience in taking standardized tests, and little or no instruction regarding procedures for test taking and studying. Also, there were a variety of academic achievement and intellectual ability tests used for the purposes of this study. The variation among measures may also have had an impact on the results.

Finally, a significant relationship was found between degree of hearing loss and academic achievement in the areas of reading and mathematics. The results indicated that students who have more residual hearing achieved closer to their actual grade level placement than students who have less residual hearing. Students with more residual hearing typically "hear" more language and, therefore, have a stronger base on which to build and learn language. Once again, no significant relationship was found between the degree of hearing loss and written language achievement.

Written language was not significantly dependent on or related to, any factors investigated in this research study. One reason may be that written language is typically the weakest area of academic achievement for all deaf/hard of hearing children. Written language is typically the weakest for deaf/hard of hearing children because they generally grow-up in a linguistically deprived environment. In addition, deaf/hard of hearing children usually have very limited vocabularies which may effect their written language ability (Rodda, Cumming \& Fewer, 1993). Written language is often taught to hearing students in 
a formal, rule-driven instructional approach. Written language in Broward County is taught to deaf/hard of hearing children through a whole-language approach. Grammar is not taught formally, but through modeling adult written language. Clearly the subjects in this study are not benefiting from the written language instructional approach currently being provided. Written language scores used in this study were all significantly below grade level. Therefore, there was not enough variation among the scores to determine any significant relationships between the factors investigated and written language achievement.

\section{Limitations of Findings}

The differences between previous research and the results found in this study can be attributed to several quantitative factors. Initially, a number of deaf/hard of hearing students were excluded from the research study due to inaccurate addresses in Broward County's database system. Additional students were excluded from the research study because their parents did not grant permission for their participation, their parent questionnaires were incomplete, and/or their school records did not contain the necessary information. Finally, several students were excluded from the study because parent permission forms were not returned. These exclusions led to a small sample size, making it difficult to show statistically significant differences.

Many of the characteristics of this sample are similar to the total population. There are significantly more deaf attending cluster programs than their boundaried schools. There are somewhat equal distributions of gender, although there is a slight difference among grade levels. Within the total population, there are more elementary level students than middle or high school students. However, within the sample, the number of students at each grade level was approximately equal.

This researcher chose to use a self-reporting survey rather than direct observation or interviewing of families and students. This self-reporting instrument may not have been 
completely understood by the parent completing it, or their recollection and/or perceptions may have been faulty. Therefore, the level of accuracy of parental reporting may have led to inaccurate information being used for this analysis, causing the results to be misleading. This is a problem whenever a researcher chooses to use a self-reporting instrument. Furthermore, this researcher chose to use the results from achievement and ability tests previously administered to the students. Due to the wide variety in instrumentation, results of this study may have been affected. In addition, only grade level equivalents were available to this researcher. A potential limitation of these results may be in the grade equivalent scores derived from different measures used by Broward County Public Schools, which could have resulted in an inconsistency in grade level equivalents reported across specific instruments. The variety of test administrators may also have biased the results. Therefore, the extent to which generalizations can be made must be considered carefully. Finally, a significant limitation was the off-level administration of the STANFORD 9. Grade equivalents reported for the STANFORD 9 therefore may not have been true measures of actual academic achievement.

The variety of IQ tests was also a limitation of this study. Some of the instruments used by Broward County Public Schools are out of date and may have affected the results of this study. The variety of evaluators administering these tests may have also influenced the results.

Students who attended their boundaried school received more individual instruction than those who attended cluster programs. Students in boundaried schools received the services of an itinerant teacher of deaf/hard of hearing students, which, in many instances, was provided in one-on-one settings or groups of two to three students. These settings afforded deaf/hard of hearing children opportunities for direct remediation of skills taught in general education classes. Therefore, achievement may have been influenced by methodology of instruction and configuration of special services. 
Various modes of communication were used by parents and school staff. The type of sign language used at school is determined by the teacher and the parent decides which mode of communication is used at home. Consistent modes of communication are not used throughout the levels of schooling, nor are consistent modes used between school and home. For the purposes of this research study, the various types of sign languages were grouped together because of the small sample size. Fluency in the use of a particular signing system by the teacher is also a limitation of this study. Historically, sign language classes have not been required for teacher certification. Therefore, teachers in Broward County may have no formal training in the various types of sign languages. This lack of consistency and fluency may have affected the results of this study.

Finally, additional analyses were attempted, but could not be completed due to the small sample size. The parent questionnaire requested information regarding the student's cause of hearing loss. There were too few participants in each category of hearing loss which precluded meaningful analyses. Analysis to determine whether boundaried or cluster placements affected academic achievement was not completed due to the number of participants. Analyses coupling degree of hearing loss with age of amplification as well as age attended preschool and type of preschool were attempted, but could not be completed due to the small sample size.

\section{Implications and Recommendations}

The following are implications and recommendations for professionals working in the field of deaf education.

1. Psychoeducational evaluations should be completed for all deaf/hard of hearing students and additional eligibilities considered if criteria are met. For example, evaluations or re-evaluations for deaf/hard of hearing students should include, but not be limited to, a measure of intellectual ability, academic achievement measures, process testing, and 
adaptive behavior testing if intellectual ability is found to be deficient. If students meet state criteria for additional eligibilities, these should be considered by an eligibility committee. Additional eligibilities may be a factor in low academic achievement. School psychologists should complete the evaluations and re-evaluations for deaf/hard of hearing students. 2. The deaf/hard of hearing program should emphasize consistent methods of communication between school, all grade levels, and home. That is, if a student uses Pidgin Signed English in elementary school, this communication system should be used throughout all educational levels, as well as within the home. Consistent methods of communication may lead to increased academic achievement. Teachers of deaf/hard of hearing students should receive extensive training in the mode of communication utilized within their classroom. Teachers who use oral communication should receive training in oral communication methods used by children with hearing losses, also techniques in developing a rich oral environment. Teachers who use a sign language system should be trained and fluent in the use of that particular signing system. This training could lead to a more comprehensive, language-rich learning environment for deaf/hard of hearing students.

3. The mode of communication recommended to parents should be based on research and individual student need. Physicians should receive training pertaining to the educational needs of deaf/hard of hearing children. In addition, packets of information related to modes of communication should be given to all parents of newly identified deaf/hard of hearing children.

4. Teachers of deaf/hard of hearing students need to integrate a variety of written language strategies within the general education curriculum. These written language strategies are a foundation for developing basic skills necessary for academic achievement. Teachers should be provided with specialized training, through inservice or university coursework, especially in the area of written language. 
5. The curriculum utilized in the deaf/hard of hearing program should be equivalent to that utilized in general education, with appropriate and necessary modifications and adaptations. This would lead to teachers of deaf/hard of hearing students having higher expectations for their students. General education curricula and higher expectations may lead to increased levels of academic achievement. Teachers should be provided with specialized training, through inservice or university coursework, in the area of general education and appropriate modifications.

6. Preschool programming should have an increased focus on educating the family about issues inherent to deafness and on creating an atmosphere of increased family involvement. This family involvement should increase the experiences available to deaf/hard of hearing children, thereby raising the academic achievement of the deaf student. Teachers should complete weekly home visits. Teachers should also provide families with opportunities to partake in ongoing training.

7. A daily period of time should be used to teach study and test taking skills to all deaf/hard of hearing students, grades K-12. This will provide deaf/hard of hearing students with the experiences necessary for completing the requirements for a regular high school diploma. Specialized materials should be purchased and utilized at all grade levels.

8. Consistent and up-to-date measures of intellectual ability and academic achievement should be employed with all deaf/hard of hearing. Psychological evaluations, completed by certified school psychologists, should be completed for all deaf/hard of hearing students. 9. Teachers of deaf/hard of hearing students at all levels should meet monthly and visit classrooms at all levels so that continuity of the curriculum can be addressed and implemented. Continuity, according to Oliva (1992, p. 523), "is the planned repetition of content at successive levels, each time at an increased level of complexity." Inservice hours or hourly stipends could be used to allow teachers at various grade levels to meet regularly and discuss the curriculum provided to deaf/hard of hearing students. 


\section{Recommendations for Future Research}

The following are recommendations for future research:

1. The study should be replicated with a larger sample size and with appropriate up-todate measures of intellectual ability and academic achievement.

2. A research study should investigate the relationship between the interaction of deaf adult role models within deaf/hard of hearing school programs and the academic achievement of deaf/hard of hearing students.

3. A study should be conducted to determine the effects of specific and consistent modes of communication used at home and at school in relation to academic achievement among deaf/hard of hearing children.

4. A study should be done to compare the academic achievement of students enrolled in residential programs with that of students enrolled in public school programs.

5. A study should be done to investigate the most difficult aspects of reading among deaf/hard of hearing children.

6. A study should be done to identify the most successful strategies for teaching deaf/hard of hearing children to read.

7. A study should be done to clarify whether factors such as perceptual skills and learning styles affect deaf/hard of hearing students' learning.

8. A study should be conducted to investigate physicians' knowledge of deafness, the implications of deafness, and the necessity for early and aggressive interventions by the parents. 
References 
Adam, A. J. (1993). Amplification, technology, and cochlear implants for infants. The Volta Review, 95, 41-49.

Adams, J. W. (1997). You and your deaf child. Washington, DC: Clerc Books, Gallaudet University Press.

Altshuler, K.Z. (1974). The social and psychological development of the deaf child: problems, their treatment and prevention. American Annals of the Deaf, 119, 365376.

Andrews, J.F., Ferguson, C. Roberts, S. Hodges, P. (1997). What's up, Billy Jo?: American Annals of the Deaf, 142, 16-25.

Babbie, E. (1992). The practice of social research (6th edition). Belmont, CA: Wadsworth Publishing Company.

Ballantyne, J. (1977). Deafness. New York: Churchill and Livingstone.

Bellugi, U. \& Klima, E.S. (1972). The roots of language in the sign talk of the deaf. Psychology Today, 6, 61-64.

Bernstein, A. (1993). A school-based parent infant program: The right step in the educational process. The Volta Review, 95, 75-84.

Bernstein, M.E. \& Martin, J. (1992). Informing parents about educational options. American Annals of the Deaf, 137, 31-39.

Bernstein, M.E. \& Morrison, M. E. (1992). Are we ready for PL 99-457? American Annals of the Deaf, 137, 7-13.

Bodner-Johnson, B. (1996). Total communication. In Schwartz, S. (Ed.), Choices in deafness. (pp. 17-38). Bethesda, MD: Woodbine House.

Braden, J.P. (1989). The criterion-rlated validity of the WISC-R Performance Scale and other non-verbal IQ tests for deaf children. American Annals of the Deaf, 134, 329332. 
Brasel, K. \& Quigley, S. (1977). The influence of certain language and community environments in early childhood on the development of language in deaf individuals. Journal of Speech and Hearing Research, 20, 95-107.

Brill, R.G., MacNeil, B. \& Newman, L.R. (1986). Framework for appropriate programs for deaf children. American Annals of the Deaf, 131, 65-77.

Brownlee, S. (1998). Baby talk. U.S. News \& World Report, 124, 48-55.

Buchanan, R. (1993). The silent worker newspaper and the building of a deaf community. In VanCleve, J.V. (Ed.), Deaf history unveiled. (pp. 172-197). Washington, D.C.: Gallaudet University Press.

Caccamise, F. \& Newell, W. (1984). A review of current terminology used in deaf education and signing. Journal of the Academy of Rehabilitative Audiology, 17, 106-129.

Carroll, C. (1997). Deaf colonials. Perspectives in Education \& Deafness, 15, 8-11.

Charlson, E., Strong, M. \& Gold, R. (1992). How successful deaf teenagers experience \& cope with isolation. American Annals of the Deaf, 121, 261-270.

Chasen, G. \& Zuckerman. W. (1976). The effects of total communication and oralism on deaf third-grade "Rubella" students. American Annals of the Deaf, 137, 394-404.

Christensen, K.M. (1990). Thinking about thinking. American Annuals of the Deaf, 135. 222-226.

Clark, T. (1994). SKI-HI applications for home-based interventions. In Roush \& Matkin (Eds.) Infants \& toddlers with hearing loss. (pp. 237-252). Baltimore: York Press, Inc.

Copmann, K.S. (1996). The audiological assessment. In Schwartz, S. (Ed.), Choices in Deafness. (pp. 17-38). Bethesda, MD: Woodbine House.

Desselle, D. D. (1994). Self-Esteem, family climate, and communication patterns in relation to deafness. American Annals of the Deaf, 139, 322-328. 
Diefendor, A.O. \& Weber, B.A. (1994). Identification of hearing loss. In Roush, J. \& Matkin, N.D. (Eds.), Infants and toddlers with hearing loss. (pp.). Baltimore: York Press, Inc.

Epstein, S. (1996). A medical approach to hearing loss. In Schwartz, S. (Ed) Choices in deafness (pp. 1-16). Bethesda, MD: Woodbine House.

Fischer, R. (1993). Abbe de lEpee \& the living dictionary. In VanCleve, J.V. (Ed). Deaf History Unveiled (pp. 13-26). Washington, DC: Gallaudet University Press.

Fitzgerald, M.T. \& Fischer, R.M. (1987). A family involvement model for hearingimpaired infants. Topics in Language Disorders, 7, 1-18.

Fromkin, VA. (1988). Sign language: Evidence for universals and the linguistic capacity of the human brain. Sign Language Studies, 59, 115-127.

Furth, H.G. (1973). Deafness and learning: Belmont: Wadsworth Publishing Company Inc.

Gallaudet Research Institute. (1996, December). Achievement Testing of deaf and hard of hearing students: The 9th edition Stanford Achievement Test. Washington DC: Gallaudet University, Gallaudet Research Institute.

Gallaudet Research Institute. (1996). Stanford Achievement Test, 9th edition Screening procedures for deaf and hard of hearing students. Washington, DC: Gallaudet University, Gallaudet Research Institute.

Gallimore, L. \& Woodruff, S. (1996). The bilingual-bicultural (Bi-Bi) approach. In Schwartz, S. (Ed) Choices in deafness (pp. 89-116). Bethesda, MD: Woodbine House.

Gannon, J. R. (1996). A cultural identity. In Schwartz, S. (Ed) Choices in deafness (pp. 255-266). Bethesda, MD: Woodbine House.

Gatty, J. (1996). The oral approach. In Schwartz, S. (Ed) Choices in deafness (pp. 163208). Bethesda, MD: Woodbine House. 
Gatty, J.C. (1994). The V.I.P. program: Clark School for the Deaf. In Roush \& Matkin (Eds.). Infants and toddlers with hearing loss. (pp. 215-236). Baltimore: York Press Company, Inc.

Gay, L.R. (1992). Educational research. New York: MacMillan Publishing Company. Geers, A. \& Schick, B. (1988). Acquisition of spoken and signed English by hearing impaired children of hearing impaired or hearing parents. Joumal of Speech and Hearing Disorders, 53, 136-143.

Goetzinger, C.P. \& Rousey, C.L. (1959). Educational achievement of deaf children. American Annals of the Deaf, 104, 221-231.

Greenberg, M. (1980). Social Interaction between deaf preschoolers and their mothers: the effects of communication method and communication competence. Developmental Psychology, 16, 465-474.

Greenberg, M. (1983). Family stress and child competence: the effects of early intervention for families with deaf infants. American Annals of the Deaf, 128, 407-417.

Greenwood-Logsdon, M. (1990). Which sign language system should be used with young deaf children? (ERIC Document Reproduction Service no. ED 347 716).

Hammill, D.D., Pearson, N.A. \& Wiederholt, J.L. (1997). Examiner's manual Comprehensive Test of Nonverbal Intelligence. Austin, Texas: PRO-ED, Inc.

Heiling, K. (1995). The development of deaf children. Hamburg, Germany: Signum. Hill, P. (1993). The need for adult deaf role models in dearly intervention programs for deaf children. ACEHI, 19, 14-20.

Hiskey, M.S. (1966). Hiskey-Nebraska Test of Learning Aptitude. Lincoln, Nebraska: Union College Press.

Holden-Pitt, L. \& Diaz, J.A. (1998). Thirty years of the annual survey of Deaf \& Hard of Hearing children and youth. American Annals of the Deaf, 142, 72-76. 
Holt, J.A., Traxler, C.B. \& Allen, T. E. (1997). Stanford 9 Interpreting the Scores: a user's guide to the 9th edition Stanford Achievement Test for educators of deaf and hard of hearing students. (Tech. Rep. No. 97-1). Washington DC: Gallaudet University, Gallaudet Research Institute.

Howse, J.M. \& Fitch, J.L. (1972). Effects of parent orientation in sign language on communication skills of preschool children. American Annals of the Deaf, 117. $459-462$.

Kampfe, C.M. (1989). Parental reaction to a child's hearing impairment. American Annals of the Deaf, 134, 255-259.

Kliebard, H.M. (1987). The struggle for the American curriculum 1893 - 1958. New York: Routledge.

Kirk, S.A. \& Gallagher, J.J. (1986). Educating exceptional children. Boston: Houghton Mifflin Company.

Kluwin, T.N., Gaustad, M.G. \& Gonter, M. (1991). Predicting family communication choices. American Annals of the Deaf, 136, 28-34.

Kluwin \& Stinson (1993). Deaf students in local public high schools. Springfield, IL: Charles C. Thomas.

Kushe, C.A., Greenberg, M.T. \& Garfield, T.S. (1983). Nonverbal intelligence \& verbal achievement in deaf adolescents. American Annals of the Deaf, 128, 458-466.

Lane, H. (1984). When the mind hears. New-York: Random-House.

Liben, L.S. (1978). The development of deaf children: An overview of issues. In L.S. Liben (Ed.) Deaf Children: Developmental Perspectives (pp. 3-20). New-York: Academic Press, Inc.

Liddell, S.K. (1983). Language of the deaf. Society, 20, 3439.

Luetke-Stahlman, B. (1991). Hearing impaired preschoolers in integrated child care. Perspectives in Education \& Deafness, 9, 8-11. 
Luetke-Stahlman, B. \& Milburn, W.O. (1996).American Annals of the Deaf, 141, 29-33.

Maller, S.J., Singleton, J.L., \& Supalla, S.J. (1997). The American Sign Language proficiency assessment. Paper presented at the annual meeting of the FERA.

Markwardt, F.C. (1989). Peabody Individual Achievement Test-Revised manual. Circle Pines, MN: American Guidance Service, Inc.

Marschark, M. (1997). Raising and educating a deaf child. New-York: Oxford University Press.

McEntee, L.J. (1994). Deaf children interacting with deaf parents. (ERIC Document Reproduction Service no. ED 385 156).

Meadow, K. P. (1980). Deafness and child development. Los Angles: University of California Press.

Meadow, K.P. (1978). The "Natural History" of a research project: An illusion of methodology issues in research with deaf children. In L.S. Liben (Ed.) Deaf children: Developmental perspectives. (p. 3-20). New York: Academic Press, Inc.

Meadow, K. P. (1968). Early manual communication in relation to the deaf child's intellectual, social, and communicative functioning. American Annals of the Deaf, $113,29-41$.

Meadow-Orlans, K.P. (1994). Stress, support and deafness: Perceptions of infants; mothers and fathers. Journal of Early Intervention, 18, 91-102.

Meadow-Orlans, K.P. \& Sass-Lehrer, M. (1995). Support services for families with children who are deaf: Challenges for professionals. TECSE, 15, 314-334.

Menyuk, P. (1976). Cognition and language. The Volta Review, 78, 250-257.

Messerly, C.L. \& Aram, D. M. (1980). Academic achievement of hearing-impaired students of hearing parents and of hearing-impaired parents: Another look. The Volta Review, 82, 25-32. 
Meyers, J.E. \& Bartee, J.W. (1992). Improvements in the signing skills of hearing parents of deaf children. American Annals of the Deaf, 137, 257-260.

Miller, D. (1988). 74-574 Auditory Problems of Children. Bloomsburg University, Bloomsburg, PA.

Miller, M.K. (1934). The Status of the preschool deaf child. American Annals of the Deaf, 79. 414-427.

Mitchell, G. (1982). Can deaf children acquire English? An evaluation of manually coded English systems in terms of the principles of language acquisition. American Annals of the Deaf, 127,331-336.

Moore, W.G., Josephson,, J.A. \& Mauk, G.W. (1991). Identification of children with hearing impairments. The Volta Review, 93, 187-196.

Moores, D.F. (1992). An Historical Perspective on School Placement. In Kluwin, T.N. \& Gaustad, M.G. (Eds.). Toward Effective Public School Programs for Deaf Students. (pp. 7-29). New York: Teachers College Press.

Moores, D.F. (1982). Educating the deaf. Boston: Houghton Mifflin Company.

Moores, D.F. \& Sweet, C. (1990). Relationships of English grammar and communicative fluency to reading in deaf adolescents. Exceptionality, 1, 97-106.

Moores, D.F., Weiss, K.L. \& Goodwin, M.W. (1978) Early education programs for hearing-impaired children: Major findings. American Annals of the Deaf, 123,925936.

Morgan-Redshaw, M. (1989). Hearing families with deaf children: Living with deafness. ACEHI, 15, 105-113.

Morgan-Redshaw, M., Wilgosh, L., \& Bibby, M.A. (1989). Hearing families with deaf children: Living with Deafness. ACEHI, 15, 105-113.

Mueller-Vollmer, P. (1990). Balancing ASL and TC in the classroom. Perspectives Education and Deafness, 8, 16-17. 
Musselman, C. \& Kircaali-Iftar, G. (1996). The development of spoken language in deaf children: Explaining the unexplained variance. Journal of Deaf Studies and Deaf Education, 1, 108-121.

Musselman, C.R., Lindsay, P.H., \& Wilson, A.K. (1988). The effect of mothers' communication mode on language development in preschool deaf children. Applied Psycholinguistics, 9, 185-204.

National Center for Law and the Deaf. (1986). Legal Rights of Hearing Impaired People. Washington, DC : Gallaudet University Press.

Nelson, K.E., Loncke, F, \& Camarata, S. (1993). Implications on deaf and hearing children's language learning. In Marschark, M. \& Clark M. D. (Eds.) Psychological Perspectives on Deafness (pp. 123 - 151). Hillsdale, New Jersey: Lawrence Erlbaum Associates.

Newby, H.A. (1979). Audiology. Englewood Cliffs: Prentice-Hall, Inc.

Nicholas, M. (1993). Family communication \& the right to sign. Perspectives in Education \& Deafness, 12, 18-21.

O'Donnell, M, Moores, D.F. \& Kluwin, T.N. (1992). Identifying the contributions of school factors to the success of deaf students. In Kluwin, T.N. \& Gaustad, M.G. (Eds.). Toward Effective Public School Programs for Deaf Students. (pp. 194 216). New York: Teachers College Press.

Oliva, P.F. (1992). Developing the curriculum. New York: Haper Collins Publisher. Orlans, H. (1989). The revolution at Gallaudet. Change, 21, 8-18.

Owens, R.E. (1988). Language development: An introduction.Columbus: Merrill Publishing Company.

Quigley, S.P. \& Kretschmer, R.E. (1982). The education of the deaf. Baltimore: University Park Press. 
Padden, C. A. (1990). Deaf children and literacy (ERIC Document Reproduction Service no. ED 321 069)

Parasnis, I. (1983). Effects of parental deafness and early exposure to manual communication on the cognitive skills, English language skill, and field independence of young deaf adults. Journal of Speech and Hearing Research. 26, 588-594.

Ritter-Brinton, K. \& Stewart, D. (1992). Hearing parents and deaf children. American Annals of the Deaf, 137, 85-91.

Rodda, M, Cumming, C. \& Fewer, D. (1993). Memory, learning, and language: Implications for deaf education. In Marschark, M. \& Clark M. D. (Eds.) Psychological Perspectives on Deafness (pp. 339 - 352). Hillsdale, New Jersey: Lawrence Erlbaum Associates.

Rogers, D. (1989). "Show -me bedtime reading". Perspectives for Teachers of the Hearing Impaired, 8, 2-5.

Roid, G.H. \& Miller, L.J. (1997). Leiter International Performance Scale-Revised. Wood Dale Illinois: Stoelting Inc,

Ross, M. \& Giolas, T.G. (1978). Auditory management of hearing-impaired children. Baltimore: University Park Press.

Roush, J. \& Gravel, J. (1994). Acoustic amplification \& sensory aids for infants \& toddlers. In Roush, J. \& Matkin, N.D. (Eds.), Infants and toddlers with hearing loss. (pp. 65-82). Baltimore: York Press, Inc.

Roush, J., Harrison, M. \& Palsha, S. (1991). Family-centered early intervention. American Annals of the Deaf, 136, 360-366.

Santrock, L.W. (1983). Life-span development. Dubuque, Iowa: Wm. C. Brown Company Publishers. 
Sass-Lehrer, M. \& Bodner-Johnson, B. (1989). Public law 99-457. American Annals of the Deaf, 134, 71-77.

Schildroth, A.N. \& Hotto, S.A (1996). Changes in students and program characteristics, 1984-85 \& 1994-95. American Annals of the Deaf, 141, 68-137.

Schirmer, B. R. (1994). Language and literacy development in children who are deaf. New York: Merrill, an imprint of Macmillan Publishing Company.

Schubert, W.H. (1986). Curriculum: perspective, paradigm, and possibility. New York: MacMillan Publishing Company.

Schwartz, S. (1996). Systems of manual communication. In Schwartz, S. (Ed) Choices in deafness (pp. 267-280). Bethesda, MD: Woodbine House.

Scouten, E.L. (1984). Turning points in the education of deaf people. Danville, Illinois: The Interstate Printers \& Publishers, Inc.

Seabrook, J. \& Rodda, M. (1991). Parental response to deafness: How can we help. ACEHI, 17, 64-70.

Shames, G.H. \& Wiig, E.H. (1982). Human communication disorders. Columbus, Ohio: Charles E. Merrill Publishing Company.

Shroyer, E.H. (1982). Signs of the times. Washington, D.C.: Gallaudet University Press. Simpson, R.L. (1982). Conferencing parents of exceptional children. Rockville, Maryland: Aspen Publishers, Inc.

Sisco, G.H. \& Anderson, R.J. (1978). Current findings regarding the performance of deaf children on the WISC-R. American Annals of the Deaf, 123, 115-121.

Soderfeldt, B., Ronnberg, J. \& Risberg, J. (1994). Regional cerebral blood flow during sign language perception: deaf $\&$ hearing subjects with deaf parents compared. $\underline{\text { Sign }}$ Language Studies, 84, 199-208.

SP \& P (1996). Special Programs \& Procedures for Exceptional Students. Tallahassee, Florida: Bureau of Student Services and Exceptional Education. 
Spencer, P. (1996). The association between language and symbolic play at two years: evidence from deaf toddlers. Child Development, 67, 867-876.

Spencer, , P. (1992). Communicating with signed language: Hearing mothers \& deaf infants. (ERIC Document reproduction Service no. ED 355 710).

Streng, A.H., Kretschmer, R.R., \& Kretschmer, L.W. (1978) Language, learning and deafness. New York: Grune \& Statton.

Stuckless, E.R. \& Birch, J.W. (1966). The influence of early manual communication on the linguistic development of deaf children. American Annals of the Deaf, 111. $452-462$.

Swisher, M.V. \& Thompson, M. (1985). Mothers learning simultaneous communication: The dimensions of the task. American Annals of the Deaf, 130, 212-217.

Taeschner, T., Devescovi, A. \& Volterra, V. (1988). Affixes and function words in the written language of deaf children. Applied Psycholinguistics, 9, 385-401.

Tabor, M.L. (1988). Acquisition of American Sign Language: A review. Contemporary Education, 59, 62-66.

Testut, E.W. \& Baldwin, R.L. (1977). Educational options. Volta Review, 79, 281-286.

Tomlinson-Keasey, C. \& Kelly, R.R. (1974). The development of thought processes in deaf children. American Annals of the Deaf, 119, 693-700.

Vernon, M. (1988). The Gallaudet Protest. American Annals of the Deaf, 133, 5-6.

Vernon, M \& Alles, B.F (1986). Psychoeducational assessment of Deaf and Hard-ofHearing children and adolescents. In Lazarus, P.J. \& Strichart, S.S. (Eds.) Psychoeducational evaluation of children and adolescents with low-incidence handicaps. (pp. 103-122). Orlando, Florida: Grune \& Stratton, Inc.

Vernon, M., \& Koh, S.D. (1970). Early manual communication and deaf children's achievement. American Annals of the Deaf, 115, 527-536. 
Vernon, M., \& Koh, S.D. (1971). Effects of oral preschool compared to early manual communication on education and communication in deaf children American Annals of the Deaf, 116, 569-574.

Walberg, (1984). Improving the productivity of American schools. Educational Leadership, 41, 19-27.

Walkney, K.M. (1984). American Sign Language Class, University of Pittsburgh.

Watkins, S. \& Clark, T.C. (1988). A model for teaching parents of young hearingimpaired children total communication the home - project RITCH. American Annals of the Deaf, 133, 289-293.

Wechsler, D. (1991). Wechsler Intelligence Scale for Children-Thrid Edition. Orlando: Harcourt, Brace \& Jovanovich.

Weisel, A. (1988). Parental hearing status, reading comprehension skills and socialemotional adjustment. American Annals of the Deaf, 133, 356-359.

Williams, C. L. (1994). The language and literacy worlds of three profoundly deaf preschool children. Reading Research Quarterly, 29, 125-155.

Williams-Scott, B. \& Kipila, E. (1996). Cued speech. In Schwartz, S. (Ed.) Choices in Deafness. (pp. 117-162). Bethesda, MD: Woodbine House.

Wilkinson, G.S. (1993). The Wide Range Achievement Test: Administration Manual. Wilmington, Delaware: Wide Range, Inc.

Winzer, M.A. (1993). The history of special education. Washington, DC: Gallaudet University Press.

Wolkomoir, R. (1992) American Sign Language: 'It's not mouth stuff- it's brain stuff'. Smithsonian, 23, 30-41.

Woodcock, R.W. \& Mather, N. (1989). Woodcock-Johnson tests of achievement. Allen, Texas: DLM Teaching Resources. 
Zwiebel, A. (1987) More on the effects of early manual communication on the cognitive development of deaf children. American Annals of the Deaf, 132, 16-20. 
Appendices 
September 9, 1998

Dear Parent or Guardian:

My name is Lisa Cunningham, and I am a Program Specialist in the Central Area Office of the Broward County Public Schools. In this capacity, I am responsible for providing technical assistance to school-based Exceptional Student Education (ESE) Specialists. I am also a certified teacher of the Deaf/Hard of Hearing and serve on the Task Force for the Deaf/Hard of Hearing (DHH).

I am writing to you today to request your assistance in a very important research study on deaf children. I am a doctoral candidate at Florida International University. I am conducting research on the factors that are related to academic achievement in deaf children for my doctoral dissertation. Less than $20 \%$ of the 1997-1998 deaf graduates from Broward County Public Schools graduated with a standard high school diploma. My goal, in conducting this research study is to use the data collected to develop programs that will help increase the number of deaf students who graduate from a Broward County school with a standard diploma. My research study will focus on deaf children between the ages of five and nineteen eligible for deaf/hard of hearing services. My research proposal has been reviewed and accepted by Broward County Public Schools.

I am asking for your permission to use information related to your child in my research. Please be assured all names will remain confidential and will only be used to match the parent questionnaire to the correct school information. Your child will not be tested or pulled from class at any time. Please read the attached permission form and indicate whether you do or do not grant permission for me to review your child's school records (i.e. test results, hearing case history forms, and initial and current evaluation reports). Also if you agree to participate in this important research study, please complete the attached parent information form.

Please complete and sign the attached forms and return them to me in the enclosed self-addressed stamped envelope by September 21, 1998. If you have any questions, please feel free to call me at (954) 321-9562. I would be happy to share the results of my study with you at your request. Thank you very much for your time and assistance.

Sincerely,

Lisa N. Cunningham

Doctoral Candidate

Florida International University 
Name of child:

Date of Birth:

School:

\section{PLEASE CHECK ONE:}

I DO grant permission for information regarding my child to be used in this research study.

Please continue on to the next page and answer the questions to the best of your ability.

I DO NOT grant permission for information regarding my child to used in this research study.

Parent/Guardian Signature:

Date:

Print Name:

\section{NOTE: ALL NAMES WILL REMAIN CONFIDENTIAL}

Please return this form to me in the enclosed self-addressed stamped envelope by September 21, 1998. Thank you. 


\section{Parent Questionnaire}

Student's name:

Date of Birth: School:

Name of person completing this form:

The student lives with

1. At what age was your child's deafness detected?

2. What was the cause of your child's hearing loss?

Please check one:

__ otitus media high fever
_ damage to tympanic membrane drug toxicity illness during pregnancy infection heredity unknown

3. At what age did your child begin using a hearing aid?

4. Did your child participate in a preschool program? yes no If the answer to question 4 is yes, please answer $a$ and $b$.

a. What type of preschool program? private day care SALT

b. At what age did your child begin attending their preschool program?

5. What mode of communication do you use with your child at home?

$\begin{array}{lll}\text { Oral only } & \text { Signed English } & \text { Simultaneous Communication } \\ \text { _ Pidgin Signed English } & \text { American Sign Language } & \text { Other }\end{array}$

6. What mode of communication do individual family members use with your child?

a.) spouse/significant other:

\section{_ Oral only}

Pidgin Signed English

_ Signed English

Pidgin Signed English

c.) grandparents:

Oral only

Pidgin Signed English

d.) aunts/uncles:

Oral only

Pidgin Signed English
Signed English

American Sign Language
Signed English

American Sign Language

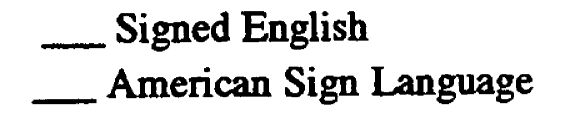
_ Simultaneous Communication Other

Signed English

American Sign Language
_ Simultaneous Communication Other

7. At what age did your child begin using language, oral or sign, to communicate their

wants and needs?

Simultaneous Communication Other
Simultaneous Communication Other 
8. Is there another language, other than English, used at home?

Please return this form in the enclosed self-addressed stamped envelope by September 21, 1998. Thank you. 
October 3, 1998

Dear Parent or Guardian:

I realize with the beginning of school and summer vacation it is very possible that you have not had the opportunity to complete the parent questionnaire I previously sent to you. I have enclosed an additional copy for your convenience along with a self-addressed stamped envelope.

I would greatly appreciate your cooperation in completing this questionnaire and returning to me at your earliest convenience. If you chose not to participate in this important research study, please return the attached permission form. If you would like to participate, please complete and sign the attached forms and return them to me in the enclosed self-addressed stamped envelope by September 13, 1998. If you have any questions, please feel free to call me at (954) 321-9562. I would be happy to share the results of my study with you at your request. Thank you very much for your time and assistance.

Sincerely,

Lisa N. Cunningham

Doctoral Candidate

Florida International University 


\section{LISA N. CUNNINGHAM}

February 15, 1964

Born, Hollywood, Florida

December, 1987

B.S., Speech Pathology and Audiology University of Pittsburgh

Pittsburgh, Pennsylvania

August, 1989

M.S., Education of the Hearing Impaired Bloomsburg University

Bloomsburg, Pennsylvania

August, 1989

Teacher of Hearing Impaired students

South Plantation High School

School Board of Broward County

Plantation, Florida

August, 1993

Exceptional Student Education Specialist

South Plantation High School

School Board of Broward County

Plantation, Florida

November, 1995

Program Specialist of Exceptional Student Education Central Area Office School Board of Broward County

Ft. Lauderdale, Florida 